\title{
Photocatalytic Degradation of Pharmaceuticals Carbamazepine, Diclofenac, and Sulfamethoxazole by Semiconductor and Carbon Materials: A Review
}

\author{
Ana S. Mestre * and Ana P. Carvalho * \\ Centro de Química e Bioquímica and Centro de Química Estrutural, Faculdade de Ciências, \\ Universidade de Lisboa, 1749-016 Lisboa, Portugal \\ * Correspondence: asmestre@fc.ul.pt (A.S.M.); ana.carvalho@fc.ul.pt (A.P.C.)
}

Academic Editors: Juan Matos Lale and Alicia Gomis Berenguer

Received: 31 August 2019; Accepted: 11 October 2019; Published: 15 October 2019

\begin{abstract}
The presence of pharmaceutical compounds in the environment is a reality that calls for more efficient water treatment technologies. Photocatalysis is a powerful technology available but the high energy costs associated with the use of UV irradiation hinder its large scale implementation. More sustainable and cheaper photocatalytic processes can be achieved by improving the sunlight harvesting and the synthesis of semiconductor/carbon composites has proved to be a promising strategy. Carbamazepine, diclofenac, and sulfamethoxazole were selected as target pharmaceuticals due to their recalcitrant behavior during conventional wastewater treatment and persistence in the environment, as properly reviewed. The literature data on the photocatalytic removal of carbamazepine, diclofenac, and sulfamethoxazole by semiconductor/carbon materials was critically revised to highlight the role of the carbon in the enhanced semiconductor performance under solar irradiation. Generally it was demonstrated that carbon materials induce red-shift absorption and they contribute to more effective charge separation, thus improving the composite photoactivity. Carbon was added as a dopant (C-doping) or as support or doping materials (i.e., nanoporous carbons, carbon nanotubes (CNTs), graphene, and derived materials, carbon quantum dots (CQDs), and biochars) and in the large majority of the cases, $\mathrm{TiO}_{2}$ was the semiconductor tested. The specific role of carbon materials is dependent on their properties but even the more amorphous forms, like nanoporous carbons or biochars, allow to prepare composites with improved properties compared to the bare semiconductor. The self-photocatalytic activity of the carbon materials was also reported and should be further explored. The removal and mineralization rates, as well as degradation pathways and toxicity of the treated solutions were also critically analyzed.
\end{abstract}

Keywords: carbamazepine; diclofenac; sulfamethoxazole; semiconductor composites; C-doping; activated carbon; CNT; graphene; CQD; biochar; sunlight-driven photocatalysis

\section{Introduction}

World's population increase along with the expected economic development, are major challenges water and energy consumption. However, nowadays 800 million people do not have access to drinking water and 1000 million live without electricity [1]. Thus, all strategies that enable to maximize water reuse, and contribute to the preservation of water resources, as well as those promoting more efficient use of renewable energies (e.g., solar energy), are essential to help in minimizing water scarcity and energy demand.

Water treatment technologies upgrade is the key to face current water quality challenges. The upmost challenge for drinking water and wastewater treatment, as well as water reuse, is linked to the presence of natural organic matter (NOM) and micropollutants in raw water, the latter often 
related to pharmaceutical compounds (PhCs). Several PhCs partially or totally resist to conventional treatments. So, it is crucial to upgrade the design and operation conditions of wastewater treatment plants (WWTPs), and water treatment plants (WTPs) with innovative, cost- and resource-effective solutions to achieve high-quality water standards.

Some of PhCs resist conventional treatments and are also highly resistant to photolysis and/or adsorption onto solid matter leading to their high persistence in the aquatic environment. Consequently, tertiary treatments are fundamental to assure the removal of these recalcitrant PhCs. These end-of-line treatments cover a large range of technologies: UV disinfection, ozone or chloride, and advanced water treatment technologies. This last class gathers activated carbons adsorption, membranes filtration, advanced oxidation processes (AOPs), and also combinations of two or more technologies. The use of technologies based on adsorption or membranes transfers the pollutant from the water to the pore structure of the adsorbent material or to the reject of the membrane filtration, originating a residue that still requests further treatment or disposal in a landfill. On the contrary, ideal AOPs allow total mineralization of the pollutant to $\mathrm{CO}_{2}$, water and inorganic compounds, or at least degrade the pollutant into more innocuous compounds.

AOPs can be broadly defined as aqueous phase oxidation methods based on the formation of highly reactive species, such as (mainly but not exclusively) hydroxyl radicals $\left(\mathrm{OH}^{\bullet}\right)$, leading the target pollutants decomposition [2]. Extensive research has been carried out on the use of AOPs to treat industrial and urban effluents. AOPs are divided into homogeneous and heterogeneous processes when considering their occurrence in a single phase or not, respectively. Depending on the methodology of $\mathrm{OH}^{\bullet}$ generation, AOPs can also be classified as chemical, electro-chemical, sono-chemical, and photo-chemical processes [3].

PhCs are a very large group of organic micropollutants of emergent concern. Thus remediation studies usually focus on a small group of PhCs classified as recalcitrant to conventional water treatment technologies and representative of distinct therapeutical classes and chemical functionalities. Following this rational three $\mathrm{PhCs}$ were selected to be addressed in this review: carbamazepine (CBZ) an antiepileptic, diclofenac (DCF) an acidic anti-inflammatory and analgesic, and sulfamethoxazole $(\mathrm{SMX})$ an antibiotic (Table 1).

Table 1. Target pharmaceutical compounds molecular structures, therapeutic classes and properties.

\begin{tabular}{|c|c|c|}
\hline $\begin{array}{c}\text { Pharmaceutical Molecular } \\
\text { Structure }\end{array}$ & Therapeutic Class & Properties \\
\hline Carbamazepine (CBZ) & Antiepileptic & $\begin{array}{c}\mathrm{MW}=236.3 \mathrm{~g} / \mathrm{mol} \\
\mathrm{p} K_{\mathrm{a}}=13.9[4] \\
\log K_{\mathrm{ow}}=2.45[4] \\
\text { Water solubility }\left(25^{\circ} \mathrm{C}\right)=18 \mathrm{mg} / \mathrm{dm}^{3}[4] \\
k_{H}=1.1 \times 10^{-10} \mathrm{~atm} \mathrm{m^{3 }} / \mathrm{mol}[4] \\
K_{\mathrm{d} \text {,prim }}<0.020 \mathrm{~L} / \mathrm{g}_{\mathrm{ss}}[5] \\
K_{\mathrm{d}, \mathrm{sec}}=0.0012 \pm 0.0005 \mathrm{~L} / \mathrm{g}_{\mathrm{ss}}[5] \\
k_{\mathrm{biol}} \leq 0.01 \mathrm{~L} / \mathrm{g}_{\mathrm{ss}} \cdot \mathrm{d}[6] \\
K_{\mathrm{OH}}=8.8 \times 10^{9} \pm 1.2 \times 10^{9} 1 / \mathrm{M} \mathrm{s}[7]\end{array}$ \\
\hline Diclofenac (DCF) & $\begin{array}{c}\text { Analgesic } \\
\text { Anti-inflammatory }\end{array}$ & $\begin{array}{c}\text { MW }(\text { acid })=296.1 \mathrm{~g} / \mathrm{mol} \\
\text { MW }(\text { sodium salt })=318.1 \mathrm{~g} / \mathrm{mol} \\
\mathrm{p} K_{\mathrm{a}}=4.15(\text { acid })[8] \\
\text { Log } K_{\mathrm{ow}}=4.51[8] \\
\text { Water solubility }\left(25^{\circ} \mathrm{C}\right)=2.37 \mathrm{mg} / \mathrm{dm}^{3}[8] \\
k_{H}=4.73 \times 10^{-12} \mathrm{~atm} \mathrm{m^{3 }} / \mathrm{mol}[8] \\
K_{\mathrm{d} \text {,prim }}=0.495 \pm 0.032 \mathrm{~L} / \mathrm{g}_{\mathrm{ss}}[5] \\
K_{\mathrm{d}, \mathrm{sec}}=0.016 \pm 0.003 \mathrm{~L} / \mathrm{g}_{\mathrm{ss}}[5] \\
k_{\text {biol }} \leq 0.1 \mathrm{~L} / \mathrm{g}_{\mathrm{ss}} \cdot \mathrm{d}[6] \\
K_{\mathrm{OH}}=7.5 \times 10^{9} \pm 1.5 \times 10^{9} 1 / \mathrm{M} \mathrm{s}[7]\end{array}$ \\
\hline
\end{tabular}


Table 1. Cont.

\begin{tabular}{cc}
$\begin{array}{c}\text { Pharmaceutical Molecular } \\
\text { Structure }\end{array}$ & Therapeutic Class \\
\hline
\end{tabular}

$\mathrm{p} K_{\mathrm{a}}$, negative log of acidity constant(s), $K_{\mathrm{ow}}$, octanol-water partition coefficient, $K_{\mathrm{d}}$, sorption constant on activated sludge $\left(K_{\mathrm{d} \text {,prim }}\right.$ and $K_{\mathrm{d} \text {,sec }}$ for, respectively, the primary and secondary treatment), $k_{\mathrm{biol}}$, pseudo first-order degradation rate constant $\left(1 \mathrm{~g} \mathrm{SS}^{-1} \mathrm{day}^{-1}\right), \mathrm{K}_{\mathrm{OH}}$, second-order rate constant with $\mathrm{OH}^{\bullet}$ radicals.

CBZ is an antiepileptic drug used to control seizures, is also used to relief neuralgia, and as an antidepressant in bipolar depression. DCF is a popular non-steroidal anti-inflammatory drug, having also antiarthritic and antirheumatic properties. In 2008, Zhang et al. estimated 1014 ton CBZ and 940 ton DCF consumption per year in accordance with IMS health data reporting 942 tons of CBZ and 877 tons of DCF sold in 2007 [11]. In 2013, the European Commission established the first watch list with 10 substances that may pose a significant risk to, or via, the aquatic environment (Directive 2013/39/EU). DCF was included in this list and maintained in next revision (Directive 2015/495/EU). The most recent revision removed DCF considering that sufficient high-quality monitoring data was already available (Directive 2018/840/EU). SMX is an extensively used antibiotic from the sulfonamide class of antibacterial compounds. It is used in clinic for the treatment of respiratory tract infections, severe urinary tract infections, and enteric infections [12], is also used in veterinary (to treat infections or for preventive care in aquaculture) and as herbicide [13].

In this context, this work starts reviewing the literature supporting the relevance of CBZ, DCF, and SMX as representatives of PhCs with recalcitrant behavior in water treatment and in natural photodegradation processes. Secondly, the use of semiconductor and carbon materials for the photocatalytic degradation of these $\mathrm{PhCs}$ will be addressed, highlighting the role of carbon materials, in particular for the improved sunlight harvesting.

\section{Pharmaceutical Compounds as Pollutants of Emergent Concern}

PhCs are essential in assuring high human health standards and well-being and are also largely employed in veterinary, being ubiquitous chemicals in modern societies. However, it is proven that the high consumption patterns of PhCs associated with their high chemical stability and low biodegradability, contributed to their widespread release in the aquatic environment (mainly for those highly soluble). Given the biological activity and recalcitrant behavior of several PhCs, they constitute a major treat firstly to aquatic life and consequently to the whole food chain. Besides the public health concerns regarding short and long-term toxicological effects related to the exposure to trace amounts of PhCs trough potable water and food chain, the environmental perspective of this problem is also a relevant topic.

The first report on PhCs occurrence in the environment dates from 1965 when Stumm-Zollinger and Fair addressed the presence of steroid hormones in the effluents of the U.S.A. WWTPs to understand their biodegradation in WWTP, and in receiving water bodies that could eventually supply drinking water to households [14]. In the 1970s clofibric acid, salicylic acid, and chlorophenoxyisobutyrate (PhCs and metabolites) were detected in the U.S.A. wastewater effluents $[15,16]$. Nowadays, PhCs are detected in all sorts of environmental waters worldwide, and some of them are part of a watch list for EU-wide monitoring to access their risk for aquatic environment and support future prioritization (2018/840/EU). 


\section{1. $C B Z, D C F$, and SMX Detections in Wastewater and Environmental Water}

Since the early monitoring studies in 1980s and 1990s CBZ, DCF, and SMX have been detected in wastewater samples and in environmental waters in the $\mathrm{ng} / \mathrm{L}-\mu \mathrm{g} / \mathrm{L}$ range (Table 2). Between 1996 and 2000 Heberer [17] monitored $24 \mathrm{PhCs}$ in sewage treatment plants (STPs) and environmental waters from the urban area of Berlin and CBZ, DCF, and SMX were the compounds detected at the higher concentrations. The results allowed to conclude that only $8 \% \mathrm{CBZ}$ and $17 \% \mathrm{DCF}$ were removed during wastewater treatment. Consequently, not surprisingly, concentrations up to $1.1 \mu \mathrm{g} / \mathrm{L} \mathrm{CBZ}$ and $0.6 \mu \mathrm{g} / \mathrm{L}$ DCF were detected in surface water of the Berlin urban area [17]. In 2001, Ternes reported negligible CBZ removal in a municipal STP, the treatment of DCF was more effective (69\%) [18]. CBZ and DCF were also detected in the same concentration range in STPs effluents and environmental waters from other European countries and Brazil [19-24]. Frist monitoring studies also report the detection of SMX in STPs effluents at $\approx 0.9 \mu \mathrm{g} / \mathrm{L}$ but reaching a maximum of $2.0 \mu \mathrm{g} / \mathrm{L}[21,25]$.

Table 2. Early detections of carbamazepine (CBZ), diclofenac (DCF), and sulfamethoxazole (SMX) in wastewater and environmental water.

\begin{tabular}{|c|c|c|c|c|}
\hline $\mathrm{PhC}$ & Type of Water & Concentration $(\mu \mathrm{g} / \mathrm{L})$ & Publication Year & Ref. \\
\hline \multirow[t]{14}{*}{ CBZ } & $\begin{array}{c}\text { STP effluents } \\
\text { Rivers and streams }\end{array}$ & $\begin{array}{c}3.7(\max 6.3) \\
0.82(\max 1.1)\end{array}$ & 1998 & [19] \\
\hline & Ground water & Up to 0.900 & 2001 & [26] \\
\hline & STP influent (Frankfurt/Mains) & 2.2 & \multirow{4}{*}{2001} & \multirow{4}{*}{ [18] } \\
\hline & STP effluent (Frankfurt/Mains) & 2.0 & & \\
\hline & Ground water & Up to 1.1 & & \\
\hline & Drinking water & Up to 0.030 & & \\
\hline & STP influent (Berlin) & $1.78(\max 3.80)$ & \multirow{3}{*}{2002} & \multirow{3}{*}{ [17] } \\
\hline & STP effluent (Berlin) & $1.63(\max 5.00)$ & & \\
\hline & Surface water (Berlin) & $0.4-1.1$ & & \\
\hline & Surface water (Berlin) & $0.025-1.075$ & 2002 & [24] \\
\hline & STP effluent (France) & $0.98-1.2$ & \multirow{4}{*}{2003} & \multirow{4}{*}{ [23] } \\
\hline & STP effluent (Greece) & 1.03 & & \\
\hline & STP effluent (Italy) & $0.3-0.5$ & & \\
\hline & STP effluent (Sweden) & 0.87 & & \\
\hline \multirow[t]{23}{*}{ DCF } & Sedimentation tank effluent & $\leq 2$ & \multirow{3}{*}{1996} & \multirow{3}{*}{ [27] (in [21]) } \\
\hline & River Rhine & $0.015-0.304$ & & \\
\hline & Different rivers & $0.038-0.489$ & & \\
\hline & STP effluents & $1.6(\max 2.1)$ & \multirow{2}{*}{1998} & \multirow{2}{*}{ [19] } \\
\hline & Rivers and streams & $0.80(\max 1.2)$ & & \\
\hline & Influent Swiss STP & $0.47-1.92$ & \multirow{3}{*}{1998} & \multirow{3}{*}{ [22] } \\
\hline & Effluent Swiss STP & $0.31-0.93$ & & \\
\hline & Swiss lakes/rivers & $0.001-0.370$ & & \\
\hline & Brazilian STP & $0.4(\max \approx 1.4)$ & \multirow{2}{*}{1999} & \multirow{2}{*}{ [20] } \\
\hline & River water & $0.02-0.06$ & & \\
\hline & STP influent (Frankfurt/Mains) & 1.9 & \multirow{4}{*}{2001} & \multirow{4}{*}{ [18] } \\
\hline & STP effluent (Frankfurt/Mains) & 0.58 & & \\
\hline & Ground water & 0.93 & & \\
\hline & Drinking water & Up to 0.006 & & \\
\hline & Ground water & Up to 0.590 & 2001 & [26] \\
\hline & STP influent (Berlin) & $3.02(\max 7.10)$ & \multirow{4}{*}{2002} & \multirow{4}{*}{ [17] } \\
\hline & STP effluent (Berlin) & $2.51(\max 4.70)$ & & \\
\hline & Surface water & $<0.1-0.6$ & & \\
\hline & Ground water (Berlin) & Up to 0.38 & & \\
\hline & Surface water (Berlin) & Up to 1.030 & 2002 & [24] \\
\hline & STP effluent (France) & $0.25-0.41$ & \multirow{3}{*}{2003} & \multirow{3}{*}{ [23] } \\
\hline & STP effluent (Greece) & 0.89 & & \\
\hline & STP effluent (Italy) & $0.47-5.45$ & & \\
\hline
\end{tabular}


Table 2. Cont.

\begin{tabular}{ccccc}
\hline PhC & Type of Water & Concentration $(\mu \mathrm{g} / \mathrm{L})$ & Publication Year & Ref. \\
\hline SMX & River water & $\approx 1$ & 1983 & [28] (in [21]) \\
\cline { 2 - 4 } & STP effluents & $0.9(\max 2.0)$ & & \\
& Surface water & $0.14(\max 0.48)$ & 1999 & [25] \\
Ground water & Up to 0.47 & & \\
\hline Ground water & Up to 0.410 & 2001 & [26] \\
\hline STPs effluent (Berlin) & 0.9 & 2002 & [17] \\
\hline STP effluent (France) & $0.07-0.09$ & & \\
STP effluent (Greece) & 0.09 & & [23] \\
STP effluent (Italy) & $0.01-0.03$ & & \\
STP effluent (Sweden) & 0.02 & & & \\
\hline
\end{tabular}

In 2010, Loos and co-workers analyzed 35 compounds (pharmaceuticals, pesticides, perfluorinated acids, benzotriazoles, hormones, and endocrine disrupters) in more than 100 river water samples from 27 European countries. Among all PhCs CBZ was the most frequently detected compound (95\%) and at the highest concentration level $\left(0.308 \mu \mathrm{g} / \mathrm{dm}^{3}\right.$ for percentile $90 \%$, and a maximum of $\left.11.561 \mu \mathrm{g} / \mathrm{dm}^{3}\right)$ [29]. Also DCF and SMX were detected with a frequency above the average frequency for all the compounds under study (61\%), i.e., DCF was detected in $83 \%$ of the samples at concentrations of $0.043 \mu \mathrm{g} / \mathrm{dm}^{3}$ in $90 \%$ percentile, and maximum values of $0.247 \mu \mathrm{g} / \mathrm{dm}^{3}$, while SMX was detected in $75 \%$ of the analysis at concentrations of $0.104 \mu \mathrm{g} / \mathrm{dm}^{3}$ in $90 \%$ percentile, and maximum values of $4.072 \mu \mathrm{g} / \mathrm{dm}^{3}$ [29]. A survey on the occurrence of 59 polar organic persistent pollutants in 164 locations of European ground water (23 countries) identified 21 relevant compounds, among which CBZ (detection frequency $42 \%$, max. $0.39 \mu \mathrm{g} / \mathrm{dm}^{3}$ ) and SMX (detection frequency $24 \%$, max. $0.038 \mu \mathrm{g} / \mathrm{dm}^{3}$ ) [30]. The study also showed that CBZ was frequently detected above the European ground water quality standard for pesticides $\left(0.1 \mu \mathrm{g} / \mathrm{dm}^{3}\right)$ [30].

The results of a systematic study regarding the fate of CBZ in eleven Austrian STPs conducted by Clara et al. in 2004, revealed that this antiepileptic medicine consistently resisted to degradation and adsorption during conventional wastewater treatment, and also during soil passage and subsurface flow, thus allowing to propose CBZ as an anthropogenic marker for detecting wastewater in the aquatic environment [31].

In 2008, Zhang et al. reviewed literature data on CBZ and DCF removal during wastewater treatment as well as their occurrence in water bodies [11]. According to monitoring data in WWTPs (1998-2007), CBZ is considered persistent since 70\% of the studies reported only 0 to $10 \%$ removal of this PhC. For DCF the removal efficiencies reported varied between 0 and $80 \%$. The justification for the distinct behavior can be related to the high resistance of CBZ to biodegradation at low concentration while DCF can be biodegraded at specific conditions (i.e., anoxic biofilm reactor, acidic conditions) [11]. Phototransformation during sunlight irradiation in WWTPs cannot be disregarded as a removal route. However, in deionized water CBZ presents very high stability with half-life of approximately 100 days while DCF and SMX present values two orders of magnitude lower (5.0 and 2.4 days, respectively) [11,23]. In real wastewater matrices the presence of organic matter that can behave as photosensitizers or inner filters must also be considered. In fact, humic acids act as inner filters for CBZ and DCF lowering their degradation, but in the case of SMX behave as photosensitizers promoting its phototransformation [11,23].

The recalcitrant nature of some $\mathrm{PhCs}$ during conventional wastewater treatment can be justified in light of their properties. According to Joss et al. [6], the biological degradation constants $\left(k_{\text {biol }}\right.$, Table 1) of CBZ and DCF are indicative of less than $20 \%$ removal during wastewater treatment with conventional activated sludge (CAS) or membrane bioreactor (MBR) technologies, supporting the systematic low biodegradability during secondary treatment. Regarding CBZ, DCF, and SMX also, no sorption onto activated sludge is expected to occur due to distribution coefficient water/sludge values ( $k_{\mathrm{d}}$, Table 1$)$ 
much lower than reference value for significant sorption $\left(0.500 \mathrm{~L} / \mathrm{g}_{\mathrm{ss}}\right)$ [11]. Volatilization could be another route to the removal of these PhCs during wastewater treatment but their low Henry constant values $\left(k_{\mathrm{H}}\right.$, Table 1$)$ indicate that they are nonvolatile compounds.

A very recent study classified $13 \mathrm{PhCs}$, including $\mathrm{DCF}$ and $\mathrm{SMX}$, as priority PhCs in the aquatic environment of China, according to the proposed ranking system that is supported on three criteria (occurrence, exposure potential, and ecological effects). [32]. DCF and erythromycin presented the highest predicted environmental risk. This prioritization is in line with other ranking studies since DCF is considered a priority PhC in eight reports, and SMX in six of the works [32]. In fact, Gou et al. identified 13 PhCs (including CBZ and DCF) and three metabolites as presenting high risk score since their estimated exposure is higher than predicted no-effect concentration (PNEC) [33]. Besse et al. calculated the risk quotient ratios with available ecotoxicity data of $76 \mathrm{PhCs}$ and their metabolites and, according to the conditions required by the European Medicine Agency (EMEA) guidelines of 2006, CBZ, DCF, and SMX are three of the six PhCs identified as presenting environmental risk [34]. The Global Water Research Coalition (GWRC) consolidated data from 25 literature studies on 153 $\mathrm{PhCs}$ and, according with the seven more relevant criteria, CBZ, DCF, and SMX were identified as the top three PhCs of the group of 10 high priority PhCs [35]. In fact, these three PhCs present the highest number of occurrences in the literature $(15,12,13$, respectively) being the only ones that fulfil all the relevant criteria (i.e, regulation, consumption/sales, physicochemical properties, toxicity, occurrence-wastewater, river water, ground water, drinking water-, degradability/persistence and resistance to treatment) [35].

\subsection{Photodegradation}

As mentioned previously, the occurrence of CBZ, DCF, and SMX in environmental waters worldwide results from the low effectiveness of conventional water treatments as barriers for these $\mathrm{PhCs}$, due to their high chemical stability and low biodegradability. Once in the environment, the fate of these PhCs in the water-cycle depends on their properties namely their hydrophobic/hydrophilic character that will determine their interactions with water, dissolved species, and solids, as well as, their stability under sunlight irradiation.

Photodegradation at the top level of surface waters may be a natural elimination pathway for recalcitrant PhCs in environmental waters. Direct and indirect photochemical processes can occur depending on the PhC nature, water matrix, and solar irradiation spectrum. Direct photolysis of an organic compound only occurs when the absorption spectrum of the compound overlaps the intensity spectrum of the incoming irradiation, resulting in the electronic excitation of the molecule that promotes its phototransformation. In indirect processes, photoactive compounds-photosensitizers-absorb sunlight producing reactive species such as hydroxyl radicals $\left(\mathrm{OH}^{\bullet}\right)$ that can induce PhCs degradation. According to the UV spectra (Figure 1) it is possible to conclude that only a very small fraction of sunlight (i.e., UV-A and UV-B) is expected to promote direct photolysis of CBZ, DCF, and SMX.

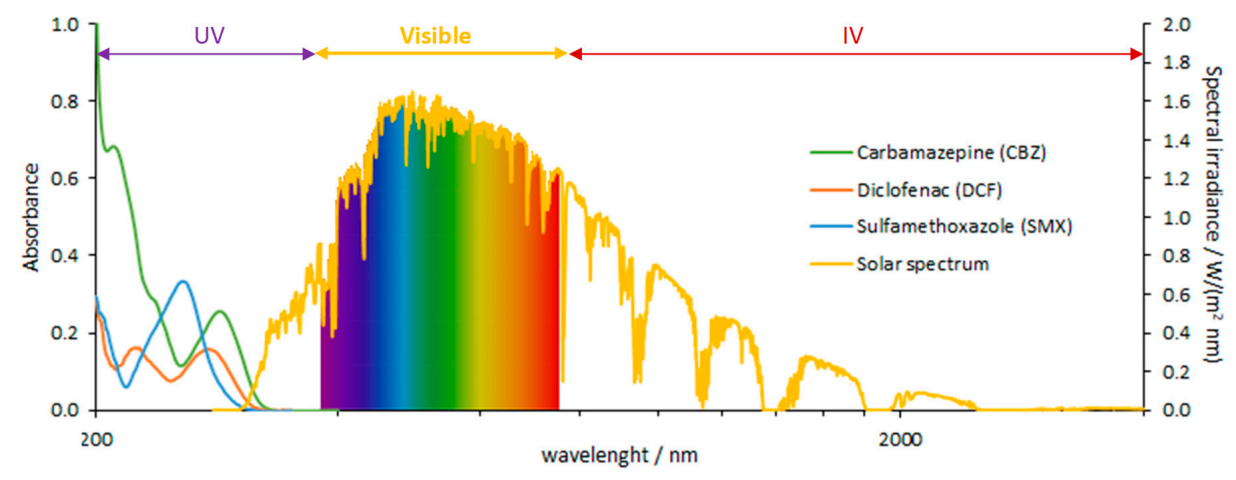

Figure 1. UV absorption spectra of CBZ, DCF, and SMX ( $5 \mathrm{mg} / \mathrm{L}$ solutions in inorganic matrix at $\mathrm{pH} 7.1)$ versus sunlight spectrum at sea level (ASTM G173-03 Global, [36]). 
Doll and Frimmel [37] evaluated the fate of CBZ in surface waters under natural and simulated solar light, concluding that although CBZ absorbs most of the incoming radiation compared with the other PhCs, it presents the lowest degradation rate constants. In real waters with low concentrations of NOM photodegradation of CBZ can be favored (indirect pathway by NOM-induced reactions), but in high concentration, NOM has a detrimental effect acting as the inner filter (radical scavenger and/or as precursor of reactive species). The presence of other PhCs also decreases the CBZ degradation rate (competitive inhibition) [37].

Andreozzi et al. studied the photodegradation of CBZ $\left(8.0 \times 10^{-6} \mathrm{~mol} / \mathrm{L}\right)$ in bi-distilled water at pH 5.5 during solar light exposure determining a pseudo-first order kinetic constant of $5.7 \times 10^{-3} \mathrm{~h}^{-1}$ and a half-life time of $121.6 \mathrm{~h}$, while in spiked natural water CBZ half-life time increased to $907 \mathrm{~h}$ [38]. Assays in the presence of nitrates reveal that these anions act as photosensitizers reducing CBZ half-life time to $69 \mathrm{~h}-11.2 \mathrm{~h}\left(5.0 \times 10^{-4}-1.5 \times 10^{-2} \mathrm{~g} / \mathrm{L}\right)$. On the other hand, dissolved humic acid increased photodegradation half-life time of CBZ to $233.7 \mathrm{~h}$ possibly related to the reduction of direct photodegradation due to strong UV absorption of humic acid that acts as inner filters [38]. The laboratorial study developed by Yamamoto et al. also pointed out relatively high resistance of CBZ (20-100 $\mu \mathrm{g} / \mathrm{L})$ to solar light photodegradation with half-life times of $84 \mathrm{~h}$, in August 2006, and 2100 h, in May 2007 [39].

Lam et al. studied the aquatic persistence of eight PhCs in sunlight-exposed pond water identifying CBZ and SMX as the most persistent with mean half-life times of 82 days and 19 days, respectively, due to their resistance to both biodegradation and photolysis [40].

The low photodegradability of CBZ is certainly related to its low quantum yield. In fact, according with the experimental quantum yields for the direct photolysis of PhCs in bi-distilled water at $\mathrm{pH}$ 5.5, CBZ has one of the lowest values $\left(4.77 \times 10^{-5}\right.$ under sunlight) [23]. For SMX the value obtained under lamplight was $4.29 \times 10^{-3} \mathrm{~mol} /$ Einstein and for DCF the results reported are $3.13 \times 10^{-2} \mathrm{~mol} /$ Einstein under lamplight, and $3.37 \times 10^{-2} \mathrm{~mol} /$ Einstein under sunlight [23]. Chiron et al. determined an average quantum yield of $1.5 \times 10^{-4} \mathrm{~mol} /$ Einstein for CBZ direct photolysis in Milli-Q water under medium-pressure mercury lamp (highest contribution from 313, 366, $406 \mathrm{~nm}$ ) [41]. In surface water at pH 7 quantum yields of CBZ irradiated with medium-pressure (205-500 nm) and low-pressure $(253.7 \mathrm{~nm})$ mercury lamps are slightly higher $\left(0.6 \times 10^{-3}\right.$ and $2.3 \times 10^{-3} \mathrm{~mol} /$ Einstein, respectively) [42].

The photodegradation of CBZ $\left(2.1 \times 10^{-4} \mathrm{~mol} / \mathrm{L}\right)$ in artificial river and estuarine water (with humic acids, $\mathrm{Fe}(\mathrm{III}), \mathrm{NO}_{3}{ }^{-}$, and $\mathrm{Cl}^{-}$) was studied by Chiron et al. who found a decrease in photodegradation rate with increasing $\mathrm{pH}$, which was attributed to the distinct iron species in solution [41]. At acidic $\mathrm{pH}$ values CBZ photodegradation occurs via dissolved $\mathrm{Fe}(\mathrm{III})$ that originates $\mathrm{OH}^{\bullet}$ while at higher $\mathrm{pH}$ values $\mathrm{Fe}(\mathrm{III})$ colloids are predominant and produce lower amounts of $\mathrm{OH}^{\bullet}$ but are able to induce charge-transfer reactions, this will not be pure photodegradation processes since from the Fenton process it is known that iron can catalyse the degradation. However, under neutral to basic conditions the presence of chlorine enhance CBZ photolysis most probably due to the interaction between Fe(III) colloids and $\mathrm{Cl}^{-}$leading to the formation of $\mathrm{Cl}_{2}{ }^{\bullet-}$ that albeit presenting slower degradation than $\mathrm{OH}^{\bullet}$ would be faster than charge-transfer processes occurring on the surface of Fe(III) colloids [41]. After $8 \mathrm{~h}$ irradiation, the toxic, mutagenic and carcinogenic acridine (major intermediate of CBZ direct photolysis) accounted for $10 \%$ of the initial carbamazepine species [41]. Since this transformation product has greater health and environmental risk than the pristine compound more effective degradation routes are needed.

In 2008, Matamoros et al. evaluated the photodegradation of four PhCs, including CBZ (10-40 mg/L), under simulated solar light and sunlight, in river water and sea water, as well as, distilled water for getting information regarding photodegradation pathways [43]. To assure irradiation close to real conditions, the authors used quartz vessels transparent to UV light. The results pointed out CBZ as the compound most resistant to photodegradation since in Milli-Q water it presented $38.5 \mathrm{~h}$ of half-life time, and in two river water or sea water, the value decreased to $8.25-14.4 \mathrm{~h}$, revealing the role of DOC in indirect photodegradation. In the assays performed under sunlight the half-life time in river 
water was eight times higher $(67.4 \mathrm{~h})$ compared with the value obtained under simulated conditions, being this decreased explained by the daily light variation.

Early studies by Buser et al. [22] reported a great decrease in DCF concentrations from a major tributary to a lake, to the outflow of the same lake (inflow from 0.005 to $0.370 \mu \mathrm{g} / \mathrm{dm}^{3}$ and outflow from $<0.001$ to $0.012 \mu \mathrm{g} / \mathrm{dm}^{3}$ ) estimating more than $90 \%$ DCF removal most likely due to photodegradation (not detected in sediments and laboratory experiments corroborate negligible absorption onto sediment particles). Lake water spiked with DCF presented minimal chemical and biological degradation under dark, however once exposed to sunlight a fast photodegradation occurred attaining the half-life time in less than $1 \mathrm{~h}$ of irradiation, most likely via direct photolysis [22]. In a further study the same authors were able to identify photodegradation products, namely 8-chlorocarbazole-1-acetic acid that was detected in all the experiments and photodegrades faster than DCF, and concludes that photochemical degradation is the predominant elimination process for DCF in the lake [44].

Literature studies report decomposition quantum yields for DCF from 0.031 to $0.22 \mathrm{~mol} /$ Einstein in the laboratory, in agreement with those determined in environmental conditions (0.094 and $0.13 \mathrm{~mol} /$ Einstein) [45]. According with simulated profiles and field measurements in a lake (three-month period) Tixier et al. estimated an average elimination rate of $\approx 2 \mathrm{~h}^{-1}\left(0.082\right.$ days $\left.^{-1}\right)$ for direct DCF photolysis which is in accordance with the model simulation based on field data (overall elimination rate constant $\approx 2.1 \mathrm{~h}^{-1}\left(0.088\right.$ days $\left.^{-1}\right)$, and eight days of half-life time), proposing this process as the main elimination route for DCF in environmental water [46]. The same study classified CBZ as fairly persistent with an overall elimination rate constant of $\approx 0.26 \mathrm{~h}^{-1}\left(0.011\right.$ days $\left.^{-1}\right)$, and 63 days of half-life time [46].

Photodegradation profiles of DCF and SMX under artificial sunlight irradiation in dechlorinated tap water at $\mathrm{pH} 8$ (mimicking surface water without bacteria or suspended solids) reveal that DCF, with a half-life time of 0.40 days, was by far much more sensitive to photolysis than SMX, which needed 54 days to decrease half of the initial concentration [47]. Although SMX has relatively low absorption in the UV-B region above $290 \mathrm{~nm}$, according to the studies of Moore and Zhou in the mid-1990s, the susceptibility of this sulfonamide antibiotic to photodegradation is highly dependent on the solution $\mathrm{pH}[12,48]$. In fact, under UV light the pseudo-first-order kinetic constant is higher than $0.15 \mathrm{~min}^{-1}$ at $\mathrm{pH}<4$, and lower than $0.025 \mathrm{~min}^{-1}$ at $\mathrm{pH} \geq 7$, with the inflection point matching the $\mathrm{p} K_{\mathrm{a} 2}$ value [48]. Also, the quantum yield of SMX photodegradation determined under UV irradiation is $0.47 \mathrm{~mol} /$ Einstein at $\mathrm{pH} 3$ and only $0.084 \mathrm{~mol} /$ Einstein at $\mathrm{pH} 9$ [48].

The complex SMX speciation profile allows concluding that while the nonionized form is extremely susceptible to photodegradation under UV or sunlight irradiation, the anion form, predominant at $\mathrm{pH}$ 5.6 or higher ( $\mathrm{pH}$ values of wastewater effluent and environmental water), is more stable. The high photostatibility of the SMX anionic form offers and explanation to the slower and less effective photolysis of SMX in seawater compared with deionized water, both at natural $\mathrm{pH}$ (4.8 and 8.1, respectively) [49] or in deionized water with $\mathrm{pH}$ values increasing from 3 to 10 [50]. This behavior is a strong indication that SMX ersistence in the environment is most likely due to its resistance to photodegradation in slightly basic conditions. The presence of natural water constituents (i.e., fluvic acids and suspended solids) were reported to have a negative effect on the photodegradation of SMX $(1-10 \mathrm{mg} / \mathrm{L})$, in the case of fluvic acid at $50 \mathrm{mg} / \mathrm{L}$ the half-life is five times higher compared to deionized water [50]. The type of organic matter is also relevant for the photolysis of SMX, Ryan et al. verified that effluent organic matter (EfOM) enhanced SMX photodegradation, while NOM had no effect, probably due to the higher concentration of nitrates in EfOM, which act as photosensitizers for the production of hydroxyl radicals, and also due to the presence of triplet excited state organic matter in EfOM [51].

Although acidic $\mathrm{pH}$ favors SMX photodegradation, the mineralization degree is negligible due to the formation of abundant transformation products [49,52]. 4-amino-N-(5-methyl-2oxazolyl)benzenesulfonamide is the main photodegradation product identified, and although presenting the same empirical formula of SMX suffered a photoisomerization reaction of the isoxazole ring $[12,40,49]$. Trovó et al. evaluated the acute toxicity of SMX photodegradation products for 
Daphina magna and Vibrio fischeri concluding that the first was the most sensitive organism (from $60 \%$ to $100 \%$ immobilization) [49]. Since SMX was totally removed after 30 min irradiation toxicity was attributed to the degradation products. Gmurek et al. also studied the toxicity of the long-term SMX phototransformation products under simulated solar light towards Vibrio fischeri growth and luminescence [52]. Regardless of the irradiation time, the bioluminescence inhibition of the mixture of transformation products retained the toxicity of the parent SMX solution. Regarding growth inhibition, the increase of irradiation times shifted the curve to higher concentrations but the growth inhibition decrease was not proportional to the degradation of the SMX entities [52].

\section{Photocatalysis}

In 1972, Fujishima and Honda discovered the photoelectrocatalytic water splitting by using $\mathrm{TiO}_{2}$ electrodes [53] and paved the way for more efficient use of light in chemical processes. Since then photocatalysis has rapidly expanded for a large range of environmental and energy applications [54-61], is considered a potential solution to the worldwide energy shortage and for counteracting environmental degradation [60]. As stated by Fujishima and co-workers, in a time-scale of ten years the basic scientific knowledge on $\mathrm{TiO}_{2}$ photocatalysis allowed the development of a technological field reaching the real large-scale industrial exploitation [62], is thus a great example of fundamental science solving real word challenges.

More efficient use of the solar spectrum for an effective photodegradation of persistant $\mathrm{PhCs}$ as is the case of CBZ, DCF, and SMX can be achieved by applying materials with photocatalytic properties, as is the case of semiconductors. As previously mentioned $\mathrm{TiO}_{2}$ is by far the most popular photocatalyst due to its unique properties: inertness, high photostability and photoactivity, cost-efficiency and also non-toxicity to humans and environment [61]. Other metal oxides (e.g., $\mathrm{ZnO}, \mathrm{WO}_{3}$ ), and their derivatives have also been explored for the degradation of organic compounds [63]. Besides the classical metal oxide semiconductors, the pioneering work by Wang et al. in 2009 reported the $\mathrm{H}_{2}$ evolution by metal-free polymeric graphitic carbon nitride $\left(\mathrm{g}-\mathrm{C}_{3} \mathrm{~N}_{4}\right)$ under visible light [64], thus proposing the first metal-free photocatalyst. Since then these organic solids- $-\mathrm{g}-\mathrm{C}_{3} \mathrm{~N}_{4}$ and derivatives, as well as other conducting polymers like polyaniline (PANI), polyacetylene, polythiophene, polypyrrole, poly- $p$-(phenylenevinylene) - proved to be promising visible-light-responsive organic photocatalysts for several key reactions (e.g., photochemical water splitting, oxidation reactions, $\mathrm{CO}_{2}$ mitigation, pollutant degradation and bacterial disinfection) [65-68], as well as, playing important roles in biomass conversion, i.e., sustainable chemistry processes [66].

Photocatalysis is initiated when a semiconductor absorbs a photon $(h v)$ with energy equal to, or greater than, the band gap $\left(\mathrm{E}_{\mathrm{g}}\right)$ of the semiconductor, causing the excitation of an electron $\left(\mathrm{e}^{-}\right)$from the valence band (VB) to the conduction band (CB), which leads to the formation of an electron-hole $\left(\mathrm{e}^{-} / \mathrm{h}^{+}\right)$pair (reaction (1)). These photogenerated charge carriers $\left(\mathrm{e}^{-} / \mathrm{h}^{+}\right)$can recombine or migrate to the surface of the catalyst. Recombination can occur (i) in the bulk of the semiconductor, (ii) and/or mediated by surface species, (iii) or adsorbed molecules. When charge carriers migrate to the surface of the photoactive material and are scavenged by the species adsorbed onto the surface of the semiconductor, they induce the redox reactions of the adsorbed species. The competition between the fast kinetic of recombination and slow kinetic of charge separation and transfer (i.e., migration) to the surface of the material determines the efficiency of the photocatalytic process. Consequently, the first requisite to boost the photo-oxidation of the target pollutant is to prevent the $\mathrm{e}^{-} / \mathrm{h}^{+}$recombination. The photo-generated hole is a strong oxidizing agent that can directly react with the target pollutant or with water to produce hydroxyl radicals $\left(\mathrm{OH}^{\bullet}\right)$ (reaction (2)), the former occurs when the redox potential of the pollutant is less negative than that of semiconductor valence band while in the latter the oxidation of the pollutant occurs through radical chain reactions. On the opposite the electron is a strong reducing agent able to react with electron acceptor species, as is the case of dissolved oxygen to 
create superoxide radicals $\left(\mathrm{O}_{2}{ }^{\bullet-}\right)$ (reaction (3)), or other species with a redox potential more positive than that of the photocatalyst conduction band.

$$
\begin{gathered}
\text { Photocatalysis initiation: semiconductor }+h v \rightarrow \mathrm{e}^{-}+\mathrm{h}^{+} \\
\text {photo-oxidation: } \mathrm{h}^{+}+\mathrm{OH}^{-} \rightarrow \mathrm{OH}^{\bullet} \text { or }^{+}+\mathrm{H}_{2} \mathrm{O} \rightarrow \mathrm{OH}^{\bullet}+\mathrm{H}^{+} \\
\text {photo-reduction: } \mathrm{e}^{-}+\mathrm{O}_{2} \rightarrow \mathrm{O}_{2}^{\bullet-}
\end{gathered}
$$

The efforts to optimize photocatalysts have been mainly focused on the increase of light efficiency, mainly by searching for solar-light-responsive photocatalysts and minimizing electron-hole recombination $[60,63]$.

Among photocatalysts, nanosized semiconductor particles have met superior photocatalytic properties due to their large surface area, distinctly good dispersion capability and quantum size effects $[63,69]$. Yet, the large scale application of semiconductor nanoparticles has two major constrains: aggregation in suspension leads to fast loss of active sites, and consequent decreased photocatalytic efficiency, and the challenging separation, recovery, and reuse [63].

The synthesis of semiconductor hybrids and/or composites by coupling a semiconductor with organic/inorganic materials is a promising option to overcome the above mentioned drawbacks and challenges [70,71]. Usually, a hybrid material consists of a mixture of two or more phases at the nanometer scale or molecular level, and the hybrid material features do not correspond to the sum of the properties of the single phases but to synergistic interactions among them [70]. Typically, a composite consists of the dispersion of a micron-level phase or nanometer-size structures in a matrix, with the properties of the composite resulting from the addition of each phase contribution. To the best of our knowledge in photocatalysis most of times the terms hybrid and (nano)composite are indistinctively used to denote a material composed by two or more compounds and/or materials, regardless the establishment or not of specific chemical interactions between both phases, and the relative proportion of each one in the final mixture.

Due to their extensive surface area, black body properties, and high charge carrier mobility, carbon materials have been largely explored as dopants, hybridizing materials or supports of semiconductors. They are, undoubtedly, a very effective route to improve photocatalytic activity, as proved by the number of literature studies reviewing $\mathrm{TiO}_{2} /$ carbon performance in the last decade [72-85]. For example Khalid et al. compared the performance of $\mathrm{TiO}_{2} /$ carbon nanomaterials against bare $\mathrm{TiO}_{2}$ concluding that carbon doping and composites with activated carbons, fullerene, carbon nanotubes (CNTs), or graphene lead to materials with enhanced photocatalytic activity, adsorption capacity, electron scavenging and sensitization ability, extended visible light absorption, and also easier separation [73]. The enhanced photocatalytic activity due to the addition of carbon to a semiconductor can be reasoned in light of two mechanisms (i) improved charge separation in the presence of carbon, (ii) carbon acting as photosensitizer (Figure 2) [86]. When porous carbons are added to semiconductors, several synergistic effects due to adsorption must be considered. The charge separation mechanism by semiconductor/carbon composites was proposed by Woan et al. considering that carbon materials with metallic conductivity are able to trap the electron generated in the semiconductor, therefore hindering the recombination (Figure 2a) [76]. Wang et al. proposed the mechanism where the carbon material acts as photosensitized by transferring electrons to the conduction band of the semiconductor (Figure 2b) [87]. 
(a)

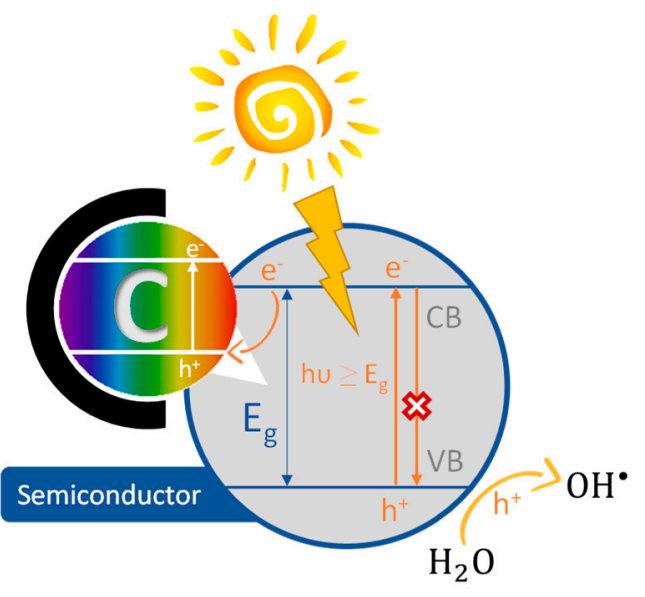

(b)

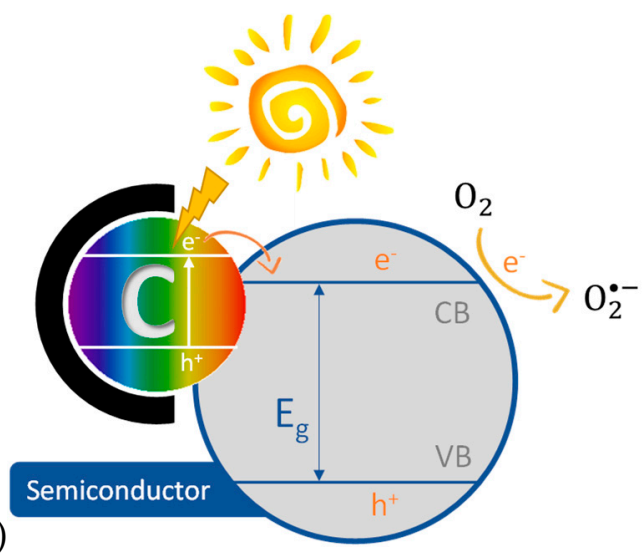

Figure 2. Simplified photocatalysis process schemes using semiconductor and carbon as addictive or support (a) charge separation in the presence of carbon, and (b) carbon acting as photosensitizer (inspired in [76,87]).

In the following a review of the literature data (2010-2019) on the role of carbon in the performance of semiconductor/carbon materials for the enhanced photocatalytic degradation of CBZ, DCF, and SMX taking special attention to the improvement of the solar light harvesting will be presented. The distribution of literature studies on semiconductor/carbon materials for the photocatalytic degradation of each of these compounds according to the type of semiconductor and type of carbon material is presented in Figure 3. As expected $\mathrm{TiO}_{2}$ is by far the most studied semiconductor, counting $75 \%$ of the works but carbon materials are evenly distributed with graphene, CNTs and activated carbons representing, respectively, 33\%, 22\%, and 19\% of the total contributions.
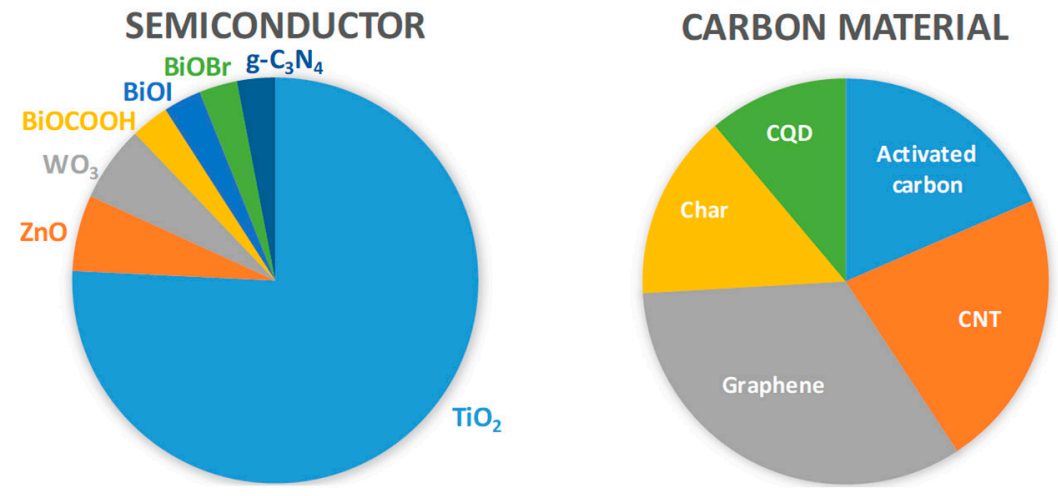

Figure 3. Semiconductor/carbon materials for the photodegradation of CBZ, DCF, and SMX according to the type of semiconductor (left) and type of carbon material (right). Source: ISI Web of Knowledge January 2019, search term "(carbamazepine OR diclofenac OR sulfamethoxazole) AND (photocat* OR photodegra*) AND (carbon)" search checked and refined by researcher.

\subsection{Semiconductor/C}

Doping semiconductors is an option to improve their optical properties since the replacement of metal or nonmetal atoms by other elements, or the addition of atoms in interstitial positions, ideally maintaining the crystalline structure of the semiconductor, can shift the onset of the response from the UV to the visible region $[88,89]$. Several metals (e.g., W, V, Fe or $\mathrm{Cu}$ ) and nonmetals (B, C, N, F, P, S, $\mathrm{Cl}$, and $\mathrm{Br}$ ) have been used to successfully dope $\mathrm{TiO}_{2}$ [88]. Among the nonmetals, $\mathrm{N}$ - and $\mathrm{C}$-doping have similarities since both favor the formation of oxygen vacancies, enhancing the photocatalytic activity of $\mathrm{TiO}_{2}$ in the visible region [89]. The theoretical study by Valentin et al. reveals that at low $\mathrm{C}$ concentration the characteristics of the $\mathrm{C}$-doped $\mathrm{TiO}_{2}$ depends on the $\mathrm{O}$ availability during 
the synthesis: substitution of $\mathrm{O}$ by $\mathrm{C}$ atoms and $\mathrm{O}$ vacancies are favored under $\mathrm{O}_{2}$-poor conditions, while interstitial $\mathrm{C}$ and substitution of Ti by $\mathrm{C}$ atoms is preferred at $\mathrm{O}_{2}$-rich conditions [89].

Irie et al. attributed the visible light responsivity of $\mathrm{C}$-doped $\mathrm{TiO}_{2}$ (anatase), prepared by mild oxidation of $\mathrm{TiC}$ and further annealing under $\mathrm{O}_{2}$, to the $0.32 \%$ of $\mathrm{C}$ atoms located at $\mathrm{O}$ sites [62]. Albeit the very small carbon content in the doped $\mathrm{TiO}_{2}$, it was enough to shift the absorbance edge and shoulder to the visible light region (bandgap narrowing). C-doped $\mathrm{TiO}_{2}$ (anatase) catalysts can be prepared by hydrolysis of $\mathrm{TiCl}_{4}$ with nitrogen bases (e.g., tetrabutylammonium hydroxide) followed by calcination at $400{ }^{\circ} \mathrm{C}$, being proved that optical properties are dependent on the doping percentage [90]. Materials with $2.98 \%$ and $0.43 \%$ of $C$ absorb light at $400-700 \mathrm{~nm}$ and were five times more active than an $\mathrm{N}$-doped for the artificial solar light degradation of 4-chlorophenol, while the unmodified $\mathrm{TiO}_{2}$ was almost inactive [90]. $\mathrm{TiO}_{2} / \mathrm{C}-0.43 \%$ was also effective for the gas-phase photodegradation of acetaldehyde, benzene, and carbon monoxide in air under diffuse indoor light [90].

Recently C-doped semiconductors have also been successfully tested for the photocatalytic degradation of CBZ and DCF under UV and visible light (Table 3) and, as expected, $\mathrm{TiO}_{2}$ is by far the most explored semiconductor. The majority of the studies use initial DCF or CBZ concentrations in the $\mathrm{mg} / \mathrm{dm}^{3}$ range, deionized water, and single-solute conditions.

In 2017, Surenjan and co-authors reported the effectiveness of C-doped spherical $\mathrm{TiO}_{2}$ in the anatase form for the photodegradation of DCF and CBZ after $4 \mathrm{~h}$ under visible light since after this time none of the pharmaceuticals or respective degradation intermediates and products were identified (mineralization degrees higher than 98\%) [91]. The characterization of the doped photocatalyst reveals that $\mathrm{C}$ atoms may substitute Ti sites or occupy interstitial positions. The authors found that in the presence of glucose the degradation rate of CBZ decreases (from $0.0348 \mathrm{~min}^{-1}$ in single-solute to $0.0249 \mathrm{~min}^{-1}$ ) indicating that glucose acts as a sacrificial agent. In dual-solute conditions (i.e., DCF and CBZ) the rate of CBZ degradation has always a more pronounced decrease than that of DCF but even thought a complete removal of both PhCs was achieved in $210 \mathrm{~min}$ [91].

In a distinct approach, Sambandam et al. evaluated the effect of the morphology of C-doped $\mathrm{TiO}_{2}$ (anatase form) catalytic activity for the degradation of CBZ under visible light [92]. The authors proposed that in comparison with other crystal morphologies the rice grain shaped catalysts enhanced visible light degradation of CBZ ( $k_{1}$ of $0.094 \mathrm{~min}^{-1}$ vs. $0.059-0.02 \mathrm{~min}^{-1}$ for the other morphologies) due to the conjugation of co-exposed low energy/high energy $\{101\} /\{001\}$ facets thermodynamically stable or not, and high surface area $\left(229 \mathrm{~m}^{2} / \mathrm{g}\right.$ vs. $33-62 \mathrm{~m}^{2} / \mathrm{g}$ for the other morphologies) [92].

Table 3. Photocatalytic degradation of CBZ and DCF by C-doped semiconductors.

\begin{tabular}{|c|c|c|c|c|}
\hline PhC & Catalyst & Experimental Conditions & Concluding Remarks & Ref. \\
\hline $\begin{array}{l}\text { CBZ } \\
\text { DCF }\end{array}$ & $\mathrm{TiO}_{2} / \mathrm{C}$ & $\begin{array}{ll}\text { - } & \text { Microwave synthesis: spherical } \\
\text { - } & {\left[\mathrm{TiO}_{2} / \mathrm{C}\right]=50-350 \mathrm{mg} / \mathrm{dm}^{3}} \\
\text { - } & {[\mathrm{PhC}]_{0}=50-250 \mu \mathrm{g} / \mathrm{dm}^{3}(\text { each } \mathrm{PhC})} \\
\text { - } & \text { Continuous } \mathrm{O}_{2} \\
\text { - } & \mathrm{pH} 6.5-8.5 \\
\text { - } & \text { Visible (intensity } 4000-10,000 \mathrm{~lx}) \\
\text { - } & 60 \text { min dark (ads) }+4 \text { h light }(\mathrm{deg}) \\
\text { - } & \text { Single-solute and multi-solute } \\
\text { - } & \text { Deionized water }\end{array}$ & 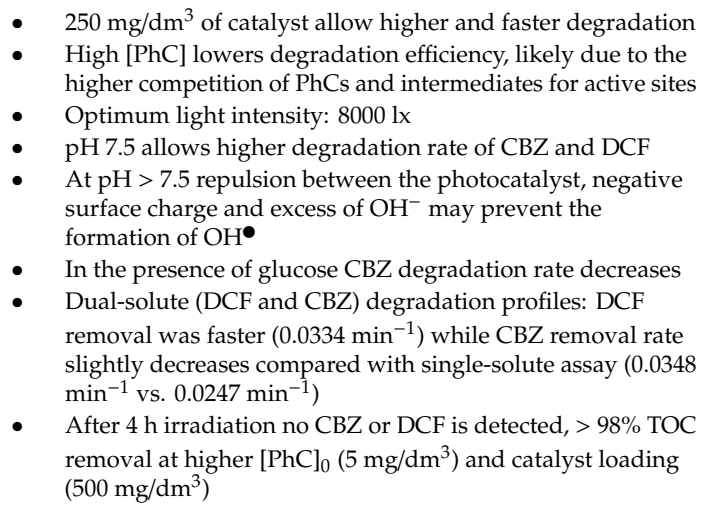 & [91] \\
\hline
\end{tabular}


Table 3. Cont

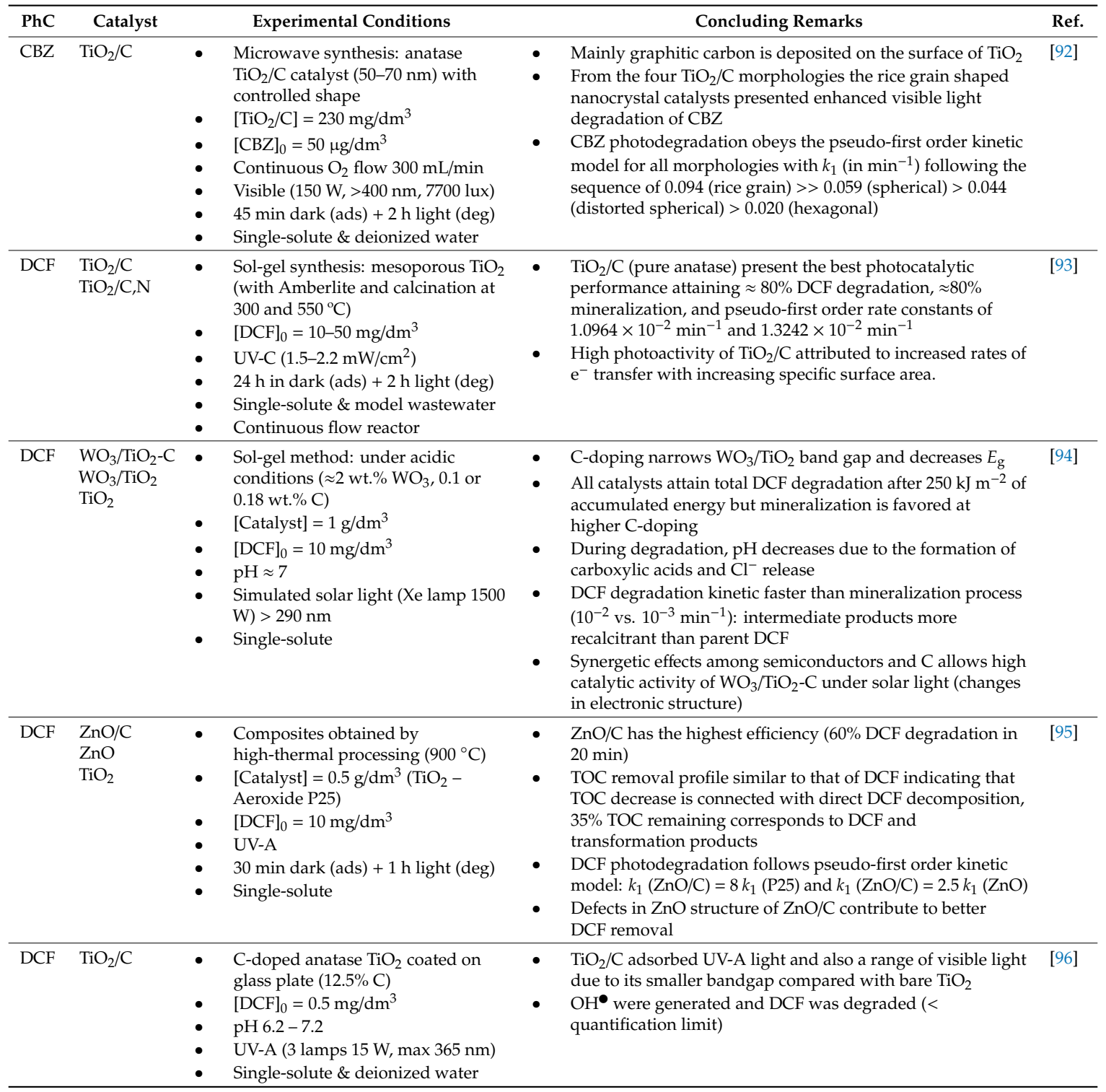

ads-adsorption, deg-degradation

The contribution of C-doping for enhanced semiconductor photodegradation of DCF under simulated solar light is clearly illustrated in the manuscript published by Cordero-Garcia et al. [94]. C-doping at percentages as low as $0.1-0.18 \mathrm{wt} . \%$ has a positive effect on: (i) the narrowing of the $\mathrm{WO}_{3} / \mathrm{TiO}_{2}$ band gap, (ii) the decrease of bandgap values to the visible light region (i.e., $\mathrm{E}_{\mathrm{g}}$ values (in eV) of 3.15 for $\mathrm{TiO}_{2}-0.04 \% \mathrm{C}, 3.10$ for $\mathrm{WO}_{3} / \mathrm{TiO}_{2}-0.05 \% \mathrm{C}, 3.05$ for $\mathrm{WO}_{3} / \mathrm{TiO}_{2}-0.1 \% \mathrm{C}$, and 2.98 for $\mathrm{WO}_{3} / \mathrm{TiO}_{2}-0.18 \% \mathrm{C}$ ), and (iii) lower recombination $\mathrm{e}^{-} / \mathrm{h}^{+}$[94]. The incremental slight displacement of the adsorption edge of the catalysts to the visible region proved to increase their mineralization efficiency for DCF, from $65 \%$ in the bare $\mathrm{TiO}_{2}$ to $76.2 \%$ in the $\mathrm{WO}_{3} / \mathrm{TiO}_{2}$, since $\mathrm{WO}_{3}$ acts as acceptor center for the photogenerated electrons. Values around $80 \%$ were attained for the C-doped mixed oxide $\left(78.1 \%\right.$ and $82.4 \%$ for, respectively $\mathrm{WO}_{3} / \mathrm{TiO}_{2}-0.1 \% \mathrm{C}$ and $\left.\mathrm{WO}_{3} / \mathrm{TiO}_{2}-0.18 \% \mathrm{C}\right)$. Regardless the catalyst, the DCF degradation kinetic is always one order of magnitude faster than the TOC removal profile pointing out the formation of degradation products (possibly quinine imide compounds) more recalcitrant than parent DCF. The synergetic effect of $\mathrm{C}$ and $\mathrm{WO}_{3}$ on the properties of anatase under solar irradiation was explained by the authors according to the mechanism presented in Figure 4 . The incorporation of $\mathrm{C}$ atoms created a narrow $\mathrm{C} 2 \mathrm{p}$ band just above $\mathrm{TiO}_{2} \mathrm{O} 2 \mathrm{p}$ valence band allowing 
the visible light absorption and further transference of these photogenerated electrons to the $\mathrm{Ti} 3 \mathrm{~d}$ conduction band. The dual-oxide W/Ti system allows the trapping of the photogenerated electrons improving the charge carrier separation. In both oxides, the holes can react with water to produce $\mathrm{OH}^{\bullet}$ while the $\mathrm{e}^{-}$can react with adsorbed $\mathrm{O}_{2}$ that is reduced to superoxide radicals and further reacts with protons to form $\mathrm{HO}_{2}^{\bullet}$ [94].

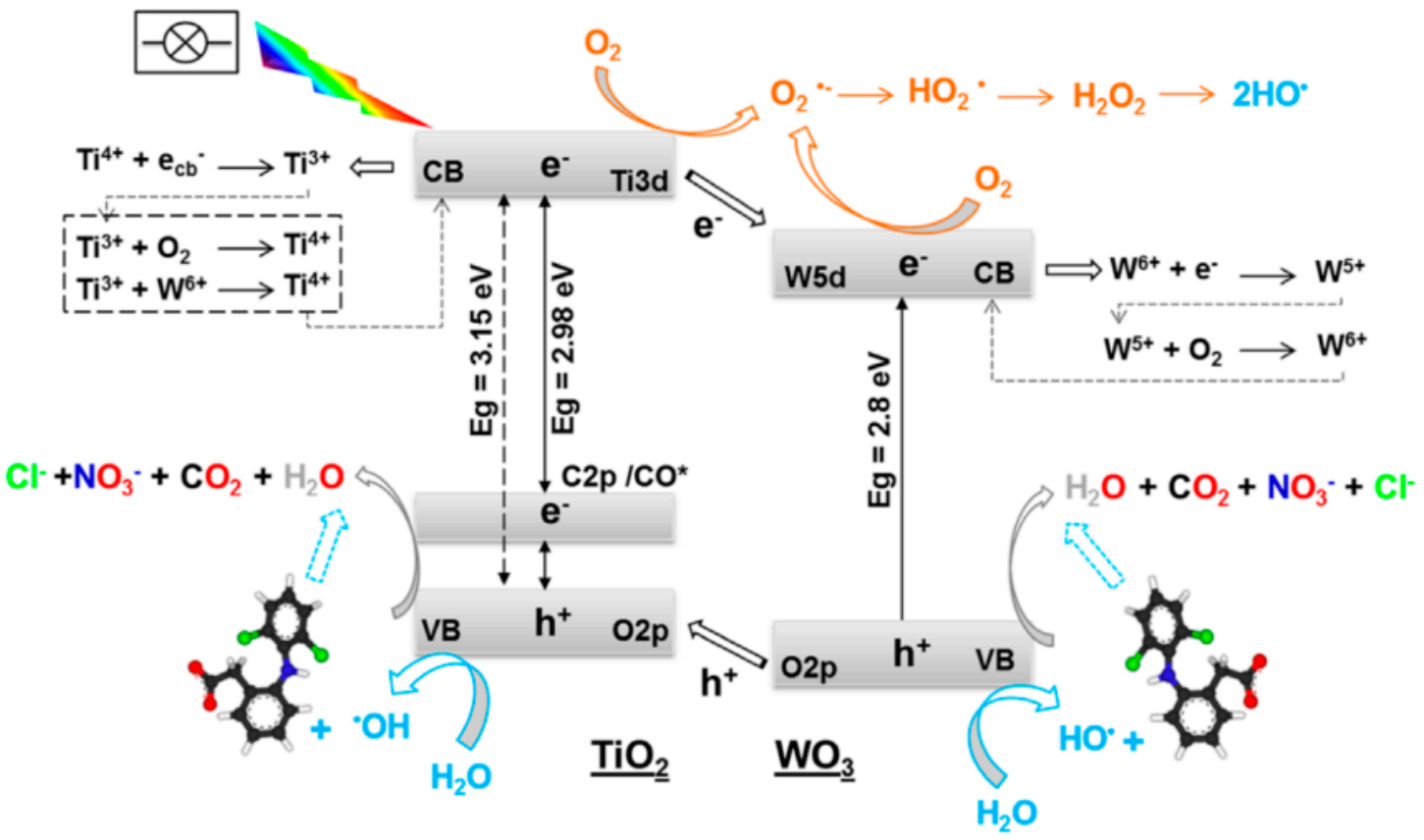

Figure 4. Mechanism of charge carrier separation proposed by Cordero-Garcia et al. [94] for photoexcited $\mathrm{WO}_{3} / \mathrm{TiO}_{2}-\mathrm{C}$ (Reprinted with permission [94], Copyright 2019, Elsevier).

\subsection{Semiconductor/Activated Carbon}

As mentioned, the use of semiconductors has several drawbacks related namely with aggregation, high recombination of photogenerated $\mathrm{e}^{-} / \mathrm{h}^{+}$pairs, limited activity under solar light and post-separation. To overcome these issues the scientific community explores different strategies. Back in early 1989, Tanguay et al. reported that anatase $\mathrm{TiO}_{2}$ supported on carbon felt was photoactive for the degradation of dicholomethane, and allowed easy separation of the catalyst from the reaction mixture [97]. Between 1998 and 2001, Matos et al. reported that the addition of an amorphous carbon phase (i.e., activated carbon) to semiconductor in mixed suspensions enhance the photoactivity for the degradation of organic pollutants [98-100]. The immobilization of semiconductor photocatalysts onto solid supports is an option to improve their performance, and among the several materials explored, activated carbons meet the criteria requested to be considered valuable supports since they (i) allow strong adherence between catalyst and support, (ii) the catalyst reactivity is not affected by the attachment process, (iii) have high specific surface area, and (iv) have a high adsorption affinity towards the pollutants [71]. In fact, several studies reveal that the use of activated carbon as support material can increase the photodegradation rate by progressively allowing an increasing quantity of substrate to come in contact with the immobilized metal oxide by means of adsorption [71], by minimizing the recombination $\mathrm{e}^{-} / \mathrm{h}^{+}$of the metal oxide [101], and due to the black character of activated carbons harvesting the solar spectrum is favored. The studies aiming to evaluate the synergetic effects of semiconductor/carbon nanocomposites revealed that an increased adsorption of the contaminants onto the activated carbon phase, followed closely by a transfer through an interphase to the $\mathrm{TiO}_{2}$ phase, gives a complete photodegradation process [71,101]. In 2011, Lim et al. reviewed the synergistic adsorption-photocatalytic processes of $\mathrm{TiO}_{2} /$ activated carbon composites addressing the challenges and further developments for water treatment and reclamation. Authors propose the coupling of 
these composites with membrane separation technologies to recover and regenerate the composites and also to enhance solar harvesting by using N-doped activated carbons [74]. The improvement of solar spectrum harvesting and catalysts immobilization strategies are also identified by Chong et al. as urgent needs in order to provide cost-effective photocatalytic technologies for water treatment sector [57].

Furthermore, as recently highlighted in the review on the photochemical activity of nanoporous carbons by Bandosz and Ania [102], activated carbons can play more than a secondary role in photochemical processes. Since 2010, works by Ania and co-workers have proven photoactivity of activated carbons due to their ability to absorb light and convert the photogenerated charge carriers into chemical reactions [103-106]. Velasco et al. identified the effect of nanoconfinement of the adsorbed aromatic species (phenol) in the pores of the nanoporous carbons as playing an important role in the photoactivity of these solids [102-105]. The optical properties of these materials are also linked with their heterogeneity (disorders/defects) along with the presence of $\mathrm{C} \mathrm{sp}{ }^{2}$ and $\mathrm{sp}^{3}$ configurations, and since their electrical conductivities, although being lower than that of graphene of carbon nanotubes, are higher than that of semiconductors contributing to lower the $\mathrm{e}^{-} / \mathrm{h}^{+}$recombination [102].

The works reporting the use of semiconductor/AC composites for the photodegradation of CBZ, $\mathrm{DCF}$, and SMX are listed in Table 4 and, again, $\mathrm{TiO}_{2}$ is the semiconductor tested and in only one study solar light irradiation is used.

Table 4. Photocatalytic degradation of CBZ, DCF, and SMX by semiconductor/activated carbon (PAC—-powdered activated carbon, ACfiber-activated carbon fiber).

\begin{tabular}{|c|c|c|c|c|}
\hline PhC & Catalyst & Experimental Conditions & Concluding Remarks & Ref. \\
\hline $\begin{array}{l}\text { SMX } \\
\text { DCF } \\
\text { CBZ }\end{array}$ & $\begin{array}{l}\mathrm{TiO}_{2} / \mathrm{PAC} \\
\mathrm{TiO}_{2}\end{array}$ & $\begin{array}{ll}\text { - } & \text { Composites: physical, mechanical } \\
\text { and chemical mixtures } \\
\text { - } & {\left[\mathrm{TiO}_{2}\right]=0.5 \mathrm{~g} / \mathrm{dm}^{3} \text { (Aeroxide P25) }} \\
\text { - } & {[\mathrm{PAC}]=2.5-35 \mathrm{mg} / \mathrm{dm}^{3}} \\
& (\text { commercial) } \\
\text { - } & \left.[\mathrm{PhC}]_{0}=0.5 \mathrm{mg} / \mathrm{dm}^{3} \text { (each } \mathrm{PhC}\right) \\
\text { - } & \mathrm{UV}-\mathrm{A}\left(1.0 \mathrm{~mW} / \mathrm{cm}^{2}\right), \mathrm{UV}-\mathrm{B}(2.5 \\
& \left.\mathrm{mW} / \mathrm{cm}^{2}\right), \mathrm{UV}-\mathrm{C}\left(3.65 \mathrm{~mW} / \mathrm{cm}^{2}\right) \\
\text { - } & 60 \mathrm{~min} \text { dark }(\mathrm{ads})+30 \mathrm{~min} \text { light } \\
\text { - } & \text { (deg) } \\
\text { - } & \text { Dulti-solute }(5 \mathrm{PhCs}) \\
\text { and spiked real water (tap water, } \\
\text { river water, sea water, wastewater) }\end{array}$ & 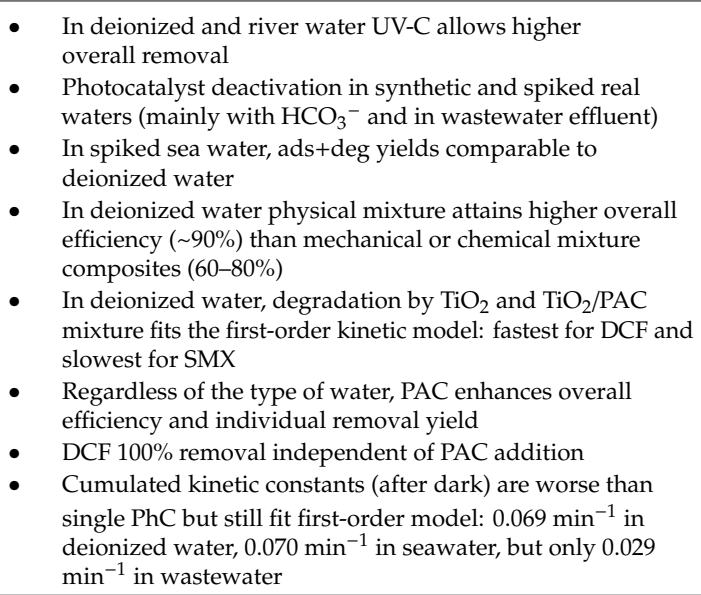 & [107] \\
\hline CBZ & $\begin{array}{l}\mathrm{TiO}_{2} / \mathrm{PAC} \\
\mathrm{TiO}_{2} \\
\mathrm{PAC}\end{array}$ & $\begin{array}{ll}\text { - } & 1: 5 \text { wt. ratio } \mathrm{TiO}_{2}: \mathrm{PAC} \\
\text { - } & \text { (conglomerates in suspension) } \\
\text { - } & \left.\left[\mathrm{TiO}_{2}\right]=0.1 \mathrm{~g} / \mathrm{dm}^{3} \text { (Aeroxide } \mathrm{P} 25\right) \\
\text { - } & {[\mathrm{PAC}]=0-20 \mathrm{mg} / \mathrm{dm}^{3} \text { (commercial }} \\
& \text { - Norit) } \\
\text { - } & {[\mathrm{PhC}]_{0}=8-9 \mathrm{mg} / \mathrm{dm}^{3} \text { (each PhC) }} \\
\text { - } & \text { UV light }(\mathrm{Hg} \text { lamp) } \\
\text { - } & \text { Single-solute \& deionized water }\end{array}$ & 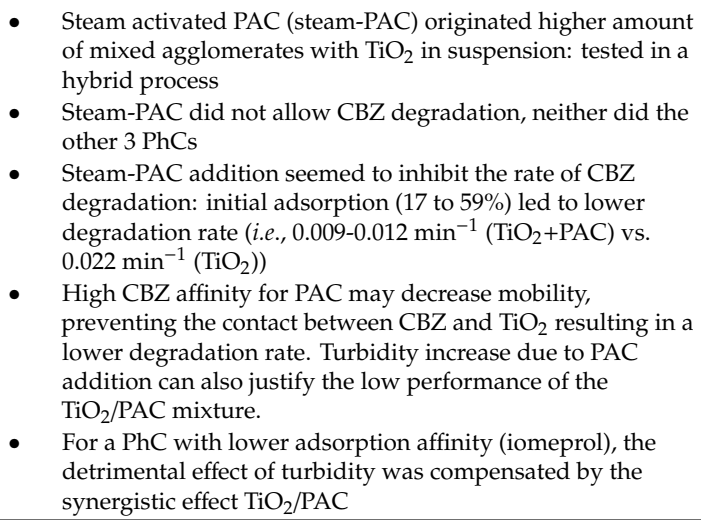 & [108] \\
\hline
\end{tabular}


Table 4. Cont.

\begin{tabular}{|c|c|c|c|c|}
\hline $\mathrm{PhC}$ & Catalyst & Experimental Conditions & Concluding Remarks & Ref. \\
\hline DCF & $\begin{array}{l}\mathrm{TiO}_{2} / \mathrm{AC} \\
\mathrm{TiO}_{2}\end{array}$ & $\begin{array}{ll}\text { - } & \mathrm{TiO}_{2} \text { : } \mathrm{AC} \text { wt. ratio } 2: 1 \text { and } \\
\text { impregnation at } 200{ }^{\circ} \mathrm{C} \\
\text { - } & {\left[\mathrm{TiO}_{2} / \mathrm{AC}\right]=0.4-1.6 \mathrm{~g} / \mathrm{dm}^{3}(\mathrm{AC}-} \\
& \left.\mathrm{Adwic}_{\mathrm{TiO}}-\mathrm{Acros}, \mathrm{commercial}\right) \\
\text { - } & {\left[\mathrm{TiO}_{2}\right]=0.2-0.8 \mathrm{~g} / \mathrm{dm}^{3}} \\
\text { - } & {[\mathrm{PhC}]_{0}=50 \mathrm{mg} / \mathrm{dm}^{3}, 4 \mathrm{dm}^{3}} \\
\text { - } & \mathrm{pH} 3-10 \\
\text { - } & \text { Solar reactor with compound } \\
\text { - } & \text { parabolic collectors } \\
\text { PhCs mixture continuous circulated } \\
\text { - } & 30 \text { min dark (ads) }+3 \text { h light (deg) } \\
\text { - } & \text { Multi-solute (4 PhCs) }\end{array}$ & 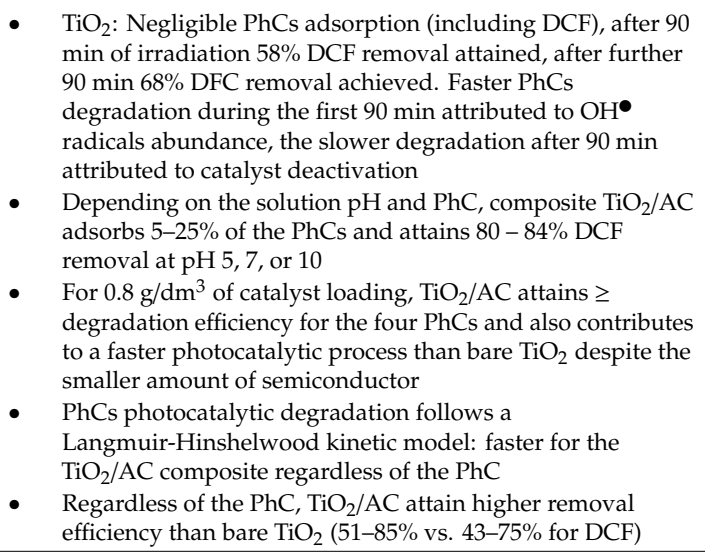 & [109] \\
\hline
\end{tabular}

ads-adsorption, deg-degradation

Rioja et al. evaluated the effect of $\mathrm{TiO}_{2} /$ powdered activated carbon $\left(\mathrm{TiO}_{2} / \mathrm{PAC}\right)$ composites' synthesis method (physical, mechanical and chemical mixtures), and UV irradiation type on the competitive degradation of five PhCs, including CBZ, DCF, and SMX, in various water matrices (deionized, synthetic and spiked real water) [107]. The authors concluded that, in general, the presence of powdered activated carbon (PAC) improved the removal of PhCs due to the additive effect of adsorption and catalysis. It was also shown that the performance of the composites was dependent on the synthesis method and calcination temperature (overall removal): physical mixture ( $\approx 90 \%)>$ mechanical or chemical mixture calcined at $400{ }^{\circ} \mathrm{C}(70-80 \%) \approx$ bare $\mathrm{TiO}_{2}(\approx 75 \%)>$ mechanical or chemical mixture calcined at $500^{\circ} \mathrm{C}(\approx 60 \%)$. These variations were mainly due to SMX, and particularly, CBZ removal. The nature of the water matrix played a crucial role in the performance of the composites. For synthetic and spiked real water (tap water, river water, wastewater) photocatalysts deactivation was observed when compared with the assays performed in deionized water in similar conditions. However, the removals obtained in sea water were comparable to those of deionized water indicating that the high ionic strength appears not to compromise the photodegradation of the PhCs [107]. Interestingly, the CBZ removal and the two acidic PhCs (ibuprofen and clofibric acid) is more dependent on the water matrix. DCF and SMX present almost constant overall removal efficiencies regardless the presence/absence of PAC and the type of water matrix. In deionized water, DCF had the fastest photodegradation kinetic $\left(0.1-0.4 \mathrm{~min}^{-1}\right)$ while SMX presented the slowest one $\left(0.01-0.03 \mathrm{~min}^{-1}\right)$.

Ziegmann et al. found no photoactivity of two commercial PACs selected to degrade target PhCs (CBZ one of them) under UV light irradiation and reported the detrimental effect of the presence of PAC [108]. The authors considered that the high CBZ adsorption affinity for PAC, and the increase of the suspension turbidity due to the presence of the carbon particles, justify the low performance of the composite $\mathrm{TiO}_{2} / \mathrm{PAC}$ when compared with the bare $\mathrm{TiO}_{2}$. The initial removal of $\mathrm{CBZ}$ by adsorption was counterbalanced by a slower photodegradation rate and the values of dissolved organic carbon indicate that the rate of mineralization was much lower than the rate of degradation [108].

The enhancement of photoactivity through the immobilization of $\mathrm{TiO}_{2}$ onto $\mathrm{AC}$ was proved by Alalm et al. that studied the degradation of DCF, among other PhCs, using a solar reactor in a competitive scenario [109]. The removal efficiency for DCF was improved from $68 \%$ with bare $\mathrm{TiO}_{2}$ to $85 \%$ using $\mathrm{TiO}_{2} / \mathrm{AC}$. Moreover, the composite also allowed total removals of amoxicillin and 
ampocilin. The photocatalytic degradation of the four PhCs in multi-solute conditions follows the Langmuir-Hinshelwood kinetic model. According to this mechanism, before degradation species must be adsorbed and this last process is faster for the $\mathrm{TiO}_{2} / \mathrm{AC}$ composite regardless the PhC. Higher removal rates with $\mathrm{TiO}_{2} / \mathrm{AC}$ were obtained in a large $\mathrm{pH}$ range (3-10), being the highest value observed for $\mathrm{pH} \geq 7$, which is, close to the values usually found in secondary effluent (wastewater). This is an advantage of this process in comparison with photo-Fenton (faster and complete degradation in 1-2 h) that is favored at $\mathrm{pH} \mathrm{3,} \mathrm{causing} \mathrm{corrosion} \mathrm{of} \mathrm{mechanical} \mathrm{facilities} \mathrm{and} \mathrm{the} \mathrm{need} \mathrm{for} \mathrm{an} \mathrm{extra}$ neutralization step. Finally, according to the authors' estimation, operating and total costs of using $\mathrm{TiO}_{2} / \mathrm{AC}$ solar photocatalysis were lower than those for bare $\mathrm{TiO}_{2}$ [109], thus highlighting the potential of these systems to be used in real water treatment facilities.

\subsection{Semiconductor/CNT}

Carbon nanotubes (CNTs) whose synthesis was reported by Iijima in 1991 [111] are another interesting class of carbon materials due to their outstanding structural, thermal and electronic properties associated with their one dimensional (1D) structure [73]. CNTs are classified as single-walled CNT (SWCNTs) and multi-walled CNT (MWCNTs) [111], presenting specific surface areas $>150 \mathrm{~m}^{2} / \mathrm{g}$, excellent mechanical properties and their high electron mobility can be compared to those of metals, i.e., they may exhibit metallic conductivity [76]. As highlighted in several reviews published over the last decade, the combination of all these attributes makes CNT superior supports to enhance semiconductors photoactivity $[72,73,76,78,85,112]$.

Woan et al. summarized the three mechanisms proposed in the literature to explain the enhancement of photoactivity in $\mathrm{TiO}_{2} / \mathrm{CNT}$ composites: (i) CNTs inhibit recombination, (ii) photosensitization due to $\mathrm{e}^{-} / \mathrm{h}^{+}$pair generation in the CNTs, and (iii) CNTs act as impurities through Ti-O-C bonds [76]. In mixtures or nanocomposites semiconductor/CNT there are strong interfacial electronic effects between both players and the large electron-storage capacity of CNTs allows them to accept photon-excited electrons. As a consequence of the inherent electron density delocalization of the carbon matrix, the $\mathrm{e}^{-} / \mathrm{h}^{+}$recombination is retarded or hindered [76,102]. MWCNT were reported to have self-photoactivity under visible light due to the presence of structural defects and vacancies [113], justifying a large number of studies using MWCNT instead of SWCNT [85]. The sensitizing role of MWCNT for visible light photoactivity was proposed by Wang et al. [87]: the electron photogenerated in the CNT is injected into the conduction band of the $\mathrm{TiO}_{2}$ and the positively charged CNT remove an $\mathrm{e}^{-}$from the $\mathrm{TiO}_{2}$ valence band creating $\mathrm{a} \mathrm{h}^{+}$, allowing the reaction with $\mathrm{O}_{2}\left(\mathrm{e}^{-}\right)$and $\mathrm{H}_{2} \mathrm{O}\left(\mathrm{h}^{+}\right)$to generate the oxygen reactive species $\left(\mathrm{O}_{2}^{\bullet-}\right.$ and $\mathrm{OH}^{\bullet}$, respectively). The third mechanism is more complex since two distinct contributions of $\mathrm{TiO}_{2} / \mathrm{CNT}$ are reported [76]. In the first one MWCNT act as carbon-doped $\mathrm{TiO}_{2}$ since the Ti-O-C bond extends the light absorption to longer wavelengths with potential to improve photoactivity and solar-light harvesting. The second is related to the electronic configuration of the CNTs that justifies the highest performance of CNTs prepared by arc-discharge CNT over CVD-grown ones, due to higher electrical conductivity and less defects of the former [76].

Owing to their great potential the use of semiconductor/CNT composites for the photodegradation of organic contaminants has been of considerable scientific interest and the works focused on the photodegradation of CBZ, DCF and SMX are listed in Table 5. As in the previous sections, $\mathrm{TiO}_{2}$ is the most tested semiconductor. Half of the works evaluated the performance of the composite under solar irradiation, and the majority use single-solute conditions and deionized water, not allowing the comparison of the behavior of the material, nor accounting for competition of other PhCs or organic matter. 
Table 5. Photocatalytic degradation of CBZ, DCF, and SMX by semiconductor/CNT (SWCNTsingle-walled carbon nanotubes, MWCNT-multi-walled carbon nanotubes).

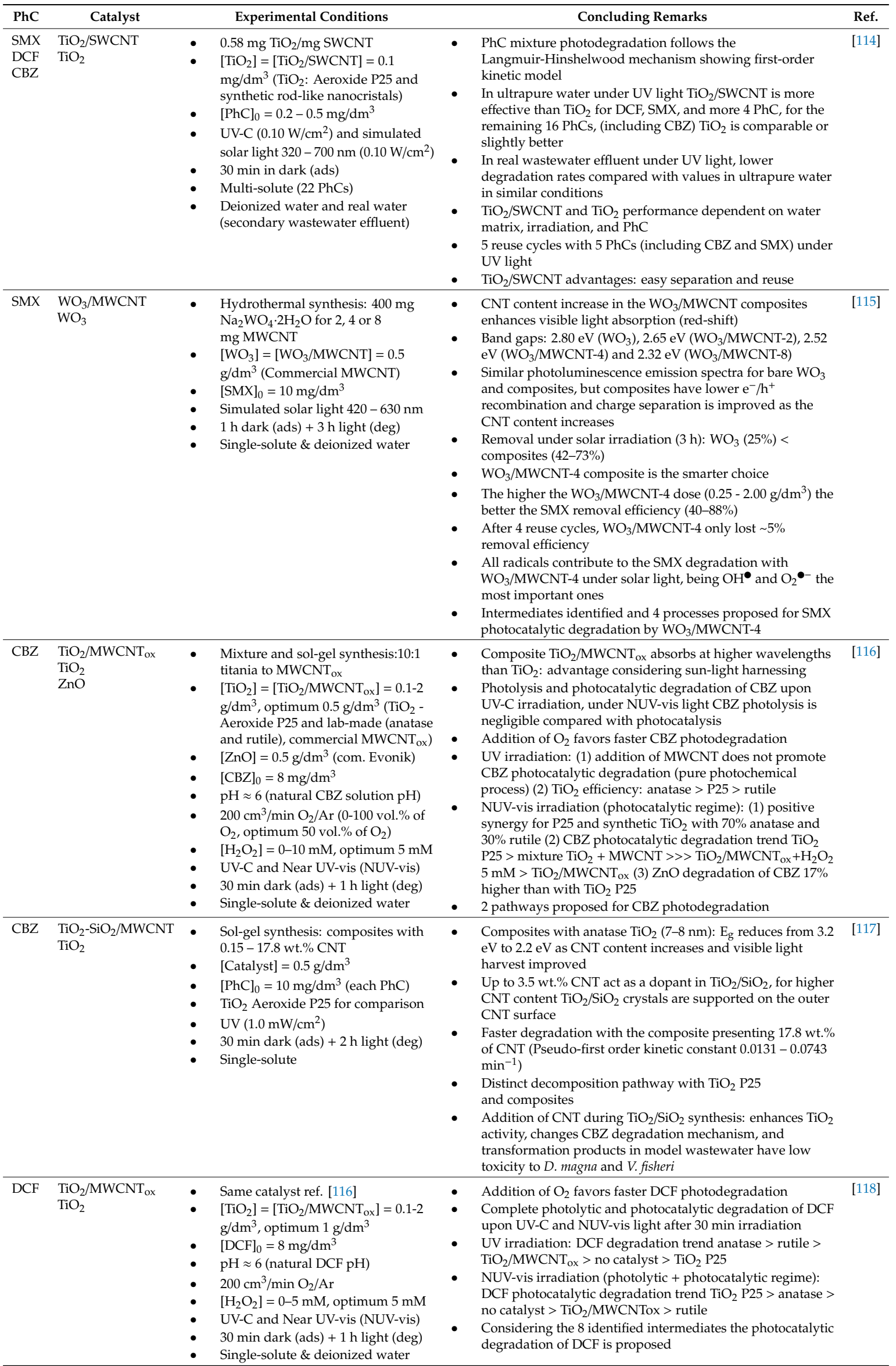


Table 5. Cont

\begin{tabular}{|c|c|c|c|c|}
\hline PhC & Catalyst & Experimental Conditions & Concluding Remarks & Ref. \\
\hline DCF & $\begin{array}{l}\mathrm{SiO}_{2}-\mathrm{TiO}_{2} / \mathrm{MWCNT} \\
\mathrm{SiO}_{2}-\mathrm{TiO}_{2} \\
\mathrm{TiO}_{2}\end{array}$ & $\begin{array}{ll}\text { - } & \text { Sol-gel method: }(0.01 \text { wt.\% } \\
& \text { MWCNT) basic and acid conditions, } \\
& \text { calcined in air }\left(400{ }^{\circ} \mathrm{C}\right) \\
\text { - } & {[\text { Catalyst }]=0.5 \mathrm{~g} / \mathrm{dm}^{3}} \\
\text { - } & \mathrm{TiO}_{2} \text { lab-made and } \mathrm{P} 25 \text { (Evonik) } \\
\text { - } & {[\mathrm{DCF}]_{0}=10 \mathrm{mg} / \mathrm{dm}^{3}} \\
\text { - } & \mathrm{UV}-\mathrm{A} \text { and visible light } \\
\text { - } & 30 \mathrm{~min} \text { dark (ads) }+1 \mathrm{~h} \text { light }(\mathrm{deg}) \\
\text { - } & \text { Single-solute }\end{array}$ & 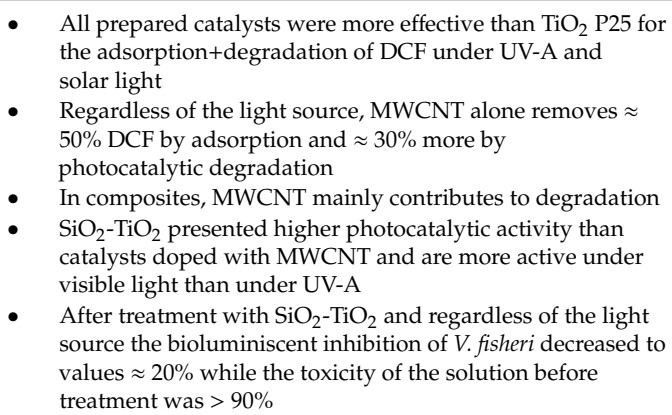 & [119] \\
\hline
\end{tabular}

ads-adsorption, deg-degradation

In 2015 Murgolo et al. tested the multi-solute photocatalytic degradation of $22 \mathrm{PhCs}$, in the ppm concentration range, under UV-C and simulated solar light in deionized water and secondary wastewater effluent. The first-order constant rates for DCF, SMX, and CBZ are summarized in Figure 5 [114]. In the most favorable experimental conditions-UV irradiation and deionized water-for DCF and SMX the first-order constant rates obtained with composite $\mathrm{TiO}_{2} / \mathrm{SWCNT}$ are much higher than with $\mathrm{TiO}_{2} \mathrm{P} 25$, while for $\mathrm{CBZ} \mathrm{TiO}_{2}$ similar values were observed. For secondary wastewater effluent irradiated with UV-C light the photodegradation rates of DCF and SMX are also favored with the composite and a detrimental effect of the real wastewater is clearly shown. Regarding simulated solar light irradiation, the only interesting results were those obtained with $\mathrm{TiO}_{2}$ in ultrapure water. The photodegradation rate of the three PhCs addressed in this review follows the order DCF $>$ SMX $>$ CBZ [114]. So, in line with the high persistence of CBZ in the environment, due to the low photolysis profiles in water streams, according to these results CBZ is also more resistant to photodegradation regardless the irradiation source and water matrix. The reuse of $\mathrm{TiO}_{2} / \mathrm{SWCNT}$ was tested for five cycles with five PhCs, including SMX and CBZ, under UV light. No variation of rate constants were observed for all but ibuprofen. Lastly, it is important to stress that this work clearly demonstrates the importance of performing studies in real water matrices since the results obtained in synthetic solutions do not allow a direct translation to water treatment facilities.

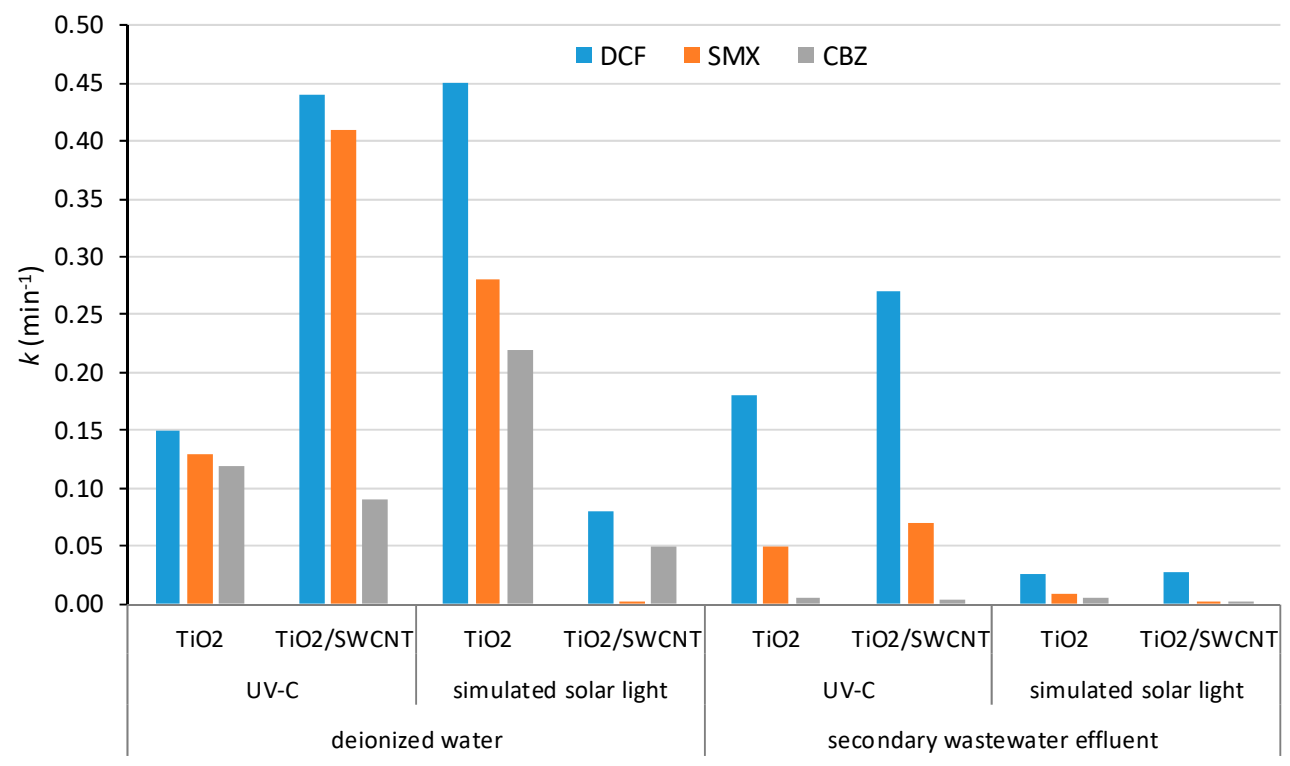

Figure 5. Effect of irradiation light and water matrix in first order kinetic constants $(k)$ for DCF, SMX, and CBZ multi-solute photodegadation by $\mathrm{TiO}_{2}$ and $\mathrm{TiO}_{2} / \mathrm{SWCNT}$ (data from [114]). 
Other studies listed in Table 5 systematically report enhanced visible light harvesting for the composites' semiconductor/CNT when compared with the bare semiconductor [115-119].

Zhu et al. prepared composites $\mathrm{WO}_{3} / \mathrm{MWCNT}$ with increasing CNT contents verifying that higher CNT amount lower both the band gap energy and $\mathrm{e}^{-} / \mathrm{h}^{+}$recombination. The composite $\mathrm{WO}_{3} / \mathrm{MWCNT}-4$ (4 $\mathrm{g}$ of MWCNT) presented the best compromise between the band gap energy $(2.52 \mathrm{eV})$, the dispersion in water and the amount of MWCNT [115]. SMX degradation efficiency under simulated solar light followed the order $\mathrm{WO}_{3}(25 \%)<\mathrm{WO}_{3} / \mathrm{MWCNT}-2(42 \%)<\mathrm{WO}_{3} / \mathrm{MWCNT}-4(65 \%)$ $<\mathrm{WO}_{3} / \mathrm{MWCNT}-8$ (73\%). The composite $\mathrm{WO}_{3} / \mathrm{MWCNT}-4$ only lost $5 \%$ efficiency after four reuse cycles [115]. The mechanism proposed for the SMX photocatalytic degradation under visible light irradiation involves the transference of the photo excited electron from the $\mathrm{WO}_{3}$ conducting band to the CNT which acts as an electron trap to hinder $\mathrm{e}^{-} / \mathrm{h}^{+}$recombination. The electron will react with $\mathrm{O}_{2}$ to produce $\mathrm{O}_{2}^{\bullet \bullet}$, while the hole reacts with water and/or surface hydroxyl to generate $\mathrm{OH}^{\bullet}$, these radicals will decompose the SMX [115].

Martinez et al. used $\mathrm{TiO}_{2} / \mathrm{MWCNT}_{\text {ox }}$ and $\mathrm{TiO}_{2}$ for the photocatalytic degradation of CBZ [116] and DCF [118] under UV-C and near UV-Vis irradiation (single-solute and deionized water). The $\mathrm{TiO}_{2} / \mathrm{MWCNT}_{\text {ox }}$ with a 10:1 weight ratio absorbes at higher wavelengths than $\mathrm{TiO}_{2}(\mathrm{P} 25$, anatase or rutile) allowing improved sunlight harnessing [116,118]. The addition of $21 \%$ of $\mathrm{O}_{2}(\mathrm{~V} / \mathrm{V})$ contributes to a huge increase in the degradation rate of CBZ and DCF by P25 leading to half-life times lower than 5 min under near UV-vis light $[116,118]$. The faster degradation of the PhCs is attributed to the reaction between them and $\mathrm{HO}_{2} \bullet / \mathrm{O}_{2} \bullet-$, and/or to the strong electrophilic character of dissolved $\mathrm{O}_{2}$ which may reduce unfavorable $\mathrm{e}^{-} / \mathrm{h}^{+}$recombination. Albeit the improved sunlight harvesting, compared with anatase for UV irradiation or P25 for near UV-vis irradiation, the composite has worst photoactivity for CBZ and DCF degradation (UV-C or near UV-vis), possibly due to $\mathrm{OH}^{\bullet}$ inhibition in the presence of MWCNTs. The fact that CBZ and DCF are electron-rich molecules that may transfer $\mathrm{e}^{-}$to MWCNT conducting band may also justify the slower oxidation process $[116,118]$.

Czech \& Buda tested nanocomposites $\mathrm{TiO}_{2}-\mathrm{SiO}_{2} / \mathrm{MWCNT}$ with $0.01 \%$ to $17.8 \%$ of $\mathrm{CNT}$ against $\mathrm{TiO}_{2}-\mathrm{SiO}_{2}$ for the photocatalytic degradation of CBZ [117] and DCF [119]. The addition of $\mathrm{SiO}_{2}$ promotes the dispersion of $\mathrm{TiO}_{2}$ [119] while the addition of MWCNT steadily reduces the band-gap of the composite $\mathrm{TiO}_{2}-\mathrm{SiO}_{2} / \mathrm{MWCNT}$ from $3.2 \mathrm{eV}$ to $2.2 \mathrm{eV}$ when the $\mathrm{CNT}$ content increases from $0.15 \%$ to $17.8 \%$, shifting absorption to visible [117]. CNT acts as a dopant for up to $3.5 \mathrm{wt}$.\% CNT but as support for higher concentrations. Under UV-A irradiation $\mathrm{TiO}_{2}-\mathrm{SiO}_{2} / \mathrm{MWCNT}$ with $17.8 \mathrm{wt} . \%$ of CNT allows faster CBZ degradation, through a decomposition pathway distinct from that obtained by $\mathrm{P} 25$, and the formation of degradation products with low toxicity to $D$. magma and $V$. fisheri. Both composites with $\mathrm{TiO}_{2}-\mathrm{SiO}_{2} / \mathrm{MWCNT}$ with $0.01 \mathrm{wt}$.\% of CNT was effective than bare P25 for the adsorption and degradation of the DCF under UV-A or solar light. Most probably due to their small weight percentage in composites, MWCNTs mainly contributes to the degradation step [119]. However $\mathrm{SiO}_{2}-\mathrm{TiO}_{2}$ presented even higher photocatalytic activity than those doped with MWCNT, being more active under visible light than under UV-A and allowing a decrease of bioluminiscent inhibition of $V$. fisheri (from $>90 \%$ to values $\approx 20 \%$ ) [119]. It must be also highlighted that MWCNTs are effective solar-responsive metal-free photocatalysts for DCF degradation regardless the light source (UV-A and visible). In fact MWCNTs removed $\approx 50 \%$ DCF by adsorption plus more $30-40 \%$ by photocatalytic degradation [119].

\subsection{Semiconductor/(r)GO}

Graphene is a two-dimensional (2D) sheet of carbon atoms connected by $\mathrm{sp}^{2}$ bonds with an aromatic $\pi$ electron system [120], it has a high thermal conductivity $(\approx 5000 \mathrm{~W} /(\mathrm{m} \times \mathrm{K}))$, allows excellent mobility of charge carriers at room temperature $\left(2000 \mathrm{~cm}^{2} /(\mathrm{V} \times \mathrm{s})\right)$, high optical transmittance $(\approx 97.7 \%)$, and has an extremely high theoretical specific surface area $\left(\approx 2600 \mathrm{~m}^{2} / \mathrm{g}\right)[121,122]$. The first report of graphene synthesis and properties dates from 2004 by Novosevol et al. and since then graphene has 
been extensively explored by the scientific community in several applications, and it also caught the attention of industry.

Graphene is the precursor of graphene oxide (GO) and reduced graphene oxide (rGO), both showing high efficiency for water treatment due to their surface functionalities (e.g., hydroxyl, carboxyl and epoxy) [72]. Due to the exceptional features of graphene and derived nanomaterials, these solids are attractive for many applications mainly in environmental protection and energy production/storage. The use of graphene-based semiconductor photocatalysts has been a hot research topic since graphene joins the most promising properties of CNTs and activated carbons, i.e., the high electron mobility with high pore structure and adsorption capacity. The advances in graphene-based semiconductor photocatalysis have been addressed in several review papers [72,73,80-84,121-123].

The enhanced photoactivity of semiconductor/graphene composites can be understood in light of the mechanisms previously described for semiconductor and activated carbon or CNT composites. The advantages and shortcomings of the use of activated carbons, CNTs and graphene on the semiconductor composites were systematized by Awfa et al. [72] identifying that easy recovery from reaction media follows the trend activated carbon $>\mathrm{CNT}>$ graphene, while the overall process cost follows the opposite trend. High mechanical strength and improved thermal stability, large electron storage capacity, and superior metallic conductivity are some of the advantages of adding CNT and graphene to semiconductors. Due to graphene's 2D structure, the interfacial contact between graphene and the semiconductor usually provides higher photoactivity [72]. The more difficult separation of the semiconductor/graphene composites can be overcome during the synthesis to obtain, for example, 3D aerogels [124], composites immobilized onto a solid supports [125] or adding magnetic features [126]. As reviewed by Dong et al. [127] the enhanced visible light photocatalytic activity of semiconductor/graphene composites is attributed to (i) the improved $\mathrm{e}^{-} / \mathrm{h}^{+}$mobility and suppression of the photo-generated $\mathrm{e}^{-} / \mathrm{h}^{+}$recombination, (ii) to their higher surface adsorption capacity for organic molecules through $\pi-\pi$ interactions, and (iii) full and intimate contact through chemical bonds of the metal semiconductor with carbon and oxygen atoms.

Certainly due to their potential graphene-based materials were the most representative group of composites studied for the photocatalytic degradation of CBZ, DCF, and SMX. It must be also noted that the majority of studies listed in Table 6, were tested under under visible irradiation, and only two works evaluate the performance of the photocatalysts in real water. In all but one study $\mathrm{TiO}_{2}$ was the semiconductor selected.

Table 6. Photocatalytic degradation of CBZ, DCF, and SMX by semiconductor/graphene (GO-graphene oxide, rGO—reduced graphene oxide).

\begin{tabular}{|c|c|c|c|c|}
\hline PhC & Catalyst & Experimental Conditions & Concluding Remarks & Ref. \\
\hline $\begin{array}{l}\text { SMX } \\
\text { CBZ }\end{array}$ & $\begin{array}{l}\mathrm{TiO}_{2} / \mathrm{rGO} \\
\mathrm{TiO}_{2}\end{array}$ & $\begin{array}{ll}\text { - } & \mathrm{TiO}_{2} / \mathrm{rGO}(0.1-10 \text { wt. } \% \text { GO:TiO } \\
& \text { coated on optical fibers } \\
\text { - } & \text { Catalyst: } 30 \text { fibers of } 10 \mathrm{~cm} \text { coated } \\
& \text { with composite and } \mathrm{TiO}_{2} \\
& \text { (synthesized and Aeroxide P25) } \\
\text { - } & {[\mathrm{PhC}]_{0}=5 \mathrm{mg} / \mathrm{dm}^{3} \text { (each PhC) }} \\
\text { - } & \mathrm{pH} 6 \\
\text { - } & \mathrm{UV}-\mathrm{vis}(\mathrm{UV}-\mathrm{B}, \mathrm{UV}-\mathrm{A} \text { and visible) } \\
\text { - } & 3 \text { h dark (ads) }+3 \text { h light }(\mathrm{deg}) \\
\text { - } & \text { Single-solute \& deionized water }\end{array}$ & $\begin{array}{l}\text { Without catalyst: } \mathrm{CBZ} \text { removal is negligible while } \mathrm{SMX} \\
\text { decreases } 30 \% \\
\text { Photoctalytic activity: synthesized } \mathrm{TiO}_{2}<\mathrm{TiO}_{2} \mathrm{P} 25< \\
\mathrm{TiO}_{2} / \mathrm{rGO}-2.7 \% \text { ( }>50 \% \mathrm{CBZ} \text { and }>90 \% \mathrm{SMX} \text { removals) } \\
\text { While } \mathrm{SMX} \text { removal is more effective than of } \mathrm{CBZ}(>90 \% \text { vs. } \\
\approx 40 \% \text { ) both reach similar mineralization }(54-59 \%) \text { after } 3 \mathrm{~h} \\
\text { irradiation: faster } \mathrm{SMX} \text { degradation but intermediates need } \\
\text { similar time as those of CBZ to achieve mineralization } \\
\text { - } \mathrm{TiO}_{2} / \mathrm{rGO}-2.7 \% \text { durability assessed for ibuprofen during } 15 \\
\text { cycles (45 h total contact time) under UV-vis irradiation: } \\
>80 \% \text { removal }\end{array}$ & [125] \\
\hline
\end{tabular}


Table 6. Cont

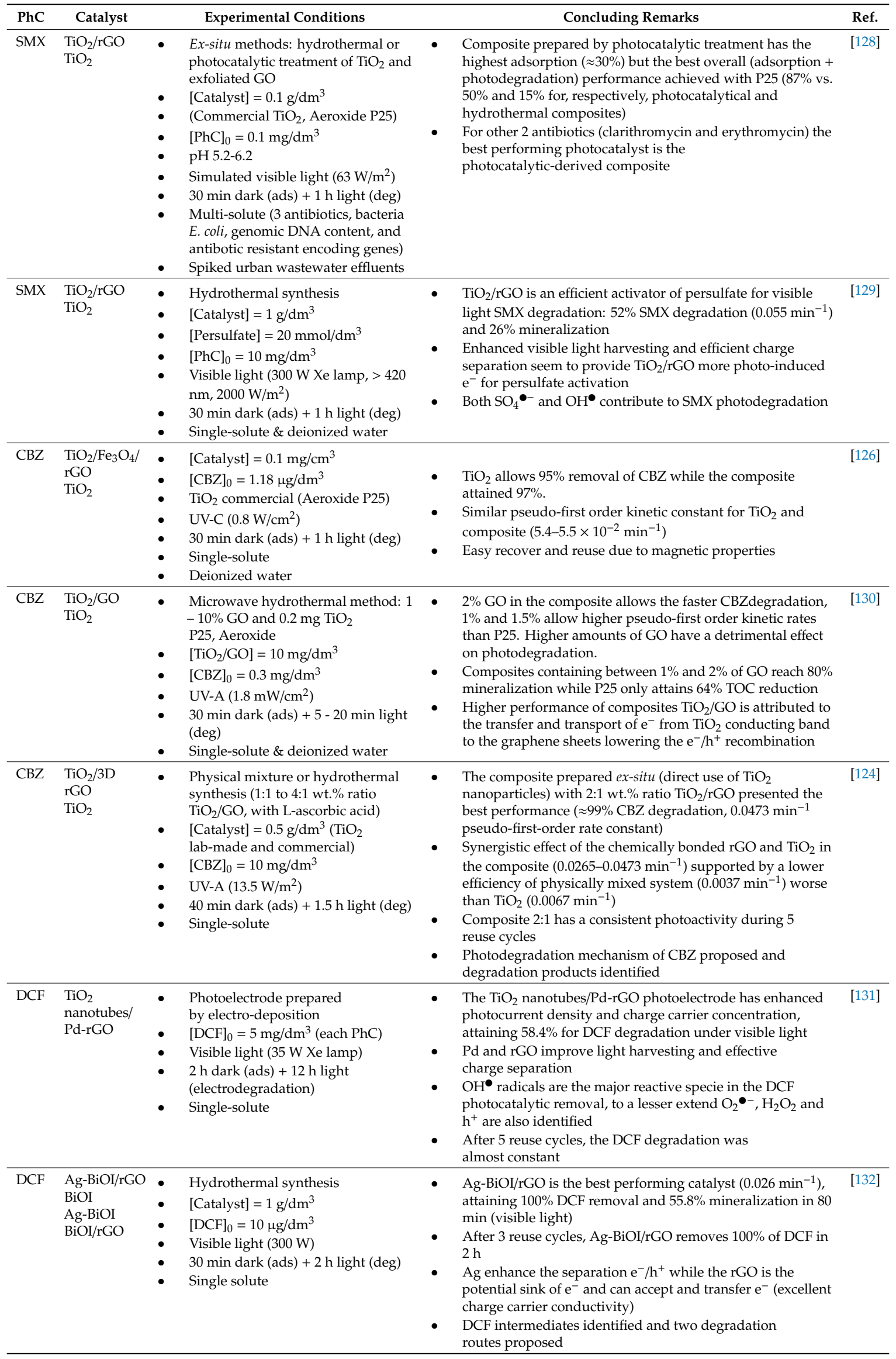


Table 6. Cont

\begin{tabular}{|c|c|c|c|c|}
\hline $\mathrm{PhC}$ & Catalyst & Experimental Conditions & Concluding Remarks & Ref. \\
\hline $\mathrm{DCF}$ & $\mathrm{TiO}_{2} / \mathrm{rGO}$ & $\begin{array}{ll}\text { - } & \text { Hydrothermal method: wt. ratios } \\
& \mathrm{TiO}_{2}: \mathrm{rGO} 100: 0.1,100: 0.5 \text { and } 100: 1 \\
\text { - } & {[\text { Catalyst }]=0.3 \mathrm{~g} / \mathrm{dm}^{3}} \\
\text { - } & {[\text { Peroxodisulfate(PDS)] }=0-5 \mathrm{mM}} \\
\text { - } & {[\mathrm{DCF}]_{0}=4 \mathrm{mg} / \mathrm{dm}^{3}} \\
\text { - } & \mathrm{pH} 4-9 \\
\text { - } & \text { Visible (blue) light LED }(450-455 \\
& \left.\mathrm{nm}, \sim 3.84 \mathrm{~mW} / \mathrm{cm}^{2}\right) \\
& 12 \mathrm{~min} \text { dark (ads) }+20 \mathrm{~min} \text { light } \\
& (\text { deg) } \\
\text { - } & \text { Single-solute } \\
\text { - } & \text { Deionized water, tap water, lake } \\
& \text { water, and river water }\end{array}$ & 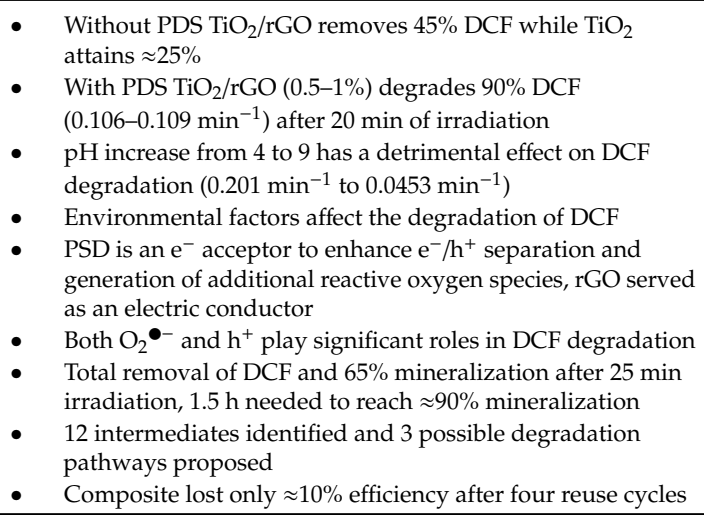 & [133] \\
\hline
\end{tabular}

ads-adsorption, deg-degradation

Lin et al. synthesized $\mathrm{TiO}_{2} / \mathrm{rGO}$ with $\mathrm{rGO}$ weight percentages $0.1-10 \%$ coated and tested the photoactivity of the composites for the photocatalytic degradation of three $\mathrm{PhC}$, including SMX and CBZ, under UV and visible light [125]. The best performing photocatalyst was $\mathrm{TiO}_{2} / \mathrm{rGO}-2.7 \%$ due to (i) lower band gap energy, (ii) formation of a heterojunction interface leading to improved charge separation [125]. Under UV-vis irradiation SMX removal is more effective than CBZ (92\% vs. $54 \%$ ) but both PhCs attain similar mineralization degrees (54-59\%) indicating that although SMX presents faster degradation its oxidation intermediates need similar time as those of CBZ to achieve mineralization [125]. The immobilization of the composite onto optical fibers proved to be a promising strategy since after 15 cycles (i.e., corresponding to $45 \mathrm{~h}$ ) under UV-vis irradiation the ibuprofen removal efficiency by $\mathrm{TiO}_{2} / \mathrm{rGO}-2.7 \%$ was over $80 \%$ [125].

SMX photocatalytic degradation by $\mathrm{TiO}_{2} / \mathrm{rGO}$ composites under visible light was also tested by Yang et al. demonstrating that $\mathrm{TiO}_{2} / \mathrm{rGO}$ is an activator of persulfate for SMX and other PhCs degradation through $\mathrm{SO}_{4}{ }^{\bullet-}$ and $\mathrm{OH}^{\bullet}$ [129]. Karaolia et al. studied SMX adsorption and photocatalytic degradation in spiked real urban wastewater effluent verifying that bare P25 is more efficient that $\mathrm{TiO}_{2} / \mathrm{rGO}$ prepared photocatalitically or by hydrothermal synthesis [128].

Three studies report CBZ photochemical degradation using single-solute conditions and UV irradiation. The best performing $\mathrm{TiO}_{2} /$ graphene composite attained higher $\mathrm{CBZ}$ degradation than bare $\mathrm{TiO}_{2}[124,126,130]$ and adding magnetic properties [126] or 3D graphene structure [124] allowed several reuse cycles. Appavoo et al. [130] and Nawaz et al. [124] concluded that there is an optimum percentage of $\mathrm{GO}$ or $\mathrm{rGO}$ to assure the best compromise between $\mathrm{CBZ}$ adsorption and photocatalytic degradation. Appavoo et al. report mineralization degrees of $80 \%$ when composites with $1 \%$ and $2 \%$ of GO are used, while P25 only reaches $64 \%$.

Metals or peroxodisulfate were used as addictive to improve photocatalytic degradation of DCF with semiconductor/graphene composites under visible light [131-133]. Cheng et al. conclude that both $\mathrm{Pd}$ and $\mathrm{rGO}$ in the $\mathrm{TiO}_{2}$ nanotubes/Pd-rGO contribute to the improved light harvesting and effective separation of the photogenerated charge carriers, and identify $\mathrm{OH}^{\bullet}$ as the most relevant radicals for DCF degradation [131]. Li et al. reported 100\% DCF removal and 55.8\% mineralization when irradiating $\mathrm{Ag}-\mathrm{BiOI} / \mathrm{rGO}$ under visible light during $80 \mathrm{~min}$, maintaining the performance after three reuse cycles [132]. The authors propose that Ag enhance the separation $\mathrm{e}^{-} / \mathrm{h}^{+}$while the $\mathrm{rGO}$ with extended $\pi$-electron conjugations has strong charge transfer capability and is the potential sink of e-. Moreover, rGO can function as e- acceptor, and transfer due to its excellent charge carrier conductivity [132]. The work by Chen et al. followed a more applied perspective by evaluating the effect of the water matrix and solution $\mathrm{pH}$ in the DCF degradation by $\mathrm{TiO}_{2} / \mathrm{rGO}$ in the presence of peroxodisulfate under visible light [133]. The authors verified that the increase of solution $\mathrm{pH}$ has a detrimental effect on DCF degradation rate and environmental factors also interfere in the degradation. 
The presence of $\mathrm{Cl}^{-}$facilitates DCF degradation but the presence of $\mathrm{HCO}_{3}^{-}$as well as tap water, lake water, river water matrices decrease DCF degradation. In this photodegradation system both $\mathrm{O}_{2}^{\bullet-}$ and $\mathrm{h}^{+}$play significant roles in DCF degradation, peroxodisulfate behaved like an electron acceptor to enhance $\mathrm{e}^{-} / \mathrm{h}^{+}$separation and generation of additional reactive oxygen species, and rGO served as electric conductor, so both addictive increase photocatalytic efficiency of the composite for DCF degradation [133].

\subsection{Semiconductor/Carbon Quantum Dots (CQDs)}

Carbon quantum dots (CQDs) were firstly reported by Xu et al. [134] in 2004 just a few months earlier than graphene, but these fluorescent carbon nanoparticles only received their most common name - CQD - from Sun et al. in 2006 [135]. CQDs are approximately flat or quasi-spherical carbon nanoparticles $(<10 \mathrm{~nm})$ composed by amorphous to nanocrystalline cores with predominantly $\mathrm{sp}^{2}$ carbon (i.e., graphitic carbon and/or graphene and GO sheets) fused by diamond-like $\mathrm{sp}^{3}$ hybridized carbon intersections [136,137]. CQDs have excellent aqueous solubility due to the considerable amounts of carboxylic surface moieties, presenting oxygen content between 5 and 50\% [135-137]. CQDs have demonstrated capability of harnessing long wavelength light and their ability to exchange energy with solution species offers excellent opportunities for their use as photocatalysts [136]. Furthermore, CQDs present up-conversion fluorescent emission, an optical phenomenon wherein the fluorescence emission wavelength is shorter than the used excitation wavelength. This property is particularly important for in vivo bioimaging since near IR (NIR) region is usually preferred [136] but is also a very valuable feature to improve semiconductor photoactivity under full sunlight spectrum [137]. In fact, CQDs proved to be excellent additives in solar photocatalytic systems since their ability to harness the full spectrum of sunlight and up-convert visible light into shorter wavelength light triggers the semiconductor charge separation (i.e., $\mathrm{e}^{-} / \mathrm{h}^{+}$generation and hinders recombination) which by reaction with $\mathrm{H}_{2} \mathrm{O} / \mathrm{O}_{2}$ will produce the active oxygen species needed to promote contaminants degradation [136,137].

Regarding the target $\mathrm{PhCs}$, to the best of our knowledge, so far semiconductor/CQD composites were only explored for the photodegradation of DCF (Table 7). The three very recent studies explore the solar light photoactivity of the composites in single-solute conditions, and only one evaluates the influence of distinct water matrices.

Table 7. Photocatalytic degradation of DCF by semiconductor/CQD.

\begin{tabular}{|c|c|c|c|c|}
\hline PhC & Catalyst & Experimental Conditions & Concluding Remarks & Ref. \\
\hline DCF & $\begin{array}{l}\mathrm{BiOCOOH} / \mathrm{CQD} \\
\mathrm{TiO}_{2}\end{array}$ & $\begin{array}{ll}\text { - } & \text { Composites obtained by ultrasonic } \\
\text { dispersion }\left(3 \mathrm{~h} \text { at } 180{ }^{\circ} \mathrm{C}\right) \\
\text { - } & {[\text { Catalyst }]=0.6 \mathrm{~g} / \mathrm{dm}^{3}} \\
\text { - } & \left(\mathrm{TiO}_{2}-\text { Aeroxide P25) }\right. \\
\text { - } & {[\mathrm{PhC}]_{0}=4 \mathrm{mg} / \mathrm{dm}^{3}} \\
\text { - } & \mathrm{pH} 7 \\
\text { - } & \text { Kinetic, by-product and toxicity: } \\
& \text { Visible light }(350 \mathrm{~W} \text { Xe lamp, } 1.15 \\
& \left.\mathrm{mW} / \mathrm{cm}^{2}\right) \text { with } 420 \mathrm{~nm} \text { cut-off } \\
\text { - } & \text { Photocatalyst mechanism tests: } \\
& \text { UV-A }\left(390-400 \mathrm{~nm}, 1.6 \mathrm{~mW} / \mathrm{cm}^{2}\right) \\
& \text { Blue }\left(455-460 \mathrm{~nm}, 3.84 \mathrm{~mW} / \mathrm{cm}^{2}\right) \\
& \text { Green }\left(515-530 \mathrm{~nm}, 4.5 \mathrm{~mW} / \mathrm{cm}^{2}\right) \\
& \text { Red }\left(655-660 \mathrm{~nm}, 4.07 \mathrm{~mW} / \mathrm{cm}^{2}\right) \\
\text { Near-IV }\left(750 \mathrm{~nm}, 3.1 \mathrm{~mW} / \mathrm{cm}^{2}\right) \\
\text { - } \quad 30 \text { min dark }(\mathrm{ads})+1-2 \mathrm{~h} \mathrm{light}(\mathrm{deg}) \\
\text { Single-solute }\end{array}$ & 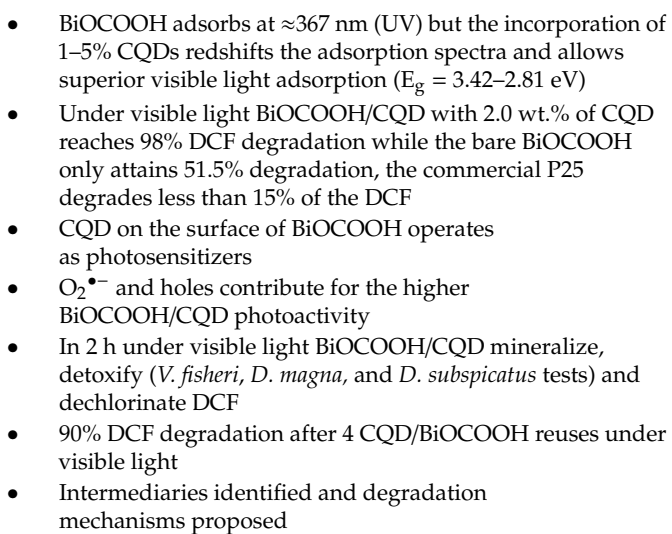 & [138] \\
\hline
\end{tabular}


Table 7. Cont

\begin{tabular}{|c|c|c|c|c|}
\hline $\mathrm{PhC}$ & Catalyst & Experimental Conditions & Concluding Remarks & Ref. \\
\hline DCF & $\begin{array}{l}\mathrm{TiO}_{2}\{001\} / \mathrm{N}-\mathrm{CQD} \\
\mathrm{TiO}_{2}\{101\} / \mathrm{N}-\mathrm{CQD} \\
\mathrm{TiO}_{2}(\mathrm{P} 25) / \mathrm{N}-\mathrm{CQD}\end{array}$ & 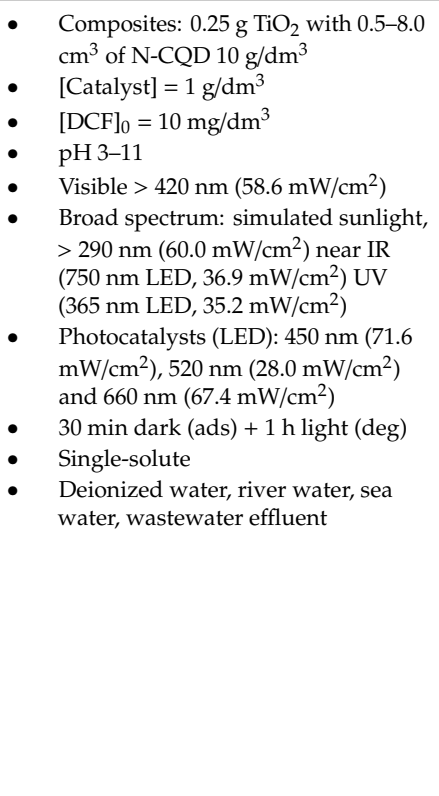 & 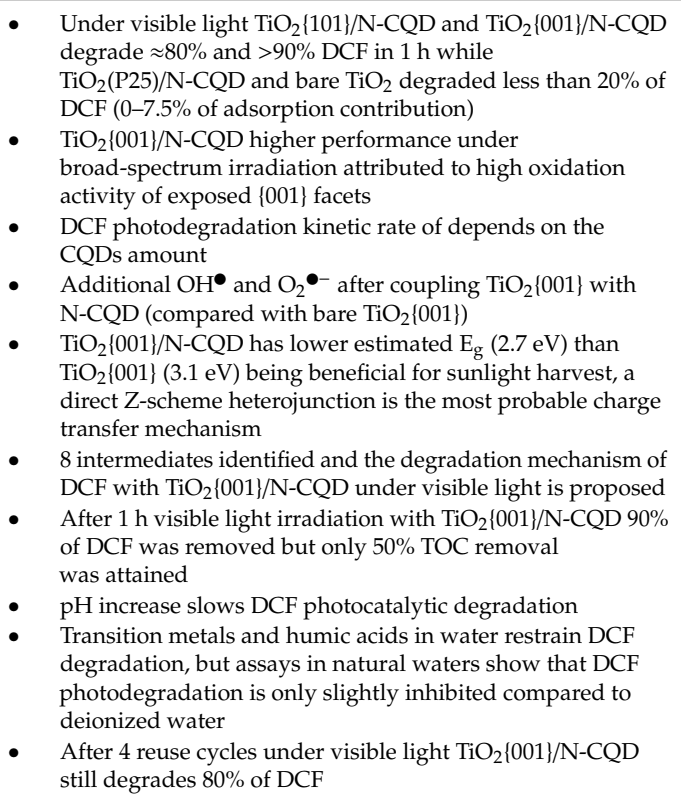 & [139] \\
\hline DCF & $\begin{array}{l}\mathrm{g}-\mathrm{C}_{3} \mathrm{~N}_{4} / \mathrm{CQD} \\
\mathrm{g}-\mathrm{C}_{3} \mathrm{~N}_{4}\end{array}$ & $\begin{array}{ll}\text { - } & \text { Composites and } \mathrm{g}-\mathrm{C}_{3} \mathrm{~N}_{4} \text { prepared } \\
& \text { via polymerization }(0.02,0.05,0.1 \\
& \left.\text { and } 0.2 \mathrm{~cm}^{3} \text { of } \mathrm{CQD}\right) \\
\text { - } & {[\text { Catalyst }]=0.2 \mathrm{~g} / \mathrm{dm}^{3}} \\
\text { - } & {[\mathrm{DCF}]_{0}=10 \mathrm{mg} / \mathrm{dm}^{3}} \\
\text { - } & \mathrm{pH} 5-9 \\
\text { - } & \text { Visible light }(300 \mathrm{~W} \mathrm{Xe} \text { lamp, } \\
& \left.400-700 \mathrm{~nm}, 150 \mathrm{~mW} / \mathrm{cm}^{2}\right) \\
\text { - } \quad 30 \mathrm{~min} \text { dark }(\mathrm{ads})+1 \mathrm{~h} \text { light }(\mathrm{deg}) \\
\text { - } \quad \text { Single-solute }\end{array}$ & 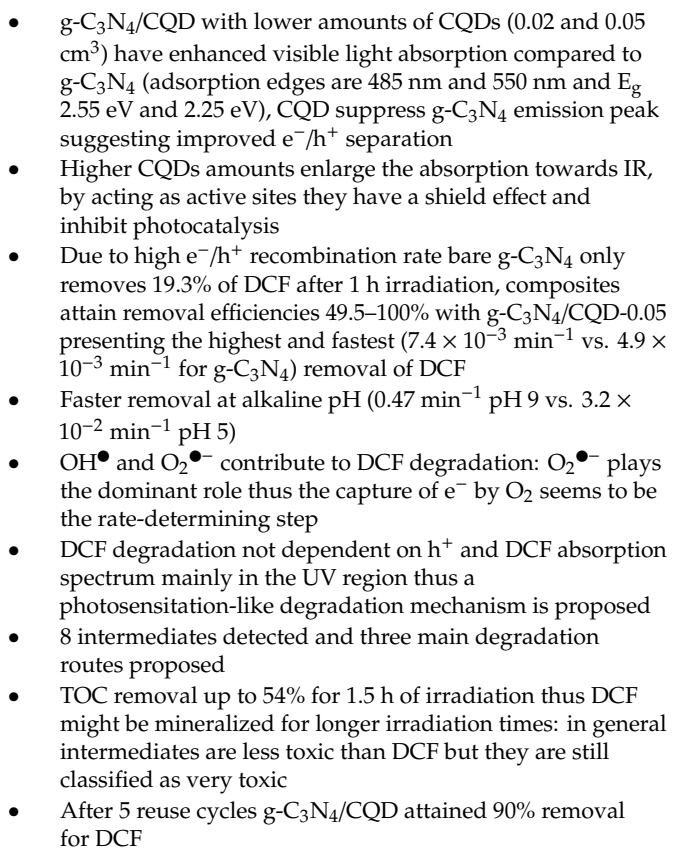 & [140] \\
\hline
\end{tabular}

ads-adsorption, deg-degradation

Chen et al. report the superior performance of $\mathrm{BiOCOOH/CQD} \mathrm{composites} \mathrm{under} \mathrm{visible-light}$ for the degradation of DCF when compared with P25 [138]. The incorporation of CQDs allows the composite to absorb in the visible range presenting band gaps $3.42-2.84 \mathrm{eV}$, as the percentages of CQDs increase from 1 to $5 \%$. The best photocatalytic activity is obtained for BiOCOOH/CQD-2\% (98\% DCF removal vs. $51.5 \%$ for $\mathrm{BiOCOOH}$ and only $15 \%$ for P25), allowing to attain $90 \%$ DCF even after four reuse cycles. This behavior was mainly attributed to the generation of $\mathrm{O}_{2}{ }^{\bullet-}$ and holes [138]. It is also remarkable that in just $2 \mathrm{~h}$ this composite effectively mineralized, detoxify and dechlorinated DCF, and it also presented high performance for the degradation of the antibiotic sulfadimidine $(>90 \%)$ and rhodamine B $(>75 \%)$, proving its potential for application in water remediation strategies. Authors propose CQDs act as photosensitizers of the $\mathrm{BiOCOOH}$, with the electron transfer properties 
of the CQDs being beneficial to constrain the $\mathrm{e}^{-} / \mathrm{h}^{+}$recombination and their up-conversion properties contributing to enhancing the visible photoactivity of the semiconductor [138].

In a more sustainable approach, Liu et al. tested metal free composites $\mathrm{g}_{-} \mathrm{C}_{3} \mathrm{~N}_{4} / \mathrm{CQD}$ for the visible light photodegradation of DCF [140]. Once again, the introduction of optimized amounts of CQDs improved visible light harvesting and increased $\mathrm{e}^{-} / \mathrm{h}^{+}$separation. Composite g- $\mathrm{C}_{3} \mathrm{~N}_{4} / \mathrm{CQD}-0.05$ showed the fastest total DCF removal just $1 \mathrm{~h}$ irradiation and degrades $90 \%$ of the DCF after five reuse cycles [140]. Alkaline medium favors a faster DCF degradation. $\mathrm{O}_{2}{ }^{\bullet-}$ plays the dominant role in the DCF degradation process which is not dependent on the holes, which allowed the proposal of a photosensitation-like mechanism. After $1.5 \mathrm{~h}$ of irradiation of $\mathrm{g}^{-} \mathrm{C}_{3} \mathrm{~N}_{4} / \mathrm{CQD}-0.05$, the DCF mineralization reached $54 \%$ and although, in general, the intermediates are less toxic than the parent compound they are still classified as very toxic, pointing out the need of longer irradiation times [140].

In 2017, Song et al. used g- $\mathrm{C}_{3} \mathrm{~N}_{4}$ for the photodegradation of sulfonamides, including SMX, under visible light attaining $90 \%$ removal under distinct water quality parameters [141]. SMX was degraded by $\mathrm{O}_{2} \bullet-$ and holes, and the degradation pathways were proposed.

Wang et al. compare the efficacy of composites of $\mathrm{TiO}_{2}$ nanosheets with two distinct surface energy facets or P25 with N-doped CQD for DCF degradation under broad spectrum irradiation [139]. The results reveal that $\mathrm{TiO}_{2}$ facets play a major role in the photodegradation process with the superior performance of $\mathrm{TiO}_{2}\{001\} / \mathrm{N}-\mathrm{CQD}$. This behavior was attributed to the synergistic effect of the high oxidation activity of exposed $\{001\}$ facets, up-conversion properties of the N-CQDs and efficient charge separation in the direct Z-scheme heterojunction [139]. Under visible light, composites with $\mathrm{TiO}_{2}\{101\}$ and $\mathrm{TiO}_{2}\{001\}$ photodegrade, respectively, around $80 \%$ and more than $90 \%$ of DCF after $1 \mathrm{~h}$ of irradiation, while composite with $\mathrm{P} 25$ and the three bare $\mathrm{TiO}_{2}$ samples degraded less than $20 \%$ of DCF [139]. Despite the high DCF removal by $\mathrm{TiO}_{2}\{001\} / \mathrm{N}-\mathrm{CQD}$, after $1 \mathrm{~h}$ of visible light irradiation, only $50 \%$ mineralization was achieved. After four reuse cycles, the composite effectively degrades $80 \%$ of DCF. Contrarily to what was reported by Liu et al. [140] for $g-\mathrm{C}_{3} \mathrm{~N}_{4} / \mathrm{CQD}$, with this composites the increase of solution $\mathrm{pH}$ from 3 to 11 has a detrimental effect on the DCF degradation rate (from 0.09 to $0.01 \mathrm{~min}^{-1}$ ) [139]. The influence of the water matrix was studied showing that the presence of transition metals and humic acids restrain the photodegradation of DCF. On the contrary the assays in natural waters (river water, sea water, and wastewater effluent) show that photocatalytic degradation of DCF is only slightly inhibited ( $84.0-84.6 \%$ vs. $90.9 \%$, in deionized water) [139].

\subsection{Semiconductor/Char}

Chars are typically obtained by the carbonization of biomass through the removal of other elements than carbon, and transformation of the precursor in an amorphous carbon-rich material usually named biochars [142]. Chars can also be designated as pyrochars, hydrochars or acid-chars depending on the carbonization process, i.e., pyrolysis, hydrothermal, or acid-mediated carbonization, respectively $[142,143]$. Chars have incipient pore networks and depending on the precursor and synthesis procedure (i.e., carbonization method, temperature, and time) it is possible to tailor their surface chemistry from highly acidic to basic surface chemistries rich in oxygen groups or even other electron rich atoms (e.g., nitrogen, sulfur, or phosphorus) in order to meet with the needs of a specific process. The oldest known use of char (carbonized wood, coal, or partially devolatilized coals), also known as charcoal, dates to the Stone Age when the material was used as black pigment for cave painting [144]. Greeks and Romans used charcoal in the treatment of various diseases, and Hindus for water treatment. In the nineteenth century, it played a crucial role in sugar refining, and as gas filters in London sewage ventilation systems [142]. Recently Chen et al. compared the photoactivity of a pyrochar vs. a hydrochar, obtained from the same precursor, verifying that due to the abundant photoactive oxygenated surface groups, the hydrochar could generate more reactive species under sunlight thus enhancing the degradation of the target pollutant (sulfadimidine) [143].

Along with the carbon materials previously discussed, biochars have also been tested to enhance semiconductor activity. The works focused on SMX and CBZ photodegradation under UV or visible 
light irradiation are gathered in Table 8. All the studies were performed in single-solute conditions and in one case the photocatalytic activity of the semiconductor/char composites in deionized water and spiked river water were compared.

Xie and co-workers reported 80\% SMX removal after $3 \mathrm{~h}$ under simulated visible light using a $\mathrm{Zn}-\mathrm{TiO}_{2} /$ biochar composite [145]. This composite outperformed $\mathrm{TiO}_{2} /$ biochar and bare $\mathrm{TiO}_{2}$, which was explained considering that $\mathrm{Zn}$-doping effectively reduced the agglomeration of $\mathrm{TiO}_{2}$ and decrease the crystal size. On the other hand, the higher photocurrent of $\mathrm{Zn}-\mathrm{TiO}_{2} /$ biochar justifies the higher charge transfer and separation [145]. The photoactivity of $\mathrm{Zn}-\mathrm{TiO}_{2} /$ biochar slightly decreases after the first cycle but remains almost constant in the next four reuses. Water matrix has a crucial role in the composite performance: in spiked river water only 53.83\% SMX removal, the presence of $\mathrm{SO}_{4}{ }^{2-}, \mathrm{Cl}^{-}$, and $\mathrm{NO}_{3}{ }^{-}$also has an inhibitory effect possibly due to trapping of $\mathrm{OH}^{\bullet}$ or capture of $\mathrm{h}^{+}$to hinder production of $\mathrm{OH}^{\bullet}$ [145].

CBZ photodagradation was studied by $\mathrm{Li}$ et al. with magnetic $\mathrm{Fe}_{3} \mathrm{O}_{4} / \mathrm{BiOBr} /$ biochar, $\mathrm{Fe}_{3} \mathrm{O}_{4} / \mathrm{BiOBr}$, and bare $\mathrm{BiOBr}$ [146]. At $\mathrm{pH} 6 \mathrm{Fe}_{3} \mathrm{O}_{4} / \mathrm{BiOBr} /$ biochar $\left(10 \%\right.$ biochar, $\left.0.05 \mathrm{~g} \mathrm{Fe}_{3} \mathrm{O}_{4}\right)$ is the best performing photocatalyst: highest rate constant $\left(0.01777 \mathrm{~min}^{-1}\right), \mathrm{CBZ}$ removal similar to that of $\mathrm{BiOBr}(95 \%)$, $70 \%$ mineralization (only $\approx 30 \%$ for $\mathrm{BiOBr}, \approx 55 \%$ for $\mathrm{Fe}_{3} \mathrm{O}_{4} / \mathrm{BiOBr}$ ). The species $\mathrm{OH}^{\bullet}, \mathrm{h}^{+}$and $\mathrm{O}_{2}^{\bullet-}$ seem $^{\bullet}$ to take part in the $\mathrm{CBZ}$ photodegradation, suggesting that oxygen radicals play the most important role. After five reuse cycles under visible irradiation, $\mathrm{Fe}_{3} \mathrm{O}_{4} / \mathrm{BiOBr} /$ biochar degraded $90 \%$ of the $\mathrm{CBZ}$, and in the fourth cycle more than $60 \%$ mineralization is achieved. Like in the previous study the presence of $\mathrm{Cl}^{-}$and $\mathrm{SO}_{4}{ }^{2-}$ has detrimental effect on CBZ degradation. Humic acid has opposite effects since while when they are present at low concentration photodegradation decreases but at higher concentrations they behaved as photosensitizers promoting CBZ photodegradation [146].

Table 8. Photocatalytic degradation of CBZ and SMX by semiconductor/char.

\begin{tabular}{|c|c|c|c|c|}
\hline PhC & Catalyst & Experimental Conditions & Concluding Remarks & Ref. \\
\hline SMX & $\begin{array}{l}\mathrm{Zn}-\mathrm{TiO}_{2} / \text { biochar } \\
\mathrm{TiO}_{2} \\
\mathrm{TiO}_{2} / \text { biochar }\end{array}$ & $\begin{array}{ll}\text { - } & \text { Sol-gel method: } \mathrm{Zn}\left(\mathrm{NO}_{3}\right)_{2}(1 \%, 10 \% \\
& \& 15 \%), 1 \mathrm{~g} \text { of pretreated reed straw } \\
\text { biochar and } 20 \mathrm{~cm}^{3} \text { tetrabutyl } \\
\left.\text { titanate (calcined at } 300{ }^{\circ} \mathrm{C}\right) \\
\text { - } \quad\left[\text { Catalyst }=0.625-2.5 \mathrm{~g} / \mathrm{dm}^{3}\right. \\
\text { - } \quad[\mathrm{SMX}]_{0}=10 \mathrm{mg} / \mathrm{dm}^{3} \\
\text { - } \quad \mathrm{pH} 2.01-10.97 \\
\text { - } \quad \text { Simulated visible light }(50 \mathrm{~W}, \mathrm{Xe} \\
\quad \text { lamp, }>420 \mathrm{~nm}) \\
\text { - } \quad 30 \text { min dark (ads) }+3 \mathrm{~h} \text { light }(\mathrm{deg}) \\
\text { - } \quad \text { Single-solute } \\
\text { - } \\
\text { reionized water \& spiked }\end{array}$ & 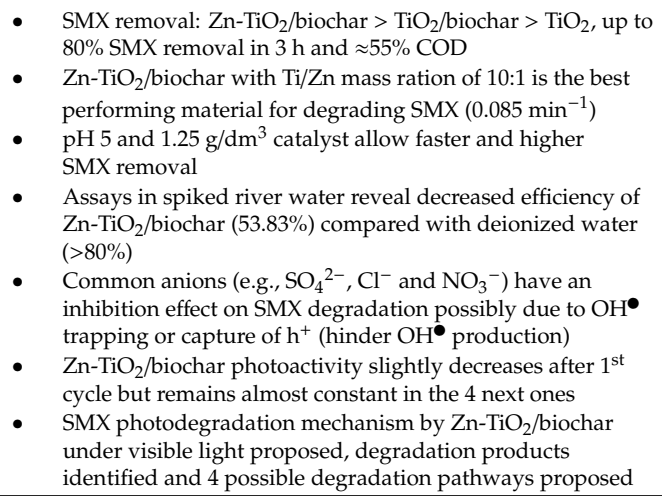 & [145] \\
\hline CBZ & $\begin{array}{l}\mathrm{Fe}_{3} \mathrm{O}_{4} / \mathrm{BiOBr} / \mathrm{Biochar} \\
\mathrm{Fe}_{3} \mathrm{O}_{4} / \mathrm{BiOBr} \\
\mathrm{BiOBr}\end{array}$ & $\begin{array}{ll}\text { - } & \text { One-step hydrolysis method: } 5 \% \text {, } \\
& 10 \%, 20 \% \text { and } 30 \% \text { (in wt. } \% \text { ) reed } \\
& \text { straw biochar } \\
\text { - } & {[\text { Catalyst }]=1 \mathrm{~g} / \mathrm{dm}^{3}} \\
\text { - } & {[\mathrm{CBZ}]_{0}=10 \mathrm{mg} / \mathrm{dm}^{3}} \\
\text { - } & \text { pH } 3-10 \\
\text { - } & \text { Visible LED light }(50 \mathrm{~W}, 475 \mathrm{~nm}) \\
\text { - } \quad & 1 \mathrm{~h} \text { dark (ads) }+3 \mathrm{~h} \text { light }(\mathrm{deg}) \\
\text { - } \quad \text { Single-solute }\end{array}$ & 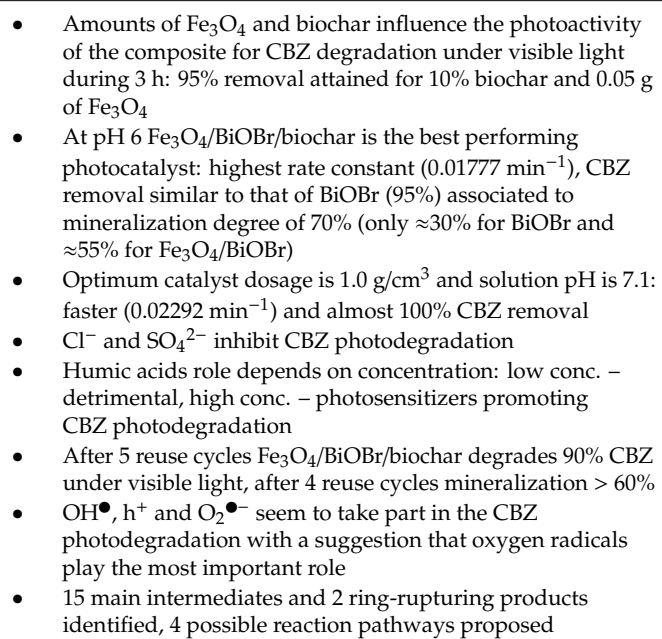 & [146] \\
\hline
\end{tabular}


Table 8. Cont

\begin{tabular}{|c|c|c|c|c|}
\hline $\mathrm{PhC}$ & Catalyst & Experimental Conditions & Concluding Remarks & Ref. \\
\hline CBZ & $\begin{array}{l}\mathrm{TiO}_{2} / \text { biochar } \\
\mathrm{TiO}_{2} \\
\text { biochar }\end{array}$ & $\begin{array}{l}\text { - } \quad \text { Sol-gel method: } \mathrm{TiO}_{2} / \text { coconut shell } \\
\text { powder char }\left(34.04 \mathrm{~cm}^{3}\right. \\
\text { titanium-n-butoxide and } 60-120 \\
\text { g biomass) } \\
\text { - } \quad \text { Pellets: mixing composites with } 10 \% \\
\text { wt. of wheat flour, calcined at } \\
500-800{ }^{\circ} \mathrm{C} \text { for } 2 \mathrm{~h} \\
\text { - } \quad\left[\text { Catalyst }=60-120 \mathrm{~g} / \mathrm{dm}^{3}\right. \\
\text { - } \quad[\mathrm{CBZ}]_{0}=10 \mathrm{mg} / \mathrm{dm}^{3} \\
\text { - } \quad 24 \mathrm{~g} / \mathrm{dm}^{3} \mathrm{O}_{2} \text { flow (bottom-to-top) } \\
\text { - } \quad \text { pH } 3-11 \\
\text { - } \quad \text { UV-C }\left(10.5 \mathrm{~mW} / \mathrm{cm}^{2}\right) \\
\text { - } \quad 60 \text { min light (ads+deg) } \\
\text { - } \quad \text { Single-solute \& deionized water }\end{array}$ & $\begin{array}{l}\text { - Composites have higher adsorption and photoactivity than } \\
\mathrm{TiO}_{2} \text { or char } \\
\text { - Composite with } 100 \mathrm{~g} \text { biomass calcined at } 700{ }^{\circ} \mathrm{C} \text { has attains } \\
98 \% \mathrm{CBZ} \text { removal possibly due to higher surface area and } \\
\text { lower crystallite size }\end{array}$ & [147] \\
\hline CBZ & $\begin{array}{l}\mathrm{TiO}_{2} / \text { biochar } \\
\mathrm{TiO}_{2} \\
\mathrm{GAC} \\
\text { biochar }\end{array}$ & $\begin{array}{ll}\text { - } & \text { Similar to ref. [147] } \\
\text { - } & {[\text { Catalyst }]=60-140 \mathrm{~g} / \mathrm{dm}^{3}} \\
\text { - } & {[\mathrm{CBZ}]_{0}=10-50 \mathrm{mg} / \mathrm{dm}^{3}} \\
\text { - } & 6-24 \mathrm{~g} / \mathrm{dm}^{3} \mathrm{O}_{2} \text { flow } \\
\text { - } & \mathrm{pH} 3-11 \\
\text { - } & \mathrm{UV}-\mathrm{A}\left(4.2 \mathrm{~mW} / \mathrm{cm}^{2}\right) \text { and UV-C }(10.5 \\
& \left.\mathrm{mW} / \mathrm{cm}^{2}\right) \\
\text { - } & 60 \mathrm{~min} \text { light (ads+deg) } \\
\text { - } & \text { Single-solute \& deionized water }\end{array}$ & $\begin{array}{l}\text { - Almost constant }\left(0.05 \mathrm{~min}^{-1}\right) \mathrm{CBZ} \text { degradation rate for } \mathrm{pH} 3 \\
\text { to } 11 \text {, attaining } 89.2-94.4 \% \mathrm{CBZ} \text { removal } \\
\mathrm{O}_{2} \text { flow increase improves the } \mathrm{CBZ} \text { photodegradation rate } \\
\text { constant more than } 1.6 \text { times }\left(0.025 \text { to } 0.042 \mathrm{~min}^{-1}\right) \\
\text { - After } 1 \mathrm{~h} \text { of } \mathrm{UV}-\mathrm{C} \text { irradiation } \mathrm{GAC} \text { and composite remove, } \\
\text { respectively, } \approx 90 \% \text { and } \approx 99 \% \mathrm{CBZ} \text { while } \mathrm{TiO}_{2} \text { and coconut } \\
\text { shell powder only remove } 35-42 \% \text { of } \mathrm{CBZ} \\
\text { - Enhanced adsorption+degradation with the composite } \\
\text { attributed to the surface area that allows adsorbing } \mathrm{CBZ} \text { that } \\
\text { is further photodegraded by the reactive oxygen species } \\
\text { produced by the semiconductor } \\
\text { - Composite has superior recycling performance over } 11 \\
\text { reuse cycles }\end{array}$ & [148] \\
\hline
\end{tabular}

ads-adsorption, deg-degradation

Khraisheh et al. assayed $\mathrm{TiO}_{2} /$ biochar, with coconut shell powder char, for the $\mathrm{CBZ}$ photodegradation under UV light irradiation in the presence of $\mathrm{O}_{2}$ flow $[147,148]$. Regardless of the biochar amount, all composites presented higher adsorption and photocatalytic activity than bare $\mathrm{TiO}_{2}$, biochar and granular activated carbon (GAC). For $\mathrm{pH} 3$ to 11 the degradation rate of CBZ is almost constant $\left(0.05 \mathrm{~min}^{-1}\right)$ attaining $89.2-94.4 \% \mathrm{CBZ}$ removal [148]. Interestingly after $1 \mathrm{~h}$ of UV-C irradiation GAC and composite attain, respectively, $\approx 90 \%$ and $\approx 99 \%$ CBZ removal while bare $\mathrm{TiO}_{2}$ and biochar only attain $42 \%$ of CBZ removal [148]. While the $90 \%$ removal with GAC is mainly attributed to adsorption (nanoporous solid), in the case of the biochar, that has an incipient pore structure, the $42 \%$ CBZ removal may result from the combined adsorption and photocatalytic degradation. Regarding recyclability $\mathrm{TiO}_{2}$ /biochar also has better performance since after 11 reuse cycles it removes $60 \%$ CBZ while for the other solids the removal is $<25 \%$ [148]. The enhanced removal of $\mathrm{CBZ}$ with the $\mathrm{TiO}_{2} /$ biochar composite is attributed to the surface area that allows adsorbing CBZ that is further photodegraded by the reactive oxygen species produced by the semiconductor [148].

\subsection{Overview of the Degradation Pathways and Intermediates/Products}

One of the major challenges of photocatalytic degradation of PhCs is to achieve total mineralization. Although in optimized conditions high and fast degradation of the target pollutants can be attained, the mineralization rate is usually slower than the removal rate leading to the presence of degradation intermediates and/or products whose toxicity can be higher than that of the parent compound.

Among all the works focused on SMX photocatalytic degradation by semiconductor/carbon materials only two address the mechanism and propose decomposition pathways $[115,145]$, in both cases under solar light irradiation. Despite the use of distinct composites- $\mathrm{WO}_{3} / \mathrm{MWCNT}$ and $\mathrm{Zn}-\mathrm{TiO}_{2} /$ biochar-four common transformation intermediates/products were identified and similar degradation pathways are proposed (Figure 6): (i) hydroxylation $\left(\mathrm{OH}^{\bullet}\right.$ attack) on the benzene ring or isoxazole ring of SMX generating mono- or di-hydroxyl derivatives, and (ii) then $\mathrm{OH}^{\bullet}$ cleavages the S-N bond. $[115,145]$. Zhu et al. propose that continuous radical attack to the benzene and isoxazole rings leads to bond cleavage [115]. The degradation products identified present $\mathrm{m} / \mathrm{z}$ down to 99 , being mainly substituted aromatic compounds. However, none of the studies report the mineralization degree or evaluated the toxicity of the solution after photocatalysis. 


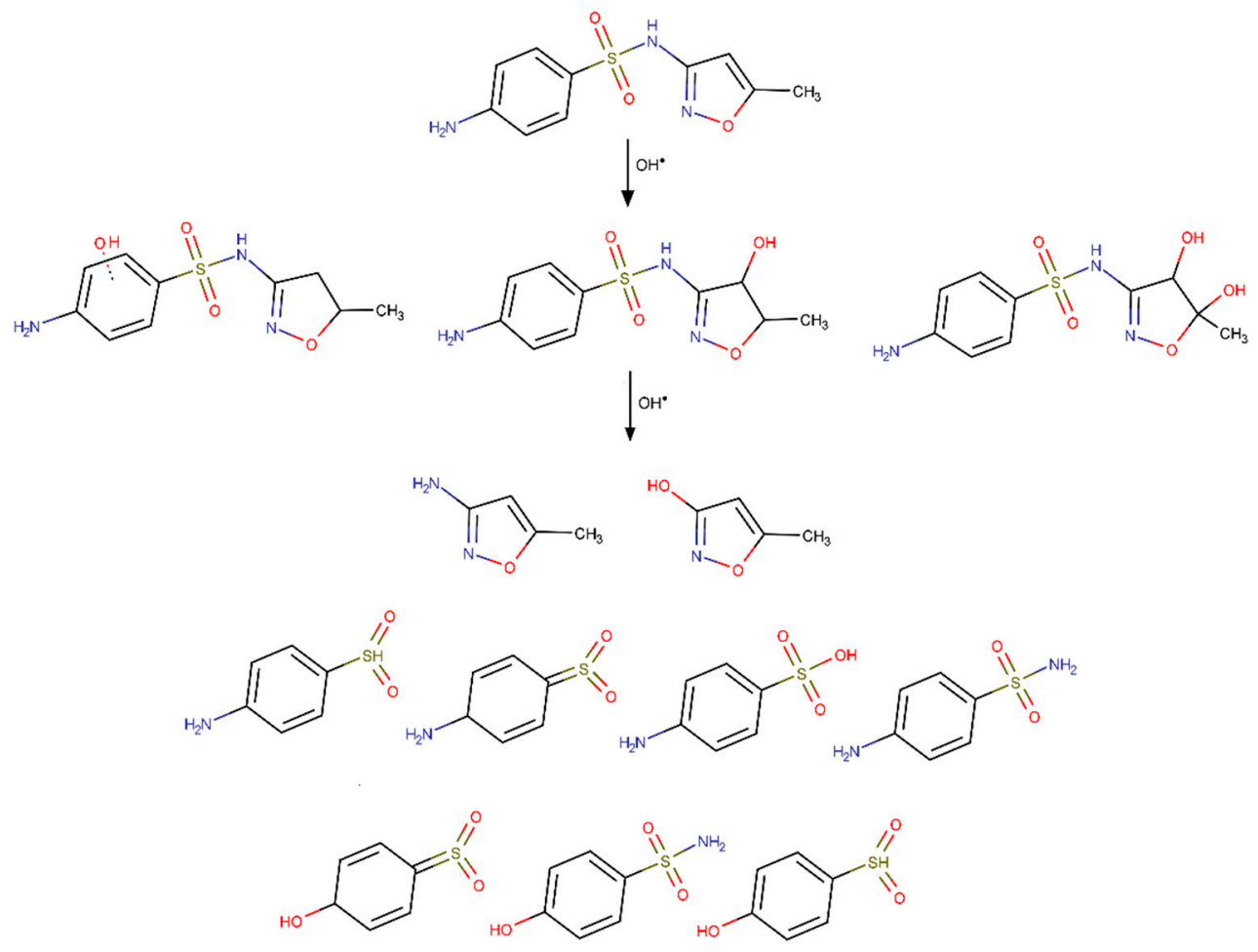

Figure 6. SMX degradation pathways and intermediates by $\mathrm{WO}_{3} / \mathrm{CNT}$ and/or $\mathrm{Zn}-\mathrm{TiO}_{2} /$ biochar under simulated solar light irradiation (based on $[115,145]$ ).

The visible-light driven photodegradation pathways of DCF by semiconductor/carbon materials were proposed by different research groups that explored the effect of CQDs and rGO addition to various semiconductors (i.e., $\mathrm{TiO}_{2}, \mathrm{TiO}_{2}\{001\}, \mathrm{BiOCOOH}, \mathrm{Ag}-\mathrm{BiOI}$ and $\mathrm{g}-\mathrm{C}_{3} \mathrm{~N}_{4}$ ) [132,133,138-140]. Hydroxylation, decarboxylation (through $\mathrm{O}_{2}{ }^{\bullet-}$ attack) and dechlorination, followed by C-N bond cleavage are the transformation pathways generally proposed (Figure 7). The smallest degradation products identified are single-ring aromatic compounds with chlorine, hydroxyl, carboxyl, and amine substituents (m/z from 127 to 194). By using $g-\mathrm{C}_{3} \mathrm{~N}_{4} / \mathrm{CQD}$ Liu et al. attained DCF mineralization degrees of $54 \%$ after $1.5 \mathrm{~h}$ of visible light irradiation and estimated the toxicity of DCF and its degradation intermediates/products by quantitative structure-activity relationship (QSAR) prediction [140]. The authors conclude that, according to acute toxicity values, although in general the degradation intermediates are less toxic than parent DFC they are still classified as very toxic $\left(\mathrm{LD}_{50}\right.$ for rat is $244 \mathrm{mg} / \mathrm{kg}$ ). However the photocatalytic process with $\mathrm{g}-\mathrm{C}_{3} \mathrm{~N}_{4} / C Q D$ significantly decreased the bioaccumulation factor and development toxicity, compared to parent DCF. Moreover while DCF is "mutagenic positive" only one of the degradation intermediates (obtained by chlorine removal and ring closure) has the same classification, and the remaining are "mutagenic negative" [140]. Czech et al. verified that after photodegradation treatment of DCF solution with $\mathrm{SiO}_{2}-\mathrm{TiO}_{2} / \mathrm{MWCNT}$, and regardless the use of UV-A or visible light, the $V$. fisheri bioluminescence inhibition decreased to values around $20 \%$ (i.e., in the border between toxic and non-toxic classification) while the toxicity of the initial DCF solution was higher than 90\% [119]. The photodegradation of DCF with BiOCOOH/CQD composites under visible light irradiation demonstrates that treatment time is a critical factor [138]. After 40-50 min of treatment DCF was totally removed, but the mineralization degree was only $47.9 \%$, certainly due to the abundant degradation intermediates. The assays with $V$. fisheri, D. magna, and D. subspicatus systematically reveal that the toxicity of the degradation intermediates presents a maximum at 40-50 min of treatment (more than double of the parent DCF) [138]. However, after $2 \mathrm{~h}$ of treatment DCF was effectively mineralized, detoxified and dechlorinated, clearly demonstrating 
the need of prolonged treatment times to assure higher mineralization degrees and consequently lower toxicity.

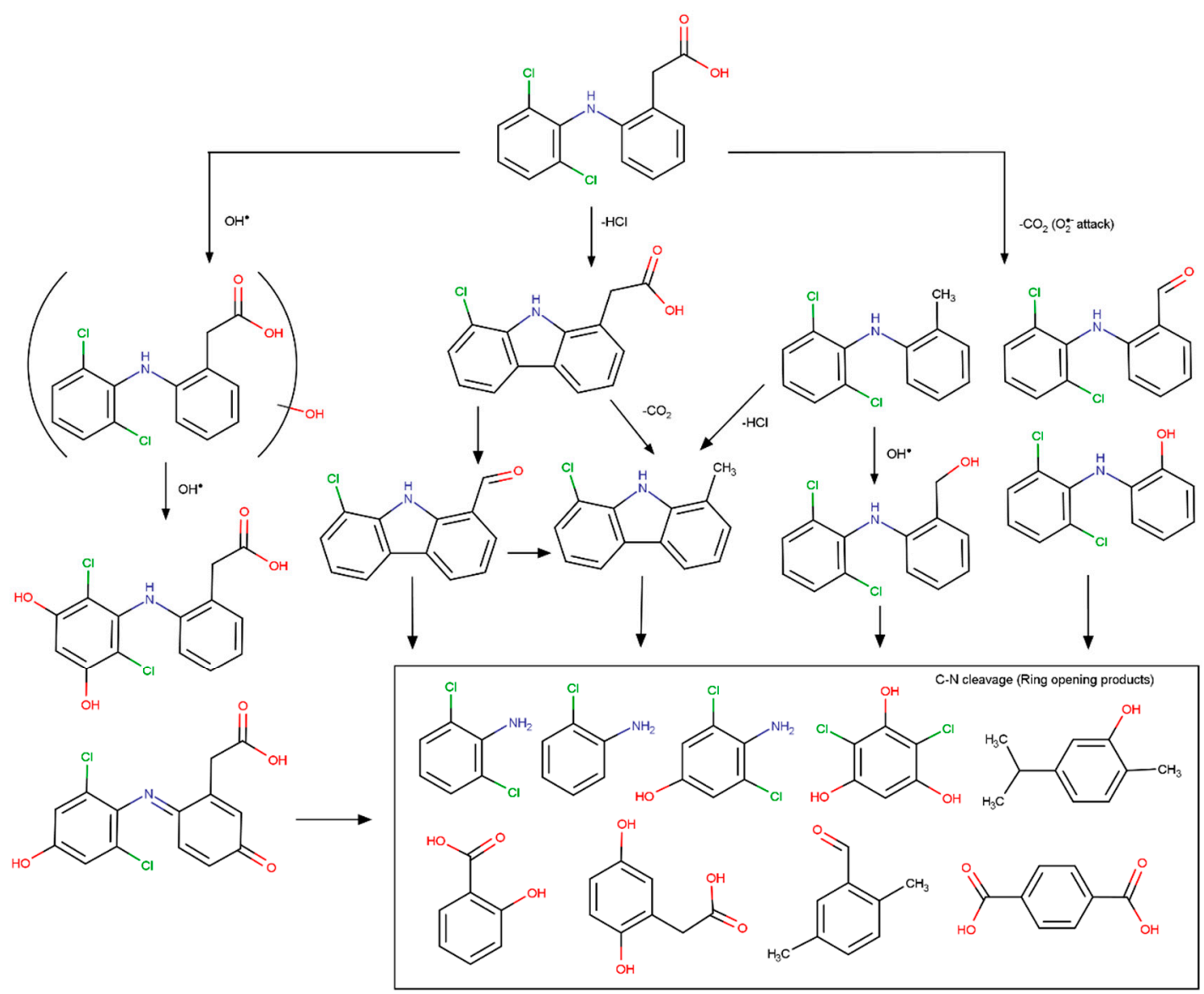

Figure 7. DCF degradation pathways and intermediates by $\mathrm{Ag}-\mathrm{BiOI} / \mathrm{rGO}, \mathrm{TiO}_{2} / \mathrm{rGO}$ with peroxodisulfate, $\mathrm{TiO}_{2}\{001\} / \mathrm{N}-\mathrm{CQD}, \mathrm{g}-\mathrm{C}_{3} \mathrm{~N}_{4} / \mathrm{CQDs}$, and/or BiOCOOH/CQDs under visible light irradiation. The $\mathrm{OH}$ substituents which can appear in different positions in the rings cross the parenthesis mark (based on [132,133,138-140]).

Regarding CBZ three of the four studies reporting degradation pathways and products used $\mathrm{TiO}_{2}$ derived composites with MWCNT, rGO, and biochar $[116,124,146]$. Figure 8 resumes the CBZ degradation pathways and intermediates by $\mathrm{TiO}_{2} / \mathrm{rGO}, \mathrm{TiO}_{2} / \mathrm{MWCNTox}$ and/or $\mathrm{Fe}_{3} \mathrm{O}_{4} / \mathrm{BiOBr} /$ biochar under distinct irradiation conditions (UV, near UV-vis, and Visible LED light). All the proposed degradation pathways start with the hydroxylation of the aromatic system or the olefinic double bond, and two of the studies reported that the hydroxylated intermediates suffer ring cleavage to originate substituted single-ring aromatic compounds ( $\mathrm{m} / \mathrm{z}$ from 93 to 137) or even an aliphatic dicarboxylic acid $\left(m / z\right.$ of 115). The study reporting the use of $\mathrm{Fe}_{2} \mathrm{O}_{3} / \mathrm{BiOBr} / \mathrm{biochar}$ for the degradation of CBZ under visible light attained $70 \%$ mineralization indicating that most of the degradation intermediates could be eliminated to small organic molecules [146]. The toxicity of model wastewater containing CBZ before and after photodegradation treatment with $\mathrm{TiO}_{2} / \mathrm{SiO}_{2} / \mathrm{MWCNTox}$ under UV light was evaluated by Czech et al. that reported lower toxicity of the treated solution to $V$. fisheri and D. magna when compared with the non-treated wastewater [117]. 


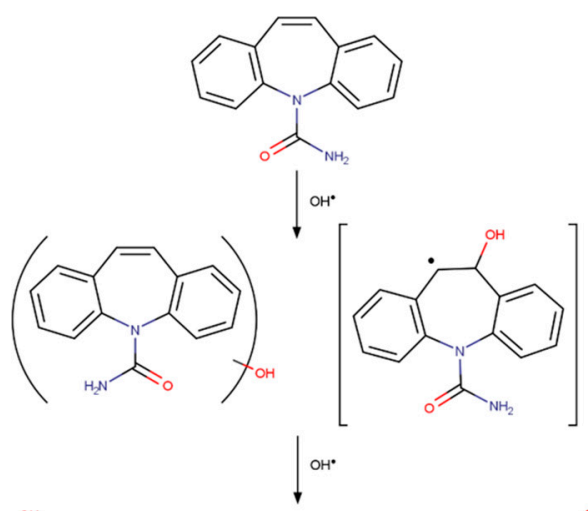

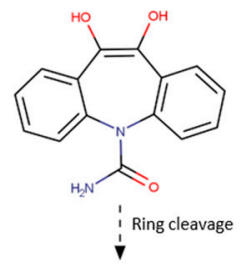

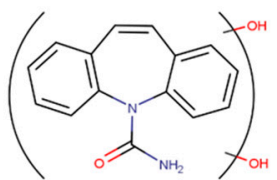<smiles>NC(=O)N1c2ccccc2C2OC2c2ccccc21</smiles><smiles>Nc1ccccc1C(=O)O</smiles><smiles>O=C(O)c1ccccc1O</smiles><smiles>O=C(O)c1ccccc1</smiles><smiles>Nc1ccccc1</smiles>

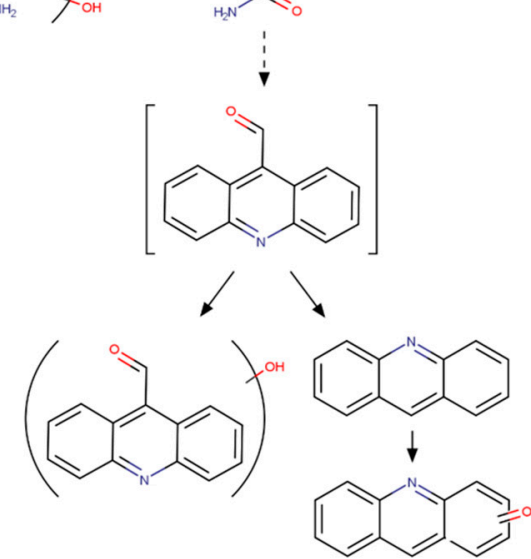

Figure 8. $\mathrm{CBZ}$ degradation pathways and intermediates by $\mathrm{TiO}_{2} / \mathrm{rGO}, \mathrm{TiO}_{2} / \mathrm{MWCNTox}$ and/or $\mathrm{Fe}_{3} \mathrm{O}_{4} / \mathrm{BiOBr} /$ biochar under distinct irradiation conditions (UV, near UV-vis, and Visible LED light). Short-lived intermediates presented between [brackets] while those between (parenthesis) correspond to stable intermediates, the $\mathrm{OH}$ substituents which can appear in different positions in the rings cross the parenthesis mark (based on [116,124,146]).

Overall, regardless of the target $\mathrm{PhC}-\mathrm{SMX}, \mathrm{DCF}$, and CBZ-and the composite used for photocatalytic degradation, the main products are mainly substituted single-ring aromatic compounds. The degradations pathways of SMZ and CBZ start with the hydroxylation of the aromatic moieties. DCF has the most complex degradation pathway since it can start by hydroxylation, decarboxylation and/or dechlorination. Besides $\mathrm{OH}^{\bullet}$ attack to the aromatic systems, $\mathrm{O}_{2}{ }^{\bullet-}$ plays a prominent role in the decomposition of the DCF carboxylic acid group. Despite the high number of degradation pathways, DCF is the PhCs with a larger amount of intermediates and products identified.

\section{Summary and Outlook}

The versatility of carbon element is well expr essed in this review, the combination of $C$ atoms with semiconductors (C-doping) or the use of carbon materials-activated carbons, CNT, graphene, and derived materials, CQD and biochars-as supports or doping materials in composites with semiconductors allows to enhance photocatalytic activity and sunlight harvesting. The black body character of the carbon materials associated with properties as distinct as texture, conductivity, or quantum effects are certain parameters responsible for the improved performance of the composites.

Regarding the three target pharmaceuticals of this review, DCF was by the most explored in photocatalytic degradation studies with semiconductor/carbon material (19 papers vs. 8 papers for SMX and 14 papers for CBZ), most likely due to its presence between 2013 and 2018 in the Watch 
Lists published by European Commission. The interest of the academy towards CBZ probably results from its high recalcitrant behavior in conventional wastewater treatment and high persistence in the environment that also supports the proposal of this pharmaceutical as a possible anthropogenic marker. In fact, also the few studies that evaluate the photocatalytic degradation of more than one of the three targets PhCs systematically identify CBZ as the PhC most resistant to photocatalytic degradation followed by DCF and SMX, in line with photolysis data and persistence after conventional wastewater treatment (biodegradation). Therefore, it is important to continue developing enhanced technologies to effectively restrain the dissemination of these recalcitrant PhCs, with special focus on CBZ, in the environment.

Regarding photocatalytic degradation of these PhCs, only few studies are focused on real water matrices, with the catalytic performance being mainly evaluated using deionized water solution at $\mathrm{pH}$ not close to the values of real water. However, the studies reporting data obtained in real water matrices reveal that the high performance of the catalyst in deionized water is not a guaranty for good results in spiked wastewater.

The majority of studies reviewed are focused on evaluating the removal efficiency of novel catalysts and composites for a specific contaminant, in most cases not assessing the mineralization rate. However the data available clearly demonstrates that the mineralization process demands longer operation times than the degradation/removal of the target PhC. Moreover, when toxicological assays are reported the data reveal that the transformation intermediates formed during the initial degradation process may be as toxic as, or even more toxic than, the pristine $\mathrm{PhC}$.

As a final remark it must be stressed that regardless of the type of carbon material present in the composite, the literature data is almost unanimous to demonstrate the beneficial effect of the carbon doping or addition for the sunlight harvesting and better overall performance of the semiconductor/carbon catalysts. The enhanced photocatalytic activity of the semiconductor/carbon composites is mainly attributed to the electron transfer properties of the carbon material and better charge separation. However, there are also reports where the carbon material (CQDs) act as photosensitizers. The bibliometric analysis shows the great interest of the scientific community in the more conducting carbon materials-CNT and graphene-derived materials-and also the recent growing research in CQD. Nevertheless, more traditional carbon forms, as is the case of nanoporous carbons or biochars, may be more sustainable and feasible for large scale applications not only due to the production cost but mainly due to the toxicity of the crystalline carbon forms. In fact, in vivo studies reveal the health issues associated with CNT and graphene-derived materials due to their rigid structures that damage the cell walls $[149,150]$. Another advantage of nanoporous carbons is related to their well-known pore structure that, besides contributing to the overall removal of the target pollutant, may also allow the adsorption of the degradation intermediates and products thus contributing to overall decrease of the toxicity level.

Lastly, it must also be mentioned that self-photoactivity of some carbon materials for these recalcitrant $\mathrm{PhCs}$, in both UV and solar irradiation, was observed in more than one work, point out the need to further explore the potential of metal-free carbon materials for the photocatalytic degradation of priority contaminants, ideally under sunlight irradiation and in real water matrices.

Author Contributions: A.S.M. conceptualized, conducted the literature research, and wrote the manuscript and A.P.C. reviewed critically the manuscript for important intellectual content.

Funding: Authors thank Fundação para a Ciência e Tecnologia (FCT, Portugal) for the financial support to CQB (Project UID/MULTI/00612/2019). ASM acknowledges FCT for the financial support to the EMBRACE project (CEECIND/01371/2017) and post-doc grant (SFRH/BPD/86693/2012).

Conflicts of Interest: The authors declare no conflict of interest. 


\section{References}

1. Jägerskog, A.; Clausen, T.J.; Holmgren, T.; Lexén, K. Energy and Water: The Vital Link for a Sustainable Future (http://wwww.worldwaterweek.org/); Stockholm International Water Institute, SIWI: Stockholm, Swedish, 2014.

2. Poyatos, J.M.; Munio, M.M.; Almecija, M.C.; Torres, J.C.; Hontoria, E.; Osorio, F. Advanced oxidation processes for wastewater treatment: State of the art. Water Air Soil Pollut. 2010, 205, 187-204. [CrossRef]

3. Ribeiro, A.R.; Nunes, O.C.; Pereira, M.F.R.; Silva, A.M.T. An overview on the advanced oxidation processes applied for the treatment of water pollutants defined in the recently launched Directive 2013/39/EU. Environ. Int. 2015, 75, 33-51. [CrossRef] [PubMed]

4. National Center for Biotechnology Information. PubChem Database. Carbamazepine, CID=2554. Available online: https://pubchem.ncbi.nlm.nih.gov/compound/Carbamazepine (accessed on 29 August 2019).

5. Ternes, T.A.; Herrmann, N.; Bonerz, M.; Knacker, T.; Siegrist, H.; Joss, A. A rapid method to measure the solid-water distribution coefficient (K-d) for pharmaceuticals and musk fragrances in sewage sludge. Water Res. 2004, 38, 4075-4084. [CrossRef] [PubMed]

6. Joss, A.; Zabczynski, S.; Göbel, A.; Hoffmann, B.; Löffler, D.; McArdell, C.S.; Ternes, T.A.; Thomsen, A.; Siegrist, H. Biological degradation of pharmaceuticals in municipal wastewater treatment: Proposing a classification scheme. Water Res. 2006, 40, 1686-1696. [CrossRef]

7. Huber, M.M.; Canonica, S.; Park, G.-Y.; von Gunten, U. Oxidation of pharmaceuticals during ozonation and advanced oxidation processes. Environ. Sci. Technol. 2003, 37, 1016-1024. [CrossRef]

8. National Center for Biotechnology Information. PubChem Database. Diclofenac, CID=3033. Available online: https://pubchem.ncbi.nlm.nih.gov/compound/Diclofenac (accessed on 29 August 2019).

9. National Center for Biotechnology Information. PubChem Database. Sulfamethoxazole CID=5329. Available online: https://pubchem.ncbi.nlm.nih.gov/compound/Sulfamethoxazole (accessed on 29 August 2019).

10. Göbel, A.; Thomsen, A.; McArdell, C.S.; Joss, A.; Giger, W. Occurrence and sorption behavior of sulfonamides, macrolides, and trimethoprim in activated sludge treatment. Environ. Sci. Technol. 2005, 39, 3981-3989. [CrossRef]

11. Zhang, Y.J.; Geissen, S.U.; Gal, C. Carbamazepine and diclofenac: Removal in wastewater treatment plants and occurrence in water bodies. Chemosphere 2008, 73, 1151-1161. [CrossRef]

12. Zhou, W.; Moore, D.E. Photochemical decomposition of sulfamethoxazole. Int. J. Pharm. 1994, 110, 55-63. [CrossRef]

13. Martini, J.; Orge, C.A.; Faria, J.L.; Pereira, M.F.R.; Soares, O.S.G.P. Sulfamethoxazole degradation by combination of advanced oxidation processes. J. Environ. Chem. Eng. 2018, 6, 4054-4060. [CrossRef]

14. Stumm-Zollinger, E.; Fair, G.M. Biodegradation of steroid hormones. J. Water Pollut. Cont. Fed. 1965, 37, 1506-1510.

15. Hignite, C.; Azarnoff, D.L. Drugs and drug metabolites as environmental contaminants: Chlorophenoxyisobutyrate and salicylic acid in sewage water effluent. Life Sci. 1977, 20, 337-341. [CrossRef]

16. Fent, K.; Weston, A.A.; Caminada, D. Ecotoxicology of human pharmaceuticals. Aquat. Toxicol. 2006, 76, 122-159. [CrossRef] [PubMed]

17. Heberer, T. Tracking persistent pharmaceutical residues from municipal sewage to drinking water. J. Hydrol. 2002, 266, 175-189. [CrossRef]

18. Ternes, T. Pharmaceuticals and metabolites as contaminants of the aquatic environment. In Pharmaceuticals and Care Products in the Environment; American Chemical Society: Washington, DC, USA, 2001; Volume 791, pp. 39-54.

19. Ternes, T.A. Occurrence of drugs in German sewage treatment plants and rivers. Water Res. 1998, 32, 3245-3260. [CrossRef]

20. Stumpf, M.; Ternes, T.A.; Wilken, R.-D.; Silvana Vianna, R.; Baumann, W. Polar drug residues in sewage and natural waters in the state of Rio de Janeiro, Brazil. Sci. Total Environ. 1999, 225, 135-141. [CrossRef]

21. Halling-Sørensen, B.; Nors Nielsen, S.; Lanzky, P.F.; Ingerslev, F.; Holten Lützhøft, H.C.; Jørgensen, S.E. Occurrence, fate and effects of pharmaceutical substances in the environment-a review. Chemosphere 1998, 36, 357-393. [CrossRef]

22. Buser, H.-R.; Poiger, T.; Müller, M.D. Occurrence and fate of the pharmaceutical drug diclofenac in surface waters: Rapid photodegradation in a lake. Environ. Sci. Technol. 1998, 32, 3449-3456. [CrossRef] 
23. Andreozzi, R.; Raffaele, M.; Nicklas, P. Pharmaceuticals in STP effluents and their solar photodegradation in aquatic environment. Chemosphere 2003, 50, 1319-1330. [CrossRef]

24. Heberer, T.; Reddersen, K.; Mechlinski, A. From municipal sewage to drinking water: Fate and removal of pharmaceutical residues in the aquatic environment in urban areas. Water Sci. Technol. 2002, 46, 81-88. [CrossRef]

25. Hirsch, R.; Ternes, T.; Haberer, K.; Kratz, K.-L. Occurrence of antibiotics in the aquatic environment. Sci. Total Environ. 1999, 225, 109-118. [CrossRef]

26. Sacher, F.; Lange, F.T.; Brauch, H.-J.; Blankenhorn, I. Pharmaceuticals in groundwaters: Analytical methods and results of a monitoring program in Baden-Württemberg, Germany. J. Chromatogr. A 2001, 938, 199-210. [CrossRef]

27. Stumpf, M.; Terries, T.A.; Haberer, K.P.S.; Baumann, W. Nachweis von arzneimittelrückänden in kläranlagen und flicssgewässern. Vom Wasser 1996, 86, 291-303.

28. Watts, C.D.; Craythorne, M.; Fielding, M.; Steel, C.P. Identification of non-volatile organics in water using field desorption mass spectrometry and high performance liquid chromatography. In Analysis of Organic Micropollutants in Water; Ageletti, G., Bjørseth, A., Eds.; Springer: Dordrech, The Netherlands, 1984; pp. 120-131.

29. Loos, R.; Gawlik, B.M.; Locoro, G.; Rimaviciute, E.; Contini, S.; Bidoglio, G. EU-wide survey of polar organic persistent pollutants in European river waters. Environ. Pollut. 2009, 157, 561-568. [CrossRef] [PubMed]

30. Loos, R.; Locoro, G.; Comero, S.; Contini, S.; Schwesig, D.; Werres, F.; Balsaa, P.; Gans, O.; Weiss, S.; Blaha, L.; et al. Pan-European survey on the occurrence of selected polar organic persistent pollutants in ground water. Water Res. 2010, 44, 4115-4126. [CrossRef] [PubMed]

31. Clara, M.; Strenn, B.; Kreuzinger, N. Carbamazepine as a possible anthropogenic marker in the aquatic environment: Investigations on the behaviour of Carbamazepine in wastewater treatment and during groundwater infiltration. Water Res. 2004, 38, 947-954. [CrossRef]

32. Li, Y.; Zhang, L.Y.; Liu, X.S.; Ding, J. Ranking and prioritizing pharmaceuticals in the aquatic environment of China. Sci. Total Environ. 2019, 658, 333-342. [CrossRef]

33. Guo, J.; Sinclair, C.J.; Selby, K.; Boxall, A.B.A. Toxicological and ecotoxicological risk-based prioritization of pharmaceuticals in the natural environment. Environ. Toxicol. Chem. 2016, 35, 1550-1559. [CrossRef]

34. Besse, J.-P.; Kausch-Barreto, C.; Garric, J. Exposure assessment of pharmaceuticals and their metabolites in the aquatic environment: application to the french situation and preliminary prioritization AU-Besse, Jean-Philippe. Hum. Ecol. Risk Assess. Int. J. 2008, 14, 665-695. [CrossRef]

35. de Voogt, P.; Janex-Habibi, M.L.; Sacher, F.; Puijker, L.; Mons, M. Development of a common priority list of pharmaceuticals relevant for the water cycle. Water Sci. Technol. 2009, 59, 39-46. [CrossRef]

36. Standard Tables for Reference Solar Spectral Irradiances: Direct Normal and Hemispherical on $37^{\circ}$ Tilted Surface. ASTM G173-03: 2012. Available online: https://www.nrel.gov/grid/solar-resource/spectra-am1.5. html (accessed on 11 October 2019).

37. Doll, T.E.; Frimmel, F.H. Fate of pharmaceuticals--photodegradation by simulated solar UV-light. Chemosphere 2003, 52, 1757-1769. [CrossRef]

38. Andreozzi, R.; Marotta, R.; Pinto, G.; Pollio, A. Carbamazepine in water: Persistence in the environment, ozonation treatment and preliminary assessment on algal toxicity. Water Res. 2002, 36, 2869-2877. [CrossRef]

39. Yamamoto, H.; Nakamura, Y.; Moriguchi, S.; Nakamura, Y.; Honda, Y.; Tamura, I.; Hirata, Y.; Hayashi, A.; Sekizawa, J. Persistence and partitioning of eight selected pharmaceuticals in the aquatic environment: Laboratory photolysis, biodegradation, and sorption experiments. Water Res. 2009, 43, 351-362. [CrossRef] [PubMed]

40. Lam, M.W.; Young, C.J.; Brain, R.A.; Johnson, D.J.; Hanson, M.A.; Wilson, C.J.; Richards, S.M.; Solomon, K.R.; Mabury, S.A. Aquatic persistence of eight pharmaceuticals in a microcosm study. Environ. Toxicol. Chem. 2004, 23, 1431-1440. [CrossRef] [PubMed]

41. Chiron, S.; Minero, C.; Vione, D. Photodegradation processes of the Antiepileptic drug carbamazepine, relevant to estuarine waters. Environ. Sci. Technol. 2006, 40, 5977-5983. [CrossRef]

42. Pereira, V.J.; Linden, K.G.; Weinberg, H.S. Evaluation of UV irradiation for photolytic and oxidative degradation of pharmaceutical compounds in water. Water Res. 2007, 41, 4413-4423. [CrossRef]

43. Matamoros, V.; Duhec, A.; Albaigés, J.; Bayona, J.M. Photodegradation of Carbamazepine, Ibuprofen, Ketoprofen and $17 \alpha$-Ethinylestradiol in Fresh and Seawater. Water Air Soil Pollut. 2008, 196, 161. [CrossRef] 
44. Poiger, T.; Buser, H.-R.; Müller, M.D. Photodegradation of the pharmaceutical drug diclofenac in a lake: Pathway, field measurements, and mathematical modeling. Environ. Toxicol. Chem. 2001, 20, 256-263. [CrossRef]

45. Boreen, A.L.; Arnold, W.A.; McNeill, K. Photodegradation of pharmaceuticals in the aquatic environment: A review. Aquat. Sci. 2003, 65, 320-341. [CrossRef]

46. Tixier, C.; Singer, H.P.; Oellers, S.; Müller, S.R. Occurrence and Fate of Carbamazepine, Clofibric Acid, Diclofenac, Ibuprofen, Ketoprofen, and Naproxen in Surface Waters. Environ. Sci. Technol. 2003, 37, 1061-1068. [CrossRef]

47. Poirier-Larabie, S.; Segura, P.A.; Gagnon, C. Degradation of the pharmaceuticals diclofenac and sulfamethoxazole and their transformation products under controlled environmental conditions. Sci. Total Environ. 2016, 557-558, 257-267. [CrossRef]

48. Moore, D.E.; Zhou, W. Photodegradation of sulfamethoxazole: A chemical system capable of monitoring seasonal changes in UVB intensity. Photochem. Photobiol. 1994, 59, 497-502. [CrossRef] [PubMed]

49. Trovo, A.G.; Nogueira, R.F.P.; Aguera, A.; Sirtori, C.; Fernandez-Alba, A.R. Photodegradation of sulfamethoxazole in various aqueous media: Persistence, toxicity and photoproducts assessment. Chemosphere 2009, 77, 1292-1298. [CrossRef] [PubMed]

50. Niu, J.; Zhang, L.; Li, Y.; Zhao, J.; Lv, S.; Xiao, K. Effects of environmental factors on sulfamethoxazole photodegradation under simulated sunlight irradiation: Kinetics and mechanism. J. Environ. Sci. 2013, 25, 1098-1106. [CrossRef]

51. Ryan, C.C.; Tan, D.T.; Arnold, W.A. Direct and indirect photolysis of sulfamethoxazole and trimethoprim in wastewater treatment plant effluent. Water Res. 2011, 45, 1280-1286. [CrossRef] [PubMed]

52. Gmurek, M.; Horn, H.; Majewsky, M. Phototransformation of sulfamethoxazole under simulated sunlight: Transformation products and their antibacterial activity toward Vibrio fischeri. Sci. Total Environ. 2015, 538, 58-63. [CrossRef] [PubMed]

53. Fujishima, A.; Honda, K. Electrochemical photolysis of water at a semiconductor electrode. Nature 1972, 238, 370. [CrossRef] [PubMed]

54. Ollis, D.F.; Al-Ekabi, H. Photocatalytic Purification and Treatment of Water and Air; Elsevier: Amsterdam, The Netherlands, 1993.

55. Pelizzetti, E.; Serpone, N. Photocatalysis: Fundamental and applications; Wiley: New York, USA, 1989.

56. Legrini, O.; Oliveros, E.; Braun, A.M. Photochemical processes for water treatment. Chem. Rev. 1993, 93, 671-698. [CrossRef]

57. Chong, M.N.; Jin, B.; Chow, C.W.K.; Saint, C. Recent developments in photocatalytic water treatment technology: A review. Water Res. 2010, 44, 2997-3027. [CrossRef]

58. Kumaravel, V.; Mathew, S.; Bartlett, J.; Pillai, S.C. Photocatalytic hydrogen production using metal doped $\mathrm{TiO}_{2}$ : A review of recent advances. Appl.Catal. B-Environ. 2019, 244, 1021-1064. [CrossRef]

59. Kudo, A.; Miseki, Y. Heterogeneous photocatalyst materials for water splitting. Chem. Soc. Rev. 2009, 38, 253-278. [CrossRef]

60. Tong, H.; Ouyang, S.X.; Bi, Y.P.; Umezawa, N.; Oshikiri, M.; Ye, J.H. Nano-photocatalytic materials: Possibilities and challenges. Adv. Mater. 2012, 24, 229-251. [CrossRef] [PubMed]

61. Hashimoto, K.; Irie, H.; Fujishima, A. TiO2 photocatalysis: A historical overview and future prospects. Jpn. J. Appl. Phys. Part. 1-Regul. Pap. Brief. Commun. Rev. Pap. 2005, 44, 8269-8285. [CrossRef]

62. Irie, H.; Watanabe, Y.; Hashimoto, K. Carbon-doped anatase $\mathrm{TiO}_{2}$ powders as a visible-light sensitive photocatalyst. Chem. Lett. 2003, 32, 772-773. [CrossRef]

63. Pan, J.H.; Dou, H.; Xiong, Z.; Xu, C.; Ma, J.; Zhao, X.S. Porous photocatalysts for advanced water purifications. J. Mater. Chem. 2010, 20, 4512-4528. [CrossRef]

64. Wang, X.C.; Maeda, K.; Thomas, A.; Takanabe, K.; Xin, G.; Carlsson, J.M.; Domen, K.; Antonietti, M. A metal-free polymeric photocatalyst for hydrogen production from water under visible light. Nat. Mater. 2009, 8, 76-80. [CrossRef] [PubMed]

65. Ong, W.J.; Tan, L.L.; Ng, Y.H.; Yong, S.T.; Chai, S.P. Graphitic carbon nitride $\left(\mathrm{g}_{-} \mathrm{C}_{3} \mathrm{~N}_{4}\right)$-based photocatalysts for artificial photosynthesis and environmental remediation: Are we a step closer to achieving sustainability? Chem. Rev. 2016, 116, 7159-7329. [CrossRef] 
66. Wang, Y.; Wang, X.C.; Antonietti, M. Polymeric graphitic carbon nitride as a heterogeneous organocatalyst: From Photochemistry to multipurpose catalysis to sustainable chemistry. Angew. Chem.-Int. Ed. 2012, 51, 68-89. [CrossRef]

67. Cao, S.W.; Low, J.X.; Yu, J.G.; Jaroniec, M. polymeric photocatalysts based on graphitic carbon nitride. Adv. Mater. 2015, 27, 2150-2176. [CrossRef]

68. Sapurina, I.Y.; Shishov, M.A. Oxidative polymerization of aniline: Molecular synthesis of polyaniline and the formation of supramolecular structures. In New Polymers for Special Applications; Gomes, A.D.S., Ed.; IntechOpen: London, UK, 12 September 2012; pp. 252-312. Available online: https://www.intechopen.com/books/new-polymers-for-special-applications/oxidativepolymerization-of-aniline-molecular-synthesis-of-polyaniline-and-the-formation-of-supramol (accessed on 2 October 2019).

69. Bell, A.T. The impact of nanoscience on heterogeneous catalysis. Science 2003, 299, 1688-1691. [CrossRef]

70. Minella, M.; Fabbri, D.; Calza, P.; Minero, C. Selected hybrid photocatalytic materials for the removal of drugs from water. Curr. Opin. Green Sustain. Chem. 2017, 6, 11-17. [CrossRef]

71. Shan, A.Y.; Ghazi, T.I.M.; Rashid, S.A. Immobilisation of titanium dioxide onto supporting materials in heterogeneous photocatalysis: A review. Appl. Catal. A-Gen. 2010, 389, 1-8. [CrossRef]

72. Awfa, D.; Ateia, M.; Fujii, M.; Johnson, M.S.; Yoshimura, C. Photodegradation of pharmaceuticals and personal care products in water treatment using carbonaceous- $\mathrm{TiO}_{2}$ composites: A critical review of recent literature. Water Res. 2018, 142, 26-45. [CrossRef] [PubMed]

73. Khalid, N.R.; Majid, A.; Tahir, M.B.; Niaz, N.A.; Khalid, S. Carbonaceous- $\mathrm{TiO}_{2}$ nanomaterials for photocatalytic degradation of pollutants: A review. Ceram. Int. 2017, 43, 14552-14571. [CrossRef]

74. Lim, T.T.; Yap, P.S.; Srinivasan, M.; Fane, A.G. $\mathrm{TiO}_{2} / \mathrm{AC}$ Composites for synergistic adsorption-photocatalysis processes: Present challenges and further developments for water treatment and reclamation. Crit. Rev. Environ. Sci. Technol. 2011, 41, 1173-1230. [CrossRef]

75. Meng, Z.D.; Choi, J.G.; Park, J.Y.; Zhu, L.; Oh, W.C. Review for fullerene materials enhanced $\mathrm{TiO}_{2}$ photocatalysis. J. Photocatl. Sci 2011, 2, 29-38.

76. Woan, K.; Pyrgiotakis, G.; Sigmund, W. Photocatalytic carbon-nanotube- $\mathrm{TiO}_{2}$ composites. Adv. Mater. 2009, 21, 2233-2239. [CrossRef]

77. Cao, Q.M.; Yu, Q.M.; Connell, D.W.; Yu, G. Titania/carbon nanotube composite $\left(\mathrm{TiO}_{2} / \mathrm{CNT}\right)$ and its application for removal of organic pollutants. Clean Technol. Environ. Policy 2013, 15, 871-880. [CrossRef]

78. Lam, S.-M.; Sin, J.-C.; Abdullah, A.Z.; Mohamed, A.R. Photocatalytic $\mathrm{TiO}_{2}$ /carbon nanotube nanocomposites for environmental applications: An overview and recent developments. Fuller. Nanotub. Carbon Nanostruct.S 2014, 22, 471-509. [CrossRef]

79. Zhang, Y.; Utke, I.; Michler, J.; Ilari, G.; Rossell, M.D.; Erni, R. Growth and characterization of $\mathrm{CNT}^{-\mathrm{TiO}} 2$ heterostructures. Beilsteinj. Nanotechnol. 2014, 5, 946-955. [CrossRef]

80. Morales-Torres, S.; Pastrana-Martínez, L.M.; Figueiredo, J.L.; Faria, J.L.; Silva, A.M.T. Design of graphene-based $\mathrm{TiO}_{2}$ photocatalysts-A review. Environ. Sci. Poll. Res. 2012, 19, 3676-3687. [CrossRef]

81. Bhanvase, B.A.; Shende, T.P.; Sonawane, S.H. A review on graphene- $\mathrm{TiO}_{2}$ and doped graphene-TiO2 nanocomposite photocatalyst for water and wastewater treatment. Environ. Technol. Rev. 2017, 6, 1-14. [CrossRef]

82. Li, X.; Yu, J.; Wageh, S.; Al-Ghamdi, A.A.; Xie, J. Graphene in photocatalysis: A Review. Small 2016, 12, 6640-6696. [CrossRef] [PubMed]

83. Tan, L.-L.; Chai, S.-P.; Mohamed, A.R. Synthesis and applications of graphene-based $\mathrm{TiO}_{2}$ photocatalysts. ChemSusChem 2012, 5, 1868-1882. [CrossRef] [PubMed]

84. Faraldos, M.; Bahamonde, A. Environmental applications of titania-graphene photocatalysts. Catal. Today 2017, 285, 13-28. [CrossRef]

85. Leary, R.; Westwood, A. Carbonaceous nanomaterials for the enhancement of $\mathrm{TiO}_{2}$ photocatalysis. Carbon 2011, 49, 741-772. [CrossRef]

86. Ania, C.O.; Velasco, L.F.; Valdés-Solís, T. Photochemical behavior of carbon adsorbents. In Novel Carbon Adsorbents; Tascón, J.M.D., Ed.; Elsevier: Oxford, UK, 2012; pp. 521-547.

87. Wang, W.; Serp, P.; Kalck, P.; Faria, J.L. Visible light photodegradation of phenol on $\mathrm{MWNT}^{-\mathrm{TiO}_{2}}$ composite catalysts prepared by a modified sol-gel method. J. Mol. Catal. A Chem. 2005, 235, 194-199. [CrossRef] 
88. Chen, X.; Mao, S.S. Titanium dioxide nanomaterials: Synthesis, properties, modifications, and applications. Chem. Rev. 2007, 107, 2891-2959. [CrossRef]

89. Valentin, C.D.; Pacchioni, G.; Selloni, A. Theory of carbon doping of titanium dioxide. Chem. Mater. 2005, 17, 6656-6665. [CrossRef]

90. Sakthivel, S.; Kisch, H. Daylight photocatalysis by carbon-modified titanium dioxide. Angew. Chem. Int. Ed. 2003, 42, 4908-4911. [CrossRef]

91. Surenjan, A.; Sambandam, B.; Pradeep, T.; Philip, L. Synthesis, characterization and performance of visible light active $\mathrm{C}-\mathrm{TiO}_{2}$ for pharmaceutical photodegradation. J. Environ. Chem. Eng. 2017, 5, 757-767. [CrossRef]

92. Sambandam, B.; Surenjan, A.; Philip, L.; Pradeep, T. Rapid synthesis of $\mathrm{C}-\mathrm{TiO}_{2}$ : Tuning the shape from spherical to rice grain morphology for visible light photocatalytic application. ACS Sustain. Chem. Eng. 2015, 3, 1321-1329. [CrossRef]

93. Buda, W.; Czech, B. Preparation and characterization of $\mathrm{C}, \mathrm{N}$-codoped $\mathrm{TiO}_{2}$ photocatalyst for the degradation of diclofenac from wastewater. Water Sci. Technol. 2013, 68, 1322-1328. [CrossRef] [PubMed]

94. Cordero-Garcia, A.; Guzman-Mar, J.L.; Hinojosa-Reyes, L.; Ruiz-Ruiz, E.; Hernandez-Ramirez, A. Effect of carbon doping on $\mathrm{WO}_{3} / \mathrm{TiO}_{2}$ coupled oxide and its photocatalytic activity on diclofenac degradation. Ceram. Int. 2016, 42, 9796-9803. [CrossRef]

95. Nazarkovsky, M.A.; Bogatyrov, V.M.; Czech, B.; Galaburda, M.V.; Wojcik, G.; Kolomys, O.F.; Strelchuk, V.V.; Malysheva, M.L.; Oranska, O.I.; Gun'ko, V.M. Synthesis and properties of zinc oxide photocatalyst by high-temperature processing of resorcinol-formaldehyde/zinc acetate mixture. J. Photochem. Photobiol. A-Chem. 2017, 334, 36-46. [CrossRef]

96. Schulze-Hennings, U.; Bruckner, I.; Gebhardt, W.; Groteklaes, M.; Bloss, S.P.; Wett, M.; Linnemann, V.; Montag, D.; Pinnekamp, J. Durability of a coating containing titanium dioxide for the photocatalytic degradation of diclofenac in water with UV-A irradiation. Water Environ. J. 2017, 31, 508-514. [CrossRef]

97. Tanguay, J.F.; Suib, S.L.; Coughlin, R.W. Dichloromethane photodegradation using titanium catalysts. J. Catal. 1989, 117, 335-347. [CrossRef]

98. Matos, J.; Laine, J.; Herrmann, J.M. Synergy effect in the photocatalytic degradation of phenol on a suspended mixture of titania and activated carbon. Appl. Catal. B-Environ. 1998, 18, 281-291. [CrossRef]

99. Matos, J.; Laine, J.; Herrmann, J.M. Association of activated carbons of different origins with titania in the photocatalytic purification of water. Carbon 1999, 37, 1870-1872. [CrossRef]

100. Matos, J.; Laine, J.; Herrmann, J.M. Effect of the type of activated carbons on the photocatalytic degradation of aqueous organic pollutants by UV-irradiated titania. J. Catal. 2001, 200, 10-20. [CrossRef]

101. Ocampo-Pérez, R.; Sánchez-Polo, M.; Rivera-Utrilla, J.; Leyva-Ramos, R. Enhancement of the catalytic activity of $\mathrm{TiO}_{2}$ by using activated carbon in the photocatalytic degradation of cytarabine. Appl. Catal. B-Environ. 2011, 104, 177-184.

102. Bandosz, T.J.; Ania, C.O. Origin and perspectives of the photochemical activity of nanoporous carbons. Adv. Sci. 2018, 5. [CrossRef] [PubMed]

103. Velasco, L.F.; Parra, J.B.; Ania, C.O. Role of activated carbon features on the photocatalytic degradation of phenol. Appl. Surf. Sci. 2010, 256, 5254-5258. [CrossRef]

104. Velasco, L.F.; Maurino, V.; Laurenti, E.; Fonseca, I.M.; Lima, J.C.; Ania, C.O. Photoinduced reactions occurring on activated carbons. A combined photooxidation and ESR study. Appl. Catal. A-Gen.L 2013, 452, 1-8. [CrossRef]

105. Velasco, L.F.; Maurino, V.; Laurenti, E.; Ania, C. Light-induced generation of radicals on semiconductor-free carbon photocatalysts. Appl. Catal. A-Gen. 2013, 453, 310-315. [CrossRef]

106. Andrade, M.A.; Mestre, A.S.; Carmona, R.J.; Carvalho, A.P.; Ania, C.O. Effect of the irradiation wavelength on the performance of nanoporous carbon as an additive to $\mathrm{TiO}_{2}$. Appl. Catal. A-Gen. 2015, 507, 91-98. [CrossRef]

107. Rioja, N.; Benguria, P.; Penas, F.J.; Zorita, S. Competitive removal of pharmaceuticals from environmental waters by adsorption and photocatalytic degradation. Environ. Sci. Pollut. Res. 2014, 21, 11168-11177. [CrossRef] [PubMed]

108. Ziegmann, M.; Frimmel, F.H. Photocatalytic degradation of clofibric acid, carbamazepine and iomeprol using conglomerated $\mathrm{TiO}_{2}$ and activated carbon in aqueous suspension. Water Sci. Technol. 2010, 61, $273-281$. [CrossRef] 
109. Alalm, M.G.; Tawfik, A.; Ookawara, S. Enhancement of photocatalytic activity of $\mathrm{TiO}_{2}$ by immobilization on activated carbon for degradation of pharmaceuticals. J. Environ. Chem. Eng. 2016, 4, 1929-1937. [CrossRef]

110. Moreno-Valencia, E.I.; Paredes-Carrera, S.P.; Sanchez-Ochoa, J.C.; Flores-Valle, S.O.; Avendano-Gomez, J.R. Diclofenac degradation by heterogeneous photocatalysis with $\mathrm{Fe}_{3} \mathrm{O}_{4} / \mathrm{Ti}_{\mathrm{x}} \mathrm{O}_{\mathrm{y}} /$ activated carbon fiber composite synthesized by ultrasound irradiation. Mater. Res. Express 2017, 4.

111. Iijima, S. Helical microtubules of graphitic carbon. Nature 1991, 354, 56-58. [CrossRef]

112. Yi, H.; Huang, D.L.; Qin, L.; Zeng, G.M.; Lai, C.; Cheng, M.; Ye, S.J.; Song, B.; Ren, X.Y.; Guo, X.Y. Selective prepared carbon nanomaterials for advanced photocatalytic application in environmental pollutant treatment and hydrogen production. Appl. Catal. B-Environ. 2018, 239, 408-424. [CrossRef]

113. Luo, Y.; Heng, Y.; Dai, X.; Chen, W.; Li, J. Preparation and photocatalytic ability of highly defective carbon nanotubes. J. Solid State Chem. 2009, 182, 2521-2525. [CrossRef]

114. Murgolo, S.; Petronella, F.; Ciannarella, R.; Comparelli, R.; Agostiano, A.; Curri, M.L.; Mascolo, G. UV and solar-based photocatalytic degradation of organic pollutants by nano-sized $\mathrm{TiO}_{2}$ grown on carbon nanotubes. Catal. Today 2015, 240, 114-124. [CrossRef]

115. Zhu, W.Y.; Li, Z.; He, C.; Sun, F.Q.; Yan, Z. Enhanced photodegradation of sulfamethoxazole by a novel $\mathrm{WO}_{3}-\mathrm{CNT}$ composite under visible light irradiation. J. Alloy. Compd. 2018, 754, 153-162. [CrossRef]

116. Martinez, C.; Canle, M.; Fernandez, M.I.; Santaballa, J.A.; Faria, J. Kinetics and mechanism of aqueous degradation of carbamazepine by heterogeneous photocatalysis using nanocrystalline $\mathrm{TiO}_{2}, \mathrm{ZnO}$ and multi-walled carbon nanotubes-anatase composites. Appl. Catal. B-Environ. L. 2011, 102, 563-571. [CrossRef]

117. Czech, B.; Buda, W. Photocatalytic treatment of pharmaceutical wastewater using new multiwall-carbon nanotubes $/ \mathrm{TiO}_{2} / \mathrm{SiO}_{2}$ nanocomposites. Environ. Res. 2015, 137, 176-184. [CrossRef]

118. Martinez, C.; Canle, M.; Fernandez, M.I.; Santaballa, J.A.; Faria, J. Aqueous degradation of diclofenac by heterogeneous photocatalysis using nanostructured materials. Appl. Catal. B-Environ. 2011, 107, 110-118. [CrossRef]

119. Czech, B.; Buda, W. Multicomponent nanocomposites for elimination of diclofenac in water based on an amorphous $\mathrm{TiO}_{2}$ active in various light sources. J. Photochem. Photobiol A-Chem. 2016, 330, 64-70. [CrossRef]

120. Novoselov, K.S.; Geim, A.K.; Morozov, S.V.; Jiang, D.; Zhang, Y.; Dubonos, S.V.; Grigorieva, I.V.; Firsov, A.A. Electric field effect in atomically thin carbon films. Science 2004, 306, 666-669. [CrossRef]

121. Xiang, Q.J.; Yu, J.G.; Jaroniec, M. Graphene-based semiconductor photocatalysts. Chem. Soc. Rev. 2012, 41, 782-796. [CrossRef]

122. Zhang, N.; Zhang, Y.H.; Xu, Y.J. Recent progress on graphene-based photocatalysts: Current status and future perspectives. Nanoscale 2012, 4, 5792-5813. [CrossRef] [PubMed]

123. An, X.Q.; Yu, J.C. Graphene-based photocatalytic composites. Rsc Adv. 2011, 1, 1426-1434. [CrossRef]

124. Nawaz, M.; Miran, W.; Jang, J.; Lee, D.S. One-step hydrothermal synthesis of porous 3D reduced graphene oxide/ $\mathrm{TiO}_{2}$ aerogel for carbamazepine photodegradation in aqueous solution. Appl. Catal. B-Environ. 2017, 203, 85-95. [CrossRef]

125. Lin, L.; Wang, $\mathrm{H} . ; \mathrm{Xu}, \mathrm{P}$. Immobilized $\mathrm{TiO}_{2}$-reduced graphene oxide nanocomposites on optical fibers as high performance photocatalysts for degradation of pharmaceuticals. Chem. Eng. J. 2017, 310, 389-398. [CrossRef]

126. Linley, S.; Liu, Y.Y.; Ptacek, C.J.; Blowes, D.W.; Gu, F.X. Recyclable Graphene Oxide-Supported Titanium Dioxide Photocatalysts with Tunable Properties. Acs Appl. Mater. Interfaces 2014, 6, 4658-4668. [CrossRef] [PubMed]

127. Dong, S.Y.; Feng, J.L.; Fan, M.H.; Pi, Y.Q.; Hu, L.M.; Han, X.; Liu, M.L.; Sun, J.Y.; Sun, J.H. Recent developments in heterogeneous photocatalytic water treatment using visible light-responsive photocatalysts: A review. RSC Adv. 2015, 5, 14610-14630. [CrossRef]

128. Karaolia, P.; Michael-Kordatou, I.; Hapeshi, E.; Drosou, C.; Bertakis, Y.; Christofilos, D.; Armatas, G.S.; Sygellou, L.; Schwartz, T.; Xekoukoulotakis, N.P.; et al. Removal of antibiotics, antibiotic-resistant bacteria and their associated genes by graphene-based $\mathrm{TiO}_{2}$ composite photocatalysts under solar radiation in urban wastewaters. Appl. Catal. B: Environ. 2018, 224, 810-824. [CrossRef]

129. Yang, L.; Xu, L.; Bai, X.; Jin, P. Enhanced visible-light activation of persulfate by $\mathrm{Ti}^{3+}$ self-doped $\mathrm{TiO}_{2} / \mathrm{graphene}$ nanocomposite for the rapid and efficient degradation of micropollutants in water. J. Hazard. Mater. 2019, 365, 107-117. [CrossRef] 
130. Amalraj Appavoo, I.; Hu, J.; Huang, Y.; Li, S.F.Y.; Ong, S.L. Response surface modeling of Carbamazepine (CBZ) removal by Graphene-P25 nanocomposites/UVA process using central composite design. Water Res. 2014, 57, 270-279. [CrossRef]

131. Cheng, X.; Deng, X.; Wang, P.; Liu, H. Coupling $\mathrm{TiO}_{2}$ nanotubes photoelectrode with Pd nano-particles and reduced graphene oxide for enhanced photocatalytic decomposition of diclofenac and mechanism insights. Sep. Purif. Technol. 2015, 154, 51-59. [CrossRef]

132. Li, W.; Yu, R.; Li, M.; Guo, N.; Yu, H.; Yu, Y. Photocatalytical degradation of diclofenac by Ag-BiOI-rGO: Kinetics, mechanisms and pathways. Chemosphere 2019, 218, 966-973. [CrossRef] [PubMed]

133. Chen, P.; Zhang, Q.; Shen, L.; Li, R.; Tan, C.; Chen, T.; Liu, H.; Liu, Y.; Cai, Z.; Liu, G.; et al. Insights into the synergetic mechanism of a combined vis- $\mathrm{RGO} / \mathrm{TiO}_{2} /$ peroxodisulfate system for the degradation of PPCPs: Kinetics, environmental factors and products. Chemosphere 2019, 341-351. [CrossRef] [PubMed]

134. Xu, X.; Ray, R.; Gu, Y.; Ploehn, H.J.; Gearheart, L.; Raker, K.; Scrivens, W.A. Electrophoretic analysis and purification of fluorescent single-walled carbon nanotube fragments. J. Am. Chem. Soc. 2004, 126, 12736-12737. [CrossRef] [PubMed]

135. Sun, Y.-P.; Zhou, B.; Lin, Y.; Wang, W.; Fernando, K.A.S.; Pathak, P.; Meziani, M.J.; Harruff, B.A.; Wang, X.; Wang, H.; et al. Quantum-sized carbon dots for bright and colorful photoluminescence. J. Am. Chem. Soc. 2006, 128, 7756-7757. [CrossRef] [PubMed]

136. Lim, S.Y.; Shen, W.; Gao, Z.Q. Carbon quantum dots and their applications. Chem. Soc. Rev. 2015, 44, 362-381. [CrossRef] [PubMed]

137. Li, H.T.; Kang, Z.H.; Liu, Y.; Lee, S.T. Carbon nanodots: Synthesis, properties and applications. J. Mater. Chem. 2012, 22, 24230-24253. [CrossRef]

138. Chen, P.; Zhang, Q.X.; Su, Y.H.; Shen, L.Z.; Wang, F.L.; Liu, H.J.; Liu, Y.; Cai, Z.W.; Lv, W.Y.; Liu, G.G. Accelerated photocatalytic degradation of diclofenac by a novel CQDs/BiOCOOH hybrid material under visible-light irradiation: Dechloridation, detoxicity, and a new superoxide radical model study. Chem.Eng. J. 2018, 332, 737-748. [CrossRef]

139. Wang, F.L.; Wu, Y.L.; Wang, Y.F.; Li, J.H.; Jin, X.Y.; Zhang, Q.X.; Li, R.B.; Yan, S.C.; Liu, H.J.; Feng, Y.P.; et al. Construction of novel Z-scheme nitrogen-doped carbon dots $/\{001\} \mathrm{TiO}_{2}$ nanosheet photocatalysts for broad-spectrum-driven diclofenac degradation: Mechanism insight, products and effects of natural water matrices. Chem. Eng. J. 2019, 356, 857-868. [CrossRef]

140. Liu, W.; Li, Y.; Liu, F.; Jiang, W.; Zhang, D.; Liang, J. Visible-light-driven photocatalytic degradation of diclofenac by carbon quantum dots modified porous $\mathrm{g}-\mathrm{C}_{3} \mathrm{~N}_{4}$ : Mechanisms, degradation pathway and DFT calculation. Water Res. 2019, 151, 8-19. [CrossRef]

141. Song, Y.L.; Tian, J.Y.; Gao, S.S.; Shao, P.H.; Qi, J.Y.; Cui, F.Y. Photodegradation of sulfonamides by g-C ${ }_{3} \mathrm{~N}_{4}$ under visible light irradiation: Effectiveness, mechanism and pathways. Appl. Catal. B-Environ. 2017, 210, 88-96. [CrossRef]

142. Mestre, A.S.; Carvalho, A.P. Nanoporous carbons synthesis: An old story with exciting new chapters. In Porosity; Ghrib, T., Ed.; IntechOpen: London, UK, 26 April 2018; pp. 37-68. Available online: https://www.intechopen.com/books/porosity-process-technologies-and-applications/nanoporouscarbon-synthesis-an-old-story-with-exciting-new-chapters (accessed on 5 August 2019).

143. Chen, N.; Huang, Y.; Hou, X.; Ai, Z.; Zhang, L. Photochemistry of hydrochar: Reactive oxygen species generation and sulfadimidine degradation. Environ. Sci. Technol. 2017, 51, 11278-11287. [CrossRef] [PubMed]

144. Jäger, H.; Frohs, W.; Collin, G.; von Sturm, F.; Vohler, O.; Nutsch, G. Carbon, 1. General. In Ullmann's Encyclopedia of Industrial Chemistry; Wiley-VCH Verlag $\mathrm{GmbH} \& \mathrm{Co}$. KGaA, 2010. Available online: https://onlinelibrary.wiley.com/doi/abs/10.1002/14356007.a05_095.pub2 (accessed on 28 August 2019).

145. Xie, X.; Li, S.; Zhang, H.; Wang, Z.; Huang, H. Promoting charge separation of biochar-based Zn-TiO $2 / p B C$ in the presence of $\mathrm{ZnO}$ for efficient sulfamethoxazole photodegradation under visible light irradiation. Sci. Total Environ. 2019, 659, 529-539. [CrossRef] [PubMed]

146. Li, S.; Wang, Z.; Zhao, X.; Yang, X.; Liang, G.; Xie, X. Insight into enhanced carbamazepine photodegradation over biochar-based magnetic photocatalyst $\mathrm{Fe}_{3} \mathrm{O}_{4} / \mathrm{BiOBr} / \mathrm{BC}$ under visible LED light irradiation. Chem. Eng. J. 2019, 360, 600-611. [CrossRef]

147. Khraisheh, M.; Kim, J.; Campos, L.; Al-Muhtaseb, A.H.; Walker, G.M.; AlGhouti, M. Removal of carbamazepine from water by a novel $\mathrm{TiO}_{2}$-coconut shell powder/UV process: Composite preparation and photocatalytic activity. Environ. Eng. Sci. 2013, 30, 515-526. [CrossRef] 
148. Khraisheh, M.; Kim, J.; Campos, L.; Al-Muhtaseb, A.H.; Al-Hawari, A.; Al Ghouti, M.; Walker, G.M. Removal of pharmaceutical and personal care products (PPCPs) pollutants from water by novel $\mathrm{TiO}_{2}-\mathrm{Coconut}$ Shell Powder (TCNSP) composite. J. Ind. Eng. Chem. 2014, 20, 979-987. [CrossRef]

149. Sanchez, V.C.; Pietruska, J.R.; Miselis, N.R.; Hurt, R.H.; Kane, A.B. Biopersistence and potential adverse health impacts of fibrous nanomaterials: What have we learned from asbestos? Wiley Interdiscip. Rev. Nanomed. Nanobiotechnol. 2009, 1, 511-529. [CrossRef]

150. Jachak, A.C.; Creighton, M.; Qiu, Y.; Kane, A.B.; Hurt, R.H. Biological interactions and safety of graphene materials. MRS Bull. 2012, 37, 1307-1313. [CrossRef]

(C) 2019 by the authors. Licensee MDPI, Basel, Switzerland. This article is an open access article distributed under the terms and conditions of the Creative Commons Attribution (CC BY) license (http://creativecommons.org/licenses/by/4.0/). 